\title{
Smoking in context : the influence of cues and contexts on urge to smoke
}

Citation for published version (APA):

Thewissen, R. (2007). Smoking in context : the influence of cues and contexts on urge to smoke. [Doctoral Thesis, Maastricht University]. Datawyse / Universitaire Pers Maastricht. https://doi.org/10.26481/dis.20070330rt

Document status and date:

Published: 01/01/2007

DOI:

10.26481/dis.20070330rt

Document Version:

Publisher's PDF, also known as Version of record

\section{Please check the document version of this publication:}

- A submitted manuscript is the version of the article upon submission and before peer-review. There can be important differences between the submitted version and the official published version of record.

People interested in the research are advised to contact the author for the final version of the publication, or visit the DOI to the publisher's website.

- The final author version and the galley proof are versions of the publication after peer review.

- The final published version features the final layout of the paper including the volume, issue and page numbers.

Link to publication

\footnotetext{
General rights rights.

- You may freely distribute the URL identifying the publication in the public portal. please follow below link for the End User Agreement:

www.umlib.nl/taverne-license

Take down policy

If you believe that this document breaches copyright please contact us at:

repository@maastrichtuniversity.nl

providing details and we will investigate your claim.
}

Copyright and moral rights for the publications made accessible in the public portal are retained by the authors and/or other copyright owners and it is a condition of accessing publications that users recognise and abide by the legal requirements associated with these

- Users may download and print one copy of any publication from the public portal for the purpose of private study or research.

- You may not further distribute the material or use it for any profit-making activity or commercial gain

If the publication is distributed under the terms of Article $25 \mathrm{fa}$ of the Dutch Copyright Act, indicated by the "Taverne" license above, 
SM OK IN G IN CON TEXT

The influence of cues and contexts on urge to smoke 


\author{
C) R. Thewissen, Maastricht 2007 \\ Druk: Datawyse, Maastricht \\ Omslag: Roy \\ ISBN?
}

ZON-MW project 985-10-006 (Programma Verslaving)

- ZonMw 


\section{SM OK IN G IN CON TE XT The influence of cues and contexts on urge to smoke}

PROEFSCHRIFT

ter verkrijging van de graad van doctor aan de Universiteit Maastricht, op gezag van de rector magnificus, prof. mr. G.P.M.F. Mols, volgens het besluit van het College van Decanen, in het openbaar te verdedigen op vrijdag 30 maart 2007 om 12:00 uur door

ROY THEWISSEN 


\section{PROMOTORES}

Prof. dr. M.A. van den Hout Universiteit Utrecht

Prof. dr. A.T.M. Jansen

CO-PROMOTOR

Dr. R.C. Havermans

BEOORDELINGSCOMMISSIE

Prof. dr. G. Kok

Prof. dr. G. Schippers

Dr. D. Vansteenwegen

Prof. dr. J. Vlaeyen

Prof. dr. R.W. Wiers (voorzitter)

AMC Universiteit van Amsterdam

Katholieke Universiteit Leuven (B) 


\section{Contents}

1 CHAPTER 1 GENERAL INTRODUCTION

the Clinic"

23 CHAPTER 2

Conditioning Incentive Motivation in Low-Dependent Smokers

45 CHAPTER 3

Context-dependency of Cue-elicited Urge to Smoke

73 CHAPTER 4

From the Office to the Pub: "The Role of Smoke Relevant Contexts on Cue-elicited Urge to Smoke"

95 CHAPTER 5

Renewal of Cue-elicited Urge to Smoke: "Implications for Cue Exposure Treatment"

117 CHAPTER 6

From the Clinic to the Pub: "The Effect of Smoke Relevant Contexts on Urge to Smoke"

145 CHAPTER 7 GENERAL DISCUSSION

Cues and Contexts in Smoking Addiction: "Theoretical and Clinical Implications 



\section{Chapter 1}

GENERAL INTRODUCTION

CUES AND CONTEXTS IN SMOKING ADDICTION:

"From THE LAB TO THE CLINIC" 
Although nowadays most people are aware of the adverse consequences of smoking tobacco, still $27.7 \%$ of the Dutch population (31.1\% males; 24.5 females) smokes on average 15 cigarettes on a daily basis (see STIVORO - voor een rookvrije toekomst; 2006 for an overview of figures of 2005). Of the smokers who quit smoking $64 \%$ does so with their own efforts without any means of help. The other $36 \%$ does seek help by means of nicotine replacement treatments, craving medication, advice from general practitioner, acupuncture, hypnoses, or 'quit smoking' courses (STIVORO - voor een rookvrije toekomst; 2005). According to a report of the USDHHS (1990) approximately one to five percent of all smokers quit with the aid of individual or group therapy (in Breteler, Schotborg \& Schippers, 1996). One way to aid smokers in quitting smoking and remaining abstinent, individually or in group, is by the use of cognitive behavioural therapy. One of the therapeutic tools stemming from the school of cognitive behavioural therapy in the treatment of addiction is cue exposure therapy. The present thesis aims to investigate recent theoretical developments that underlie cue exposure therapy applied to the treatment of smoking addiction. In this introducing chapter of this thesis a brief overview will be presented of the most important theoretical concepts and accounts that underlie cue exposure therapy in the treatment of smoking addiction.

\section{FROM THE LAB...}

\section{URGE TO SMOKE AND RELAPSE}

Relapse into smoking is very common among self-quitters: between 60 and $98 \%$ of attempts to quit end in relapse (Garvey, Bliss, Hitchcock, Heinold \& Rosner, 1992). Further, relapse curves for smoking addiction are similar to those for alcohol and heroin 
addiction (Hunt \& Bespalec, 1974). Even after brief or more extensive cognitive and/or behavioural treatment relapse rates are very high (up to $90 \%$ within one year after treatment, Niaura et al., 1999) and have not changed a lot over the last decades (e.g. Shiffman, 1993). At best clinically based behavioural interventions for smoking cessation produce 20 to $30 \%$ abstinence rates at one year follow-up (e.g. Lichtenstein \& Glasgow, 1992). The question that arises is why smokers find it so difficult to quit smoking. A frequently opted answer to this question is a seemingly irresistible urge (or craving) to smoke.

Numerous studies have found that urges are an important predictor of smoking lapses or relapse and play a key role in motivating smoking behaviour (Shiffman, 1979; West \& Schneider, 1987). Not only has it been found that people who quit smoking and who experience more intense urges early in abstinence are more likely to relapse (Killen, Fortmann, Newman, Kraemer, Varady \& Newman, 1992; Killen Fortmann, Newman \& Varady, 1991, Killen \& Fortmann, 1997), it has also been shown that daily urges predict first episodes of lapses (Shiffman, Paty, Gnys, Kassel \& Hitckcox, 1996; Shiffman, et al., 1997). However, a substantial minority (re)lapsed without experiencing urge to smoke, hence subjective urges are not a necessary condition for smoking (re)lapses (Shifmann, et al., 1996; see also Shiffman, Read, Maltese, Rapkin \& Jarvik, 1985; Tiffany, 1990). Despite these clinical and empirical observations, urges to smoke are directly (Shiffman, et al. 1996; 1997) or indirectly (e.g. Gwaltney, Shiffman, Balabanis \& Paty, 2005) associated with lapses and relapses.

\section{URGE TO SMOKE AND CUE REACTIVITY}

Although there is still much debate about how exactly craving or urge could be defined (Lowman, Hunt, Litten \& Drummond, 2000) and under what conditions it is 'causally' involved in the 
process of drug use (Drummond, 2000), there is still considerable interest in the craving phenomenon from both a theoretical and clinical perspective (Drummond, Litten, Lowman \& Hunt, 2000). In general, urges to use a drug are defined as a subjective emotional state in which the individual is motivated to seek and use the drug (See Baker, et al, 1987; Tiffany, 1990). But where do these urges come from?

Learning based theories about craving or urge to use a drug have always played and still play a prominent role in today's theoretical accounts of addictive behaviour. A Pavlovian conditioning account of addiction states that drug-related stimuli, or cues (e.g., a cigarette), become associated with drug intake (e.g. smoke intake) and as a result these cues will elicit conditioned drug responses: physiological as well as psychological cue reactivity (see Figure 1). This in turn can lead to behavioural cue-reactivity, such as drugseeking behaviour (see also Figure 1). Cue reactivity can be experienced by the addict as urge or craving to use a drug (Lavez, Herzog, \& Brandon, 1999).

Research has reliably demonstrated that smokers experience an increase in urge to smoke when confronted with smoking related cues (e.g. Carter \& Tiffany, 1999). For example, exposing smokers to exteroceptive cues like holding and watching a cigarette (Herman, 1974) or looking at video images of somebody else smoking (Surawy, Stepney \& Cox, 1985) increases urge to smoke. Likewise, exposure to smoking-related imagery increases the urge to smoke (Tiffany \& Hakenewerth, 1991). Interoceptive cues such as induced negative affect, induced either in vivo by exposure to an uncontrollable loud white noise (Payne, Schare, Levis \& Colletti, 1991) or in vitro by imaginary scripts (Tiffany \& Drobes, 1990) also provokes smoke cue reactivity. 


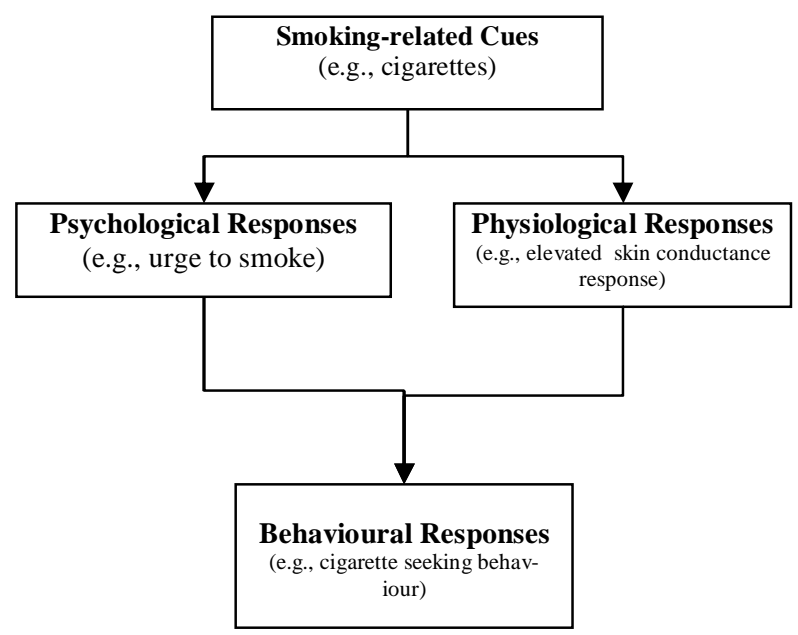

Figure 1: The cue reactivity model of smoking behaviour. Smoking-related cues will elicit both psychological and physiological reactivity which in turn promotes smoking-related behaviour.

Several accounts for addiction have incorporated a Pavlovian cuereactivity model in their theoretical framework. Traditionally, scientists viewed addiction as a state in which drugs are taken not for their pleasant rewarding effects, as initially with drug use, but to elevate withdrawal symptoms that arise upon cessation of drug abuse. For example, Wikler (1948) believed that stimuli or cues that become associated with withdrawal symptoms will acquire the ability to elicit conditioned withdrawal responses. Upon cessation of the drug these cues thus act as conditioned stimuli (CSs) evoking withdrawal responses, which in turn motivate the addict to relieve or avoid this conditioned withdrawal state. In his conditioned opponent or compensatory response model, Siegel $(1975 ; 1989)$ proposed that drug cues (CSs) become associated with drug intake (US) and will elicit conditioned responses (CRs) that are opposite to, or compen- 
sate for, the direct unconditioned effect (i.e., unconditioned psychophysiological responses: URs) of drug intake. Just as in Wikler's model these CRs resemble withdrawal effects and the addict will be motivated to alleviate them by taking the drug again (lapse) or relapsing into drug use (negative reinforcement). However, research into these withdrawal based models did not found convincing evidence for the view that drug cues specifically elicit drug withdrawal responses either drug opposite or in the same direction (See Glautier $\&$ Remington, 1995). These criticisms against these withdrawal relief accounts of addiction led to the conditioned incentive or appetitive motivational model which states that drug cues become associated with drug intake and thereby elicit the positive incentive responses of drug use (Stewart, de Wit \& Eikelboom, 1984). Thus, these cues become positive incentives that motivate further drug use (positive reinforcement).

More recently, based on the same incentive learning principles, Robinson and Berridge (1993; 2003) developed an incentivesensitisation learning theory of addiction. It states that initially drugs at use evoke 'liking' (subjective affective state), but with repeated drug use, through the process of Pavlovian conditioning, drug-related cues become increasingly associated with the 'incentive value' of the drug. Hence these cues become more 'incentive salient' and as a result will grab the attention and will elicit approach behaviour ('wanting'). Other accounts of addictive behaviour have focused on habit formation in addiction acquisition and maintenance. Tiffany (1990) already emphasised the role of unconscious automatic action schemata at work during drug use, where these action schemata will habitually control drug-taking behaviour and will only lead to a conscious experience of urge to use the drug when the habitual processes involved in addictive behaviour are interrupted. 


\section{LEARNING TO SMOKE OR NOT TO SMOKE: SMOKING AVAIL-} ABILITY

The cue reactivity paradigm has been adopted by many researchers to study different aspects of cue-induced processes and responses in addicts. One factor that influenced cue-elicited urge to use a drug is the availability to use a drug. The influence of perceived availability of drug use as a moderator of urge or craving has been studied by several researchers and, recently, these studies were reviewed by Wertz and Sayette (2001). They conclude that smokers, alcoholics, cocaine addicts and opiate addicts in different studies directly or indirectly addressing drug availability - consistently reported higher self-reported urges when they perceived their drug available for use than when not. A practical example of this theoretical notion of the influence of availability on cue reactivity can easily be considered: when one sees somebody smoke a cigarette from their office window, one doe(s) not feel an urge to smoke because one is not allowed to smoke inside the office building; however, if the same person goes out for lunch and again sees somebody smoke a cigarette, this person will feel urge to smoke because he/she is allowed to smoke outside in the open air. Thus, cue reactivity depends on the availability of smoking signalled by other cues in the environment. Carter and Tiffany (2001) argue that a cueavailability paradigm extends the classical procedure of cue reactivity by taking into account the effect of drug availability on cuereactivity.

Dols, Willems, van den Hout and Bittoun (2000) investigated the influence of cues signalling smoking availability on urge to smoke. The researchers used a discriminative Pavlovian conditioning paradigm to investigate the role of availability cues on online measurement of self-reported urge to smoke (see Figure 2). Smokers were exposed to a cue (e.g. a blue card) predicting smoking availability and another cue (e.g. a yellow card) predicting 
smoking unavailability. During each presentation of the cue (i.e. coloured card), urge to smoke was rated before and after the presentation of smoking cues (i.e., favourite brand of cigarettes, ashtray, and lighter). Results showed that when participants were exposed to the cue signalling smoking availability self-reported urge to smoke was higher than when participants were exposed to a cue signalling the absence of smoking. Moreover, the availability cues immediately acquired the ability to control urge to smoke. Smoking cues elicited less urge to smoke during presentation of the unavailability cue than during presentation of the availability cue. These results were successfully replicated under more stringent conditions (see Dols, van den Hout, Kindt, \& Willems, 2002). Moreover, now the urge to smoke came under the complete control of the availability cues. That is smoking cues did not modify urge to smoke. It was concluded that smoking cues elicit urges as a result of the expectation of smoking rather than a long history of Pavlovian learning. This is a somewhat strange conclusion. Demonstrating that cueelicited urges are the result of an acquired smoking expectancy does not preclude a potential role of Pavlovian learning. Expectancies can be acquired through explicit instructions, but are also learned through experience. Most contemporary learning theorists agree that Pavlovian conditioning is experientially learning of the expectancy that the CS is followed by the US.

The work of Dols and colleagues $(2000 ; 2002)$ and other research regarding the influence of availability on cue reactivity make clear that smoking cues elicit urge to smoke only when these other situational (environmental or mental) cues that predict the occurrence of smoking are present. However, it remains unclear how exactly other situational cues or contexts influence the potential of smoking cues to elicit urge responses. 


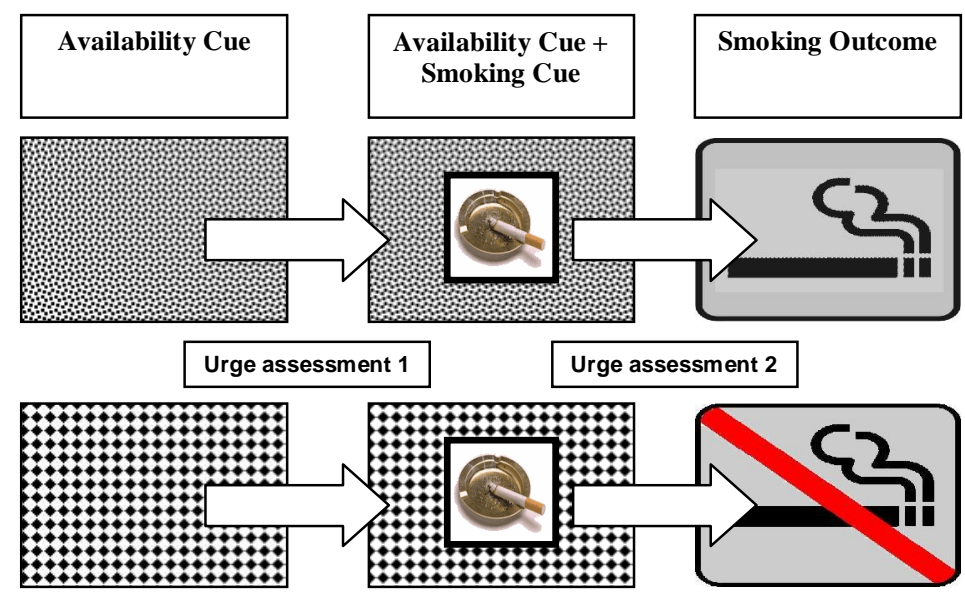

Figure 2: The discriminative Pavlovian conditioning paradigm of Dols et al. (2000; 2002). Smokers are first presented with an availability cue (i.e. coloured card, counterbalanced) after which they rate their momentary urge to smoke (urge assessment 1). Next, smoking cues are presented along with the availability cue, after which smokers again rate their urge to smoke (urge assessment 2). Directly after the second urge rating, smokers are instructed to smoke or not, depending on the meaning of the availability cue. The cue (i.e. coloured card) predicting the availability of smoking elicited higher levels of urge to smoke than the cue predicting the unavailability of smoking.

\section{...TO THE CLINIC...}

\section{Cue Exposure Therapy}

Clinical implications derived from the cue-reactivity models led to the application of an exposure based treatment for addiction, 
as being used in the treatment of obsessive compulsive disorders, phobias, PTSD, etc (e.g. Lee \& Oei, 1993). Exposure-based therapeutic tools are widely practiced in the treatment of a variety of psychopathologies such as anxiety disorders, eating disorders and addictive behaviours (e.g. Öst, 1997; Jansen, 1998; Drummond, Tiffany, Glautier \& Remington, 1995).

Cue exposure is a therapeutic strategy specially designed to deal with the aspect of craving of the abused drug. In accordance with the Pavlovian learning perspective of addiction, cue exposure therapy is analogous to an extinction procedure in which the addict is repeatedly exposed to smoking cues (CSs), but is not allowed to smoke (No US). At the end of treatment cue reactivity should be extinguished, hence, confrontation with smoking cues should no longer elicit any craving. Cue exposure therapy has been extensively used in the clinical domain and some research into its effectiveness has been published, for example, for alcoholics (e.g. Drummond \& Glautier, 1994; Monti, Rohsenow, Rubonis, Niaura, Sirota, Colby, Goddard \& Abrams, 1993), for smoking addiction (e.g. Niaura, Abrams, Shadel, Rohsenow, Monti \& Sirota, 1999), for opiate addicts (e.g. Powell, Gray \& Bradley, 1993; Franken, de Haan, van der Meer, Haffmans \& Hendriks, 1999), and for cocaine addiction (e.g. O'Brien, Childress, McLellan \&Ehrman, 1990). Although some of these studies show promising results some researchers argue that cue exposure can even be counterproductive. For example, Marissen (2005) investigated whether cue exposure treatment can be an effective intervention for reducing relapse rates in abstinent heroin addicts in residential treatment. She found that 9 sessions of cue exposure treatment above treatment as usual led to a higher relapse rate than a placebo psychotherapy (40\% versus 12.9 $\%$ relapse rates). It can be questioned whether the placebo psychotherapy condition was really a 'placebo' treatment given the unusually low incidence of relapse in this condition (the 'placebo' treat- 
ment consisted of relaxation techniques and means of how to deal with disturbing emotions and thoughts; see also Kirsch [2005] for a fundamental criticism on the use of placebo psychotherapy in treatment-evaluation research). This makes it difficult to interpret the study. Although cue exposure alone (Niaura et al., 1999 for smoking; Drummond \& Glautier, 1994; for alcohol) and in combination with cognitive behavioural therapy (CBT) (e.g. Niaura, et al., 1999 for smoking; Sitharthan, Sitharthan, Hough \& Kavanagh, 1997 for alcohol) or coping skills training (Monti, et al., 1993 for alcohol) has found to have some effect, there is no evidence that cue exposure treatment in its present form adds significantly to the effectiveness of standard CBT (Kavanagh, Sitharthan, Young, Sitharthan, Saunders, Shockley \& Giannopoulos, 2006). The most recent metaanalysis of cue exposure studies concluded that cue exposure treatment does not increase abstinence rates among drug-dependent persons. There is still much room for improvement of cue exposure treatment (Conklin \& Tiffany, 2002).

\section{Cue EXPOSure Therapy: A DEAD END OR A NEW DIREC- TION...?}

So far, the future for cue exposure therapy does not look very bright. Still, more fundamental research into learning processes has shed some light on the limitations of extinction/exposure procedures and suggests possible ways to overcome these limitations. The work of Bouton and colleagues (Bouton, 1988; 2002; Bouton \& Bolles, 1979; Bouton \& Swartzentruber, 1991) on the influence of context on extinction indicates that extinction is not 'unlearning' of the CS - US association, but instead the learning of a new association (CS - No US). This newly learned association during extinction is moderated by the context in which extinction took place. Extinction was proven to be context-dependent and therefore subject to renewal and spontaneous recovery of the conditioned responses, 
when tested in a context different from the extinction context.

Renewal of previously extinguished responding is a well established phenomenon within the animal literature (see Bouton, $1988 ; 2002)$. It concerns the return of previously acquired and extinguished conditioned responding to a conditioned stimulus (CS) when this CS is presented in a context different from the extinction context. Renewal can occur when extinction of conditioned responding takes place in a context $\mathrm{B}$ and the $\mathrm{CS}$ is subsequently presented in the original acquisition context A (i.e. ABA renewal; e.g. Bouton \& King, 1983; Rosas \& Bouton, 1997; Bouton \& Peck, 1989 ) or when tested in a completely new context (ABC renewal; e.g. Bouton \& Brooks, 1993; Bouton \& Swartzentruber, 1986 or AAB renewal; e.g. Bouton \& Ricker, 1994). In humans, the renewal effect has also been demonstrated, though not as extensively as in animals. For example, Vansteenwegen and colleagues (2005) found evidence for $\mathrm{ABA}$ renewal using a differential fear conditioning paradigm. They clearly demonstrated a return of previously extinguished conditioned fear after a context change. Havermans, Keuker, Lataster, and Jansen (2005) also found evidence for ABA renewal in human subjects. Using a conditioned suppression task they found that extinguished responses could be renewed when presenting the CS in the original acquisition context. Theoretically, the renewal effect demonstrates that extinguished performance is greatly context specific. That is, what is learned during extinction is not the 'unlearning' of the original excitatory association between the CS and the unconditioned stimulus (the US), but the learning of a new inhibitory association in which the CS predicts the absence of the US (Bouton, 1988; 2002). After extinction, the CS will have an ambiguous meaning: predicting both the occurrence and nonoccurrence of the US. The meaning of the CS is disambiguated by the environmental context. When the CS is presented in the extinction context the inhibitory CS- no US association is retrieved, 
whereas in all other contexts the excitatory CS-US association will be retrieved.

These findings have clear clinical implications for treating various psychopathologies with exposure-based treatments (Conklin \& Tiffany, 2002). Renewal of previously conditioned responses directly points out to the vulnerability of extinction/exposure procedures, that is, relapse after exposure therapy is very likely to occur when a context switch is made from the treatment environment to the personal living environment (e.g. Bouton, 1988). Moderate evidence for these clinical implications with humans is mainly offered by studies with spider phobic subjects showing a return of fear (i.e. renewal) after a physical context switch or with the mere passage of time (Mineka, Mystkowski, Hladek, \& Rodriguez, 1999; Rodriguez, Craske, Mineka, \& Hladek, 1999; Rowe \& Craske, 1998; Lang \& Craske, 2000). Also in the field of addiction research, the renewal effect has been demonstrated. Collins and Brandon (2002) conducted a clinical analogue experiment with moderate to heavy social drinkers and found a significant renewal of extinguished alcohol cue reactivity (but see Staiger, Greeley, \& Wallace, 1999). Additionally, they demonstrated that renewal was attenuated when a retrieval cue was present during the extinction and test phase (see also Vansteenwegen, Vervliet, Hermans, Beckers, Baeyens, \& Eelen, 2006; Mystowski, Craske, Echiverri, Labus \&, 2006). The use of retrieval cues as a possible mean to handle the problem of renewal was already suggested by animal researchers (e.g. Brooks \& Bouton, 1994), and has been favoured by some researchers in the addiction field (Conklin \& Tiffany, 2002; Havermans \& Jansen, 2003). The use of retrieval cues may render cue exposure treatment more effective at limiting renewed cue-elicited urges and hence relapse. Although until now evidence for the effectively of cue expose therapy is weak (Conklin \& Tiffany, 2002) based on recent fundamental grounds cue exposure still holds a potential merit in the treatment of 
addiction. This thesis will build upon one of these possible roads that will lead to improvement of cue exposure therapy.

\section{...TO THE LAB...}

\section{OUTLINE OF THIS THESIS}

The main purpose of this thesis was to investigate whether (a) one can condition a motivation to smoke and (b) how cues and contexts together affect the acquisition, generalisation and extinction of the urge to smoke. This thesis presents clinical analogue studies that provide a paradigm to further study the role of environmental cues and contexts on urge to use a drug within the tradition of contemporary learning psychology in humans. From this research, new potentially beneficial ways of treatment within the domain of (cognitive) behavioural therapy for addictive behaviour might be derived to overcome the fundamental problems of mere exposure-based treatments.

It has frequently been argued that cue-elicited incentive motivation to use a given drug is the result of Pavlovian learning. This assumption has, however, rarely been investigated. In the first study of the present thesis (chapter 2) the possibility to condition a behavioural approach bias towards initially neutral cues in smokers was investigated. This is predicted by recent learning models of addiction, for example by the incentive sensitisation model of Robinson and Berridge (1993; 2003). Furthermore, the role of contingency awareness - being aware of the predictive relationship between the smoking-related cues (CSs) and smoke intake (USs) - in a discriminative Pavlovian conditioning task was being examined. Previous research has demonstrated that explicit contingency knowledge about the association between drug cues (CSs) and drug-taking behaviour is necessary for humans to discriminatively condition urge 
to use a drug, selectively command attention to drug cues and control drug seeking behaviour (See Hogarth, \& Duka, 2006; Hogarth, Dickinson, Hutton, Bamborough \& Duka, 2006).

The next four experimental studies were specially designed to model the more complex real-life situation in which smokingrelated cues and contexts influence a smoker's urge to smoke. To accomplish this the discriminative Pavlovian conditioning procedure of Dols et al $(2000 ; 2002)$ was adopted and extended to investigate the relationship between smoking cues, availability cues and environmental contexts and their effect of urge to smoke. More importantly, the role of smoke relevant contexts on cue-elicited urge to smoke was examined to emphasise the role of meaningful contexts in human contemporary conditioning theory. Due to this it will be possible to link more traditional learning models (e.g. Siegel, 1975; 1989) with social learning models (see e.g. Marlatt \& Gordon, 1985) and cognitive accounts (see Beck, Wright, Newman \& Liese, 1993) of addictive behaviour.

In the first experiment (chapter 3) of this series of four experiments the question whether differentially acquired cue-elicited urges to smoke would generalise to a different environmental context was addressed. In the next experiment (chapter 4) it was again investigated whether differentially acquired cue-elicited urge to smoke would generalise to another context. However, in this study the smoke relevance of the environmental contexts was manipulated to investigate the potential role of this factor on generalisation of cue-elicited urges. In the third study (chapter 5), the issue of renewal of previously extinguished cue reactivity in smokers was directly addressed. After acquisition of differentially cue-elicited urges in one context $\mathrm{A}$ and subsequent extinction of these differentially acquired cue-elicited urges to smoke in another context B, possible renewal was tested in the original acquisition context $A$ (ABA renewal paradigm). Finally, in the last experiment of this the- 
SMOKING IN CONTEXT

sis (chapter 6), the potential role of smoke relevant contexts on renewal of cue-elicited urges to smoke was examined using an $\mathrm{ABC}$ renewal design. 


\section{References}

Baker, T.B., Morse, E. \& Sherman, J. E. (1987). The motivation to use drugs: A psychobiological analysis of urges. In C. Rivers (Ed.), The Nebraska Symposium on Motivation: Alcohol use and abuse (pp. 257-323) Lincoln: University of Nebraska Press.

Beck, A. T., Wright, F. D., Newman, C. F., \& Liese, B. S. (1993). Cognitive therapy of substance abuse. New York: The Guilford press.

Bouton, M. E. (1988). Context and ambiguity in the extinction of emotional learning: implications for exposure therapy. Behaviour Research and Therapy, 26, 137-149.

Bouton, M. E., \& Bolles, R. C. (1979). Contextual control of the extinction of conditioned fear. Learning and motivation, 10, 445-466.

Bouton, M. E. \& Brooks, D. C. (1993). Time and contexts effects on performance in a Pavlovian discrimination reversal. Journal of Experimental Psychology: Animal Behavior Processes, 19, 165-179.

Bouton, M. E., \& King, D. A. (1983). Contextual control of the extinction of conditioned fear: Tests for the associative value of the context. Journal of Experimental Psychology: Animal Behavior Processes, 9, 248-265.

Bouton, M. E., \& Peck, C. A. (1989). Context effects on conditioning, extinction, and reinstatement in an appetitive conditioning preparation. Animal Learning \& Behavior, 17, 188-198.

Bouton, M. E., \& Ricker, S. T. (1994). Renewal of extinguished responding in a second context. Animal Learning \& Behavior, 22, 317-324.

Bouton, M. E., \& Swartzentruber, D. (1986). Analysis of the associative and occasion-setting properties of contexts participating in a Pavlovian discrimination. Journal of Experimental Psychology: Animal Behavior Processes, 12, 333-350.

Bouton, M. E., \& Swartzentruber, D. (1991). Sources of relapse after extinction in Pavlovian and instrumental learning. Clinical Psychology Review, 11, 123-140.

Bouton, M. E. (2002). Context, ambiguity, and unlearning: Sources of relapse after behavioural extinction. Biological Psychology, 52, 976-986.

Breteler, M. H. M., Schotborg, E. J., \& Schippers, G. M. (1996). The effectiveness of smoking cessation programs: Determinants and outcomes. Psychology and Health, 11, 133-153.

Brooks, D. C., \& Bouton, M. E. (1994). A retrieval cue for extinction attenuates response recovery (renewal) caused by a return to the conditioning context. Journal of Experimental Psychology: Animal Behavior Processes, 20, 366-379.

Carter, B. L. \& Tiffany, S. T. (1999) Meta-analysis of cue reactivity in addiction research. Addiction, 94, 327-340.

Carter, B. L., \& Tiffany, S. T. (2001). The cue-availability paradigm: the effects of cigarette availability on cue reactivity in smokers. Experimental and Clinical Psychopharmacology, 9, 183-190.

Collins, B. N., \& Brandon, T. H. (2002). Effects of extinction context and retrieval cues on alcohol cue reactivity among non-alcoholic drinkers. Journal of Consulting and Clinical Psychology, 70, 390-397. 


\section{SMOKING IN CONTEXT}

Conklin, C. A., \& Tiffany, S. T. (2002). Applying extinction research and theory to cueexposure addiction treatments. Addiction, 97, 155-167.

Dols, M., Willems, B., Van den Hout, M., \& Bittoun, R. (2000). Smokers can learn to influence their urge to smoke. Addictive Behaviors, 25, 103-108.

Dols, M., Van den Hout, M., Kindt, M., \& Willems, B. (2002). The urge to smoke depends on the expectation of smoking. Addiction, 97, 87-93.

Drummond, D. C. (2000). What does cue-reactivity have to offer clinical research. Addiction, 95, (suppl. 2), S129-144.

Drummond, D. C., \& Glautier, S. (1994). A controlled trial of cue exposure treatment in alcohol dependence. Journal of Consulting \& Clinical Psychology, 62, 809-817.

Drummond, D. C., Litten, R. Z., Lowman, C. \& Hunt, W. A. (2000). Craving research: future directions. Addiction, 95, (suppl. 2), S247-255.

Drummond, D. C., Tiffany, S.T., Glautier, S., \& Remington, B. (1995). Addictive Behaviour: Cue Exposure Theory and Practice. New York: John Wiley \& Sons.

Franken, I. H. A., de Haan, H. A., van der Meer, C. W., Haffmans, P. M. J., \& Hendriks, V. M. (1999) Cue reactivitity and effects of cue exposure in abstinent posttreatment drug users. Journal of Substance Abuse Treatment, 16, 81-85.

Garvey, A. J., Bliss, R. E., Hitchcock, J. L., Heinold, J. W., \& Rosner, B. (1992). Predictors of smoking relapse amoung self-quitters: A report from the Normative Aging Study. Addictive Behaviours, 17, 367-377.

Glautier, S., \& Remington, B. (1995). The form of responses to drug cues. In D. C. Drummond, S. T. Tiffany, S. Glautier, \& B. Remington (Eds.). Addictive Behaviour: Cue Exposure Theory and Practice, (pp. 21-46). New York: John Wiley \& Sons.

Gwaltney, C. J., Shiffman, S., Balabanis, M. H., \& Paty, J. A. (2005). Dynamic self-efficacy and outcome expectancies: Prediction of smoking lapse and relapse. Journal of $A b-$ normal Psychology, 114, 661-675.

Havermans, R. C., \& Jansen, A. T. M. (2003). Increasing the efficacy of cue exposure treatment in preventing relapse of addictive behavior. Addictive Behaviors, 28, 989-994.

Havermans, R. C., Keuker, J., Lataster, T., \& Jansen, A. (2005). Contextual control of extinguished conditioned performance in humans. Learning and Motivation, 36, 1-19.

Herman, C. P. (1974). External and internal cues as determinants of the smoking behaviour of light and heavy smokers. Journal of Personality and Social Psychology, 30 (5), 664672 .

Hogarth, L., \& Duka, T. (2006). Human nicotine conditioning requires explicit contingency knowledge: is addictive behaviour cognitively mediated? Psychopharmacology, 184, 553-566.

Hogarth, L., Dickinson, A., Hutton, S. B., Bamborough, H., \& Duka, T. (2006). Contingency knowledge is necessary for learned motivated behaviour in humans: relevance for addictive behaviour. Addiction, 101, 1153-1166.

Hunt, W. A., \& Bespalec, D. A. (1974). An evaluation of current methods of modifying smoking behaviour. Journal of Clinical Psychology, 30, 431-438.

Jansen, A. (1998). A learning model of binge eating: Cue reactivity and cue exposure. Behaviour Research and Therapy, 36, 257-272. 


\section{GENERAL INTRODUCTION}

Kavanagh, D. J., Sitharthan, G., Young, R. M., Sitharthan, T., Saunders, J. B., Shockley, N., \& Giannopoulos, V. (2006). Addiction of cue exposure to cognitive-behaviour therapy for alcohol misuse: a randomized trial with dysphoric drinkers. Addiction, 101, 1106-1116.

Killen, J. D., \& Fortmann, S. P. (1997). Craving is associated with smoking relapse: findings from three prospective studies. Experimental and Clinical Psychopharmacology, 5, 137-142.

Killen, J. D., Fortmann, S. P., Kraemer, H. C., Varady, A., \& Newman, B. (1992). Who will relapse? Symptoms of nicotine dependence predict long term relapse after smoking cessation. Journal of Consulting and Clinical Psychology, 60, 797-801.

Killen, J. D., Fortmann, S. P., Newman, B., \& Varady, A. (1991). Prospective study of factors influencing the development of craving associated with smoking cessation. Psychopharmacology, 105, 191-196.

Kirsch, I. (2005). Placebo Psychotherapy: Synonym or Oxymoron? Journal of Clinical Psychology, 61 (7), 791-803.

Lavez, A. B., Herzog, T. A., \& Brandon, T. H. (1999). Classical conditioning of environmental cues to cigarette smoking. Experimental and Clinical Psychopharmacology, 7, 56-63.

Lang, A. J., \& Craske, M. G. (2000). Manipulations of exposure-based therapy to reduce return of fear: A replication. Behaviour Research and Therapy, 38, 1-12.

Lee, N. K. \& Oei, T. P. S. (1993) Exposure and response prevention in anxiety disorders: implication for treatment and relapse prevention in problem drinkers. Clinical Psychological Review, 13, 619-632.

Lichtenstein, E., \& Glasgow, R. E. (1992). Smoking cessation: What have we learned over the past decade? Journal of Consulting and Clinical Psychology, 60(4), 518-527.

Lowman, C., Hunt, W. A., Litten, R. Z., \& Drummond, D. C. (2000). Research perspectives on alcohol craving: an overview. Addiction, 95, (suppl. 2), S45-S54.

Marissen, M. A. E. (2005). Cue exposure therapy for the treatment of heroin addiction. Unpublished Doctoral Dissertation, University of Amsterdam, Amsterdam.

Marlatt, G. A., \& Gordon, J. R. (1985). Relapse Prevention: Maintenance Strategies in the Treatment of Addictive Behaviors. New York: Guilford Press.

Mineka, S., Mystkowski, J. L., Hladek, D., \& Rodriguez, B. I. (1999). The effects of changing contexts on return of fear following exposure therapy for spider fear. Journal of Consulting and Clinical Psychology, 67, 599-604.

Monti, P. M., Rohsenow, D. J., Rubonis, A. V., Niaura, R. S., Sirota, A. D., Colby, S. M., Goddard, P. \& Abrams, D. B. (1993) Cue Exposure with coping skill treatment for male alcoholics: A preliminary investigation. Journal of Consulting and Clinical Psychology, 61, 1011-1019.

Mystkowski, J. L., Craske, M. G., Echiverri, A. M., \& Labus, J. S. (2006). Mental reinstatement of context and return of fear in spider-fearful participants. Behavior Therapy, 37, 49-60.

Niaura, R., Abrams, D. B., Shadel, W. G., Rohsenow, D. J., Monti, P. M. \& Sirota, A. D. (1999). Cue exposure treatment for smoking relapse prevention: a controlled clinical trial. Addiction, 94, 685-695. 


\section{SMOKING IN CONTEXT}

O’Brien, C. P., Childress, A. R., McLellan, T. \& Ehrman, R. (1990) Integrating systematic cue exposure with standard treatment in recovering drug dependent patients. Addictive Behaviors, 15, 355-365.

Öst, L. G. (1997). Rapid treatment of specific phobias. In G. Davey (Ed.). Phobias: A handbook of theory, research and treatment (pp. 227-246). Chichester: Wiley.

Payne, T. J., Schare, M. L., Levis, D. J., \& Colletti, G. (1991). Exposure to smoking-relevant cues: Effects on desire to smoke and topographical components of smoking behaviour. Addictive Behaviors, 16, 467-479.

Powell, J., Gray, J., \& Bradley, B. P. (1993) Subjective craving for opiates: Evaluation of a cue exposure protocol for use with detoxified opiate addicts. British Journal of Clinical Psychology, 32, 39-53.

Robinson, T. E., \& Berridge, K. C. (1993). The neural basis of drug craving: an incentive sensitization theory of addiction. Brain Research and Review, 18, 247-291.

Robinson, T. E., \& Berridge, K. C. (2003). Addiction. Annual Review of Psychology, 54, $25-$ 53.

Rodriguez, B. I., Craske, M. G., Mineka, S., \& Hladek, D. (1999). Context-specificity of relapse: effects of therapist and environmental context on return of fear. Behaviour Research and Therapy, 37, 845-862.

Rosas, J. M. \& Bouton, M. E. (1997). Renewal of conditioned taste aversion upon return to the conditioning context after extinction in another one. Learning and Motivation, 28, 216-229.

Rowe, M. K., \& Craske, M. G. (1998). Effects of an expanding-spaced vs massed exposure schedule on fear reduction and return of fear. Behaviour Research and Therapy, 36, 701-717.

Siegel, S. (1975). Evidence from rats that morphine tolerance is a learned response. Journal of Comparative and Physiological Psychology, 89, 498-506.

Siegel, S. (1989). Pharmacological conditioning and drug effects. In A.J. Goudie and M.W. Emmett-Oglesby (Eds), Psychoactive Drugs: Tolerance and Sensitization, pp. 115180. Clifton, NJ: Humana Press.

Shiffman, S. (1979). The tobacco withdrawal syndrome. In N. M. Krasnegor (Ed.), Cigarette smoking as a dependence process. (NIDA Research Monograph No. 23, pp. 158184). Washington, D.C.: U.S. Governement Printing Office.

Shiffman, S. (1993). Smoking cessation treatment: Any Progress? Journal of Consulting and Clinical Psychology, 61(5), 718-722.

Shiffman, S., Engberg, J., Paty, J. A., Perz, W. G., Gnys, M., Kassel, J.D., \& Hickcox, M. (1997). A day at a time: Predicting smoking lapse from daily urge. Journal of Abnormal Psychology, 106, 104-116.

Shiffman, S., Paty, J. A., Gnys, M., Kassel, J. A., \& Hickcox, M. (1996). First lapses to smoking: Within-subjects analysis of real-time reports. Journal of Consulting and Clinical Psychology, 64, 366-379. 


\section{GENERAL INTRODUCTION}

Shiffman, S., Read, L., Maltese, J., Rapkin, D., \& Jarvik, M. E. (1985). Preventing relapse in exsmokers: A self-management approach. In G. A. Marlatt \& J. R. Gordon (Eds.), Relapse Prevention: Maintenance strategies in treatment of addictive behaviours, pp. 472-520. New York: Guilford Press.

Sitharthan, T., Sitharthan, G., Hough, M., Kavanagh, D. J. (1997). Cue exposure in alcohol abuse: a comparison with cognitive-behaviour therapy. Journal of Consulting \& Clinical Psychology, 65, 878-882.

Staiger, P. K., Greeley, J. D., \& Wallace, S. D. (1999). Alcohol exposure therapy: generalisation and changes in responsivity. Drug and Alcohol Dependence, 57, 2940.

Stewart, J., de Wit, H., \& Eikelboom, R. (1984). Role of unconditioned and conditioned drug effects in the self administration of opiates and stimulants. Psychological Review, 91, 251-268.

STIVORO - rookvrij (2005). Roken, de harde feiten: volwassenen 2004. Den Haag: STIVORO - rookvrij.

STIVORO - rookvrij (2006). Roken, de harde feiten: volwassenen 2005. Den Haag: STIVORO - rookvrij.

Surawy, C., Stepney, R., \& Cox, T. (1985). Does Watching Others Smoke Increase Smoking? British Journal of Addiction, 80, 207-210.

Tiffany, S. T. (1990) A cognitive model of urges and drug-use behavior: Role of automatic and non-automatic processes. Psychological Review, 97, 147-168.

Tiffany, S. T., \& Drobes, D. J. (1990). Imagery and smoking urges: The manipulation of affective content. Addictive Behaviours, 15, 531-539.

Tiffany, S. T., \& Hakenewerth, D. M. (1991). The production of smoking urges through an imagery manipulation: Psychophysiological and verbal manifestations. Addictive Behaviours, 16, 389-400.

Vansteenwegen, D., Hermans, D., Vervliet, B., Francken, G., Beckers, T., Baeyens, F., \& Eelen, P. (2005). Return of fear in a human differential conditioning paradigm caused by a return to the original acquisition context. Behaviour Research and Therapy, 43, 323-336.

Vansteenwegen, D.,Vervliet, B., Hermans, D., Beckers, T., Baeyens, F., \& Eelen, P. (in press). Stronger renewal in human fear conditioning when tested with an acquisition retrieval cue than with an extinction retrieval cue. Behaviour Research and Therapy.

USDHHS. (1990). The Health Benefits of Smoking Cessation. A report of the surgeon General. Maryland: USDHHS.

West, R., \& Schneider, N. (1987). Craving for cigarettes. British Journal of Addiction, 82, 407-415.

Wertz, J. M. \& Sayette, M. A. (2001) A review of the effects of perceived drug use opportunity on self-reported urge. Experimental and Clinical Psychopharmacology, 9, 3-13.

Wikler, A. (1948). Recent progress in research on the neurophysiologic basis of morphine addiction. American Journal of Psychiatry, 105, 329-338. 
SMOKING IN CONTEXT 


\section{Chapter 2}

CONDITIONING INCENTIVE MOTIVATION IN LOW-DEPENDENT SMOKERS

Roy THEWISSEN, REMCO C. HAVERMANS, NicOlE GESCHWIND MARCEL VAN DEN HOUT, AND ANITA JANSEN 


\section{Abstract}

Aims: In the present study, it was investigated whether smokers can acquire a conditioned incentive motivation as suggested by the incentive sensitization model of addiction. More specifically, it was tested whether pairing neutral stimuli with either smoking availability or unavailability would lead to both differential urge responding to these stimuli and a corresponding shift in approach bias.

Design: Firstly, participants conducted the stimulus-response compatibility (SRC) task. Secondly, participants received a conditioning session in which one cue (either a blue or yellow background screen colour) was paired with the opportunity to smoke (CS+) and another cue was paired with the absence of the opportunity to smoke (CS-) (half of the participants contingency awareness was prompted). Thirdly, all participants again performed the same SRC-task.

Participants: 39 low-dependent smokers who smoked at least 5 cigarettes a day for at least 2 years.

Measurements: Self-reported urge to smoke (11-points Likert scales) and approach tendency using a Stimulus-Response Compatibility (SRC) task.

Findings and conclusions: Evidence for the conditioning of an approach bias, but not differential urge responding was found. This effect, though, was only apparent when smokers had been prompted to try and determine the contingency between the stimuli and smoking outcome. It is concluded that one can condition an incentive motivation in low-dependent smokers and that an approach bias may be a more sensitive measure of cue-induced incentive motivation to smoke than cue-elicited urge to smoke.

Keywords: urge to smoke, smoking availability, incentive motivation, differential conditioning 


\section{Introduction}

Most addiction researchers agree that addictive behaviour is the result of learning processes. Addictive behaviour is learned through experience with addictive substances. One particular form of such learning through experience comprises Pavlovian conditioning, the learning of an association between a conditioned stimulus and a biologically relevant unconditioned stimulus. Pavlovian conditioning has been suggested to play an important role in the development of the motivation to use drugs, that is, craving. According to this view, drug-related stimuli, or cues (e.g., a cigarette), become associated with drug intake (e.g., smoke intake) and as a result these cues will elicit conditioned drug responses, or cue reactivity (Drummond, 2000; Drummond, Litten, Lowman \& Hunt, 2000). Cue reactivity can be experienced as urges or craving to use a drug (Siegel, 1975, 1989; Lavez, Herzog, Thaddeusm \& Brandon, 1999). Such cueelicited craving is a key characteristic of drug dependence, including smoking behaviour, and has been found to predict relapse (Killin \& Fortmann, 1997; Shiffman, Paty, Gnys, Kassel \& Hickcox, 1996; Shiffman, et al. 1997). However, it has also been found that smoking and relapse of smoking behaviour is not necessarily preceded by cue-elicited urges to smoke (Shiffman, et al., 1996; Shiffman, Read, Maltese, Rapkin \& Jarvik, 1985). Apparently, craving is not a necessary prerequisite for addictive behaviours (see also Tiffany, 1990).

A recent and prominent model of addictive behaviour can account for the fact that drug use is not necessarily preceded by cueelicited urges. Robinson and Berridge (1993, 2003) developed an incentive sensitization theory of addiction. According to this model, drug use leads to neural sensitization of certain brain substrates such as the nucleus accumbens. This leads to an increased incentive value of the drug. Furthermore, through the process of Pavlovian condi- 
tioning, drug-related cues become increasingly associated with the sensitized incentive value of the drug. Hence these cues become more incentive salient and as a result will grab the attention and elicit approach behaviour. Robinson and Berridge termed this process incentive sensitization. Drug-related cues can thus elicit a strong incentive motivation to seek and use drugs, but this motivation according to Robinson and Berridge - is not necessarily experienced consciously as strong urges or craving. The incentive sensitization model has primarily been tested in animals, but there are a few human studies that provide some evidence for this model. Mogg, Bradley, Field and De Houwer (2003), for example, found that smokers, in comparison with non-smokers, maintained their gaze longer on smoking-related pictures than control pictures. Furthermore, smokers demonstrated a much stronger approach bias towards smoke cues in a stimulus-response compatibility task. During this task subjects are instructed to move a manikin figure towards or away from smoking-related and control stimuli. Responses to stimuli with a positive valence are compatible with a behavioural approach tendency, whereas responses to stimuli with a negative valence are compatible with a behavioural avoidance tendency (See De Houwer, 2003). As these measures (attentional bias and behavioural approach bias) correlated, Mogg and colleagues suggest that these response biases are mediated by a common underlying mechanism of incentive motivation as would be predicted by the incentive sensitization model. More recently however, Mogg, Field and Bradley (2005) found greater attentional and approach biases for smoking-related cues in low-dependent smokers as compared to highdependent smokers (see also Hogarth, Mogg, Bradley, Duka, \& Dickinson, 2003). Further, the urge to smoke was a positive predictor of these biases, whereas severity of nicotine dependence was a negative predictor of these attentional and approach biases. This pattern of results cannot be explained by the incentive sensitization 
model of addiction unless one assumes that $t$ incentive sensitization diminishes with progressive drug use (see e.g., Di Chiara, 2000, 2002).

Although the studies by Mogg, Bradley et al. (2003), Mogg, Field, et al. (2005) and other studies (for an overview of these studies see for example, Walters \& Sayette, 2006) have convincingly demonstrated an attentional and/or approach bias for smokingrelated cues in smokers, only two studies showed that initially neutral cues discriminatively signalling the availability of smoking reinforcement acquire the ability to selectively attend to these cues. Hogarth, Dickinson \& Duka (2003) found that smokers who learned to discriminate between a stimulus predicting smoking reinforcement ( $\mathrm{S}+$ ) and a stimulus predicting no smoking reinforcement (S-) also exhibit a bias concerning the allocation of the focus of visual attention with a preference to the $\mathrm{S}+$, as measured with a dot-probe task. Hence, the capacity of a novel stimulus (i.e., S+) to control attention allocation as a result of Pavlovian contingency learning between this stimulus and smoking reinforcement can be seen as a demonstration of incentive sensitization. However, in a more recent investigation, Hogarth et al. (2005) discovered that smokers do not develop an attentional bias towards a stimulus predicting smoking availability when they are repeatedly prompted about the specific stimulus-smoking availability contingency. They argued that prompting facilitates contingency learning and that attention is only focussed on less well trained stimuli. This too may account for the apparent failure to observe an attentional bias for smoking related cues in heavy smokers.

Although heavy smokers typically do not show a strong attentional bias for smoking-related cues, this does not discount the main tenet of the incentive sensitization view, namely that drugrelated cues through incentive sensitization become desirable and will be able to elicit an incentive motivation to use drugs (see Rob- 
inson \& Berridge, 1993; 2003). The present study aimed to test the incentive sensitization hypothesis by examining whether it is possible to condition an approach bias to initially neutral conditioned stimuli in smokers. Furthermore it is investigated whether prompting contingency awareness has an effect on subjective urge to smoke and on the tendency to approach smoking-related cues.

Firstly, participants' approach bias for smoking cues as compared to control stimuli was determined with a stimulusresponse compatibility task. Trials were presented against a blue and yellow background screen colour. Secondly, participants received a conditioning session in which half of the participants were instructed to pay close attention to possible contingencies between certain stimuli and the opportunity to smoke. Conditioning comprised trials in which one cue (either a blue or yellow background screen colour) was paired with the opportunity to smoke (CS+) and another cue was paired with the absence of the opportunity to smoke (CS-). Thirdly, all participants again performed the same stimulusresponse compatibility task. It was hypothesized that due to the conditioning participants would demonstrate stronger urges to smoke when exposed to CS+ as compared to CS- and at test would show an approach tendency when trials in the stimulus-response compatibility task would be presented against the background screen colour corresponding with CS+. Furthermore, it was hypothesized that such conditioning would be more prominent in the participants having been prompted to pay attention to the contingency between the availability cues and smoking. This should lead to more contingency awareness, which is thought to be necessary for effectively conditioning motivated behaviour in humans (Hogarth, Dickinson, Hutton, Bamborough, \& Duka, 2006). 


\section{Method}

\subsection{PARTICIPANTS}

Thirty-nine smokers (13 males, 26 females; $\mathrm{M}$ age $=23.11$ years; $\mathrm{SD}=6.87$ ) who smoked a minimum of five cigarettes a day for at least two years were recruited at different faculties of Maastricht University. All participants completed the Fagerström test for nicotine dependence (FTND; Heatherton, Kozlowski, Frecker, \& Fagerstrom, 1991). The average score on the FTND was 2.41 (SD = 1.89), which indicates that participants, on average, had a low level of 'nicotine dependence'. Fifteen participants smoked less than 10 cigarettes a day, twenty-two participants smoked between 11 and 20 cigarettes a day, and two participants smoked between 21 and 30 cigarettes a day. Participants had to abstain from smoking for two hours prior to the experiment. An abstinence period of two hours was chosen to avoid floor or ceiling effects of urge to smoke during the conditioning task.

\subsection{INDEPENDENT VARIABLES}

Smoking cues. The smoking cues were stimuli presumed to elicit conditioned urge responses as a result of smoking history. The participant's favourite brand of cigarettes, a lighter, and an ashtray were used as smoking cues.

Availability cues. A blue or a yellow colour of a computer screen signalled the occurrence or non-occurrence of smoking. For half of the participants, a blue coloured computer screen indicated that smoking - after presentation of the smoking cues - was allowed, and a yellow coloured computer screen indicated that smoking was not allowed. For the other half, the meaning of the colours of the computer screens was reversed. These availability cues served as CSs respectively predicting the occurrence of smoking (CS+) and 
absence of smoking (CS-). The US consisted of one puff of a cigarette.

\subsection{DEPENDENT VARIABLES}

Self-reported urge to smoke. During the conditioning task 11 point Likert scales displayed on the computer screen ("At this moment, I feel": 0 "no urge to smoke at all"- 10 "an almost irresistible urge to smoke") were used to measure urge to smoke.

Stimulus-response compatibility (SRC) task. The SRC task the participants had to perform in the present experiment was based on the SRC task described by Mogg, Bradley, Field and De Houwer (2003) and was programmed in E-prime (Psychology Software Tools, Inc). The task comprised two blocks of 80 trials. In each trial, either a $160 \mathrm{~mm}$ high x $215 \mathrm{~mm}$ wide smoking-related picture (10 different smoking-related pictures were used; e.g., a picture of a woman smoking a cigarette, a pack of cigarettes, a glass ashtray, a close-up of a hand holding a burning cigarette, et cetera) or control picture (10 different control pictures were used; e.g., a picture of a woman putting on lipstick, a box of crayons, a glass jar, a close-up of a hand holding a pencil, et cetera) was displayed in the center of the screen together with a manikin (an approximately 18 $\mathrm{mm}$ high x $10 \mathrm{~mm}$ wide matchstick figure) placed exactly between the outer border (either the upper or lower border) of the picture and the edge of the screen. For each block, each of these four different trials was presented 10 times against a blue background screen color and another 10 times against a yellow background, thus rendering a total of 8 different trial types.

Each block of trials had a different stimulus response assignment. In one block the participants were instructed to approach the smoking-related pictures with the manikin by using the up- or down arrow keys depending on the starting position of the manikin, and to avoid the control picture by moving the manikin away from 
the picture outside the screen. The following trial was initialized upon completion of the correct response (i.e., approach or avoidance) and the time to complete each trial was recorded (in ms). A correct response required a minimum of 5 consecutive key presses. In the other block, participants received the instruction to avoid the smoking-related pictures and to approach the control pictures. The order of these two blocks was counterbalanced between participants per group and within each block the eight different trial types were presented in a random order for each separate participant.

Participants performed this SRC task twice. The first task was preceded by a practice session in which the participants were given the opportunity to practice the task at hand. This practice session too comprised two blocks. In one block they had to approach pictures depicting a chair and to avoid pictures displaying a lamp. This stimulus response assignment was reversed for the other block. Each block comprised 16 trials and the order of the two blocks was counterbalanced between the participants.

\subsection{PROCEDURE}

The experiment was approved by a local ethics committee. The experiment started with a brief verbal description of the general procedure of the experiment. After this, all participants also received written information regarding the experiment and were asked to sign a consent form if they still wished to participate. All participants provided informed consent prior to their participation in the present experiment. In addition, participants completed a general smoking questionnaire and the FTND. Further, end-expired air carbon monoxide (Smokerlyzer, Bedfont Scientific, Ltd, CO in parts per million [ppm]) was measured before the start of the experiment. First, participants performed the SRC task, followed by the conditioning task. The conditioning procedure was also programmed in E-prime (Psychology Software Tools, Inc) and required participants 
to follow instructions presented on screen. During the conditioning task, participants were presented with two situations in which they would be exposed to smoking cues, indicated by a blue or yellow background screen colour. Half of the participants received instructions to pay careful attention to stimuli predicting the opportunity to smoke or not (instruction group), whereas the other half did not receive such instructions (no instruction group). Instructions concerning the contingency of the screen colour and smoking opportunity were manipulated as it has been found that such contingency instructions facilitate conditioning (see e.g., Hogarth, et al., 2006).

The conditioning procedure thus started with the presentation of a blue or a yellow screen. Participants were instructed to concentrate on the screen for 25 seconds and to attend to their urge to smoke, after which they rated their momentary urge to smoke on an 11-points Likert scale presented on the coloured computer screen. Next, a participant's favourite pack of cigarettes, a lighter and an ashtray were placed in front of the computer. The participant was instructed to take one cigarette out of the pack and to handle the cigarette (touch it, place it between their lips, holding it) without lighting the cigarette. After 25 seconds, the participant again rated his urge to smoke on a second 11-points Likert scale presented on the coloured screen. Following the second urge assessment, an instruction would appear on the coloured screen stating that now it was allowed or not allowed to take one puff of a cigarette. This instruction was paired with one of the two screen colours. Per group, half of the participants were allowed to smoke when the background screen colour was yellow and not allowed to smoke when the screen was blue. The other half of the participants received the opposite arrangement.

When the instruction on the computer screen indicated that smoking was allowed, the participant took one puff and exhaled the smoke through a respiratory tube. If the instruction indicated that 
smoking was not allowed, the participant held the cigarette between his lips and a burning lighter next to it, but did not light the cigarette. In between trials, participants were instructed to read in a magazine for two minutes during which the screen colour switched to a neutral grey. Each participant completed a total of 8 trials: 4 trials with a blue coloured screen and four trials with a yellow coloured screen presented in a random order with the restriction of no more than three consecutive conditioning trials of the same type. In total, the conditioning task had a duration of approximately 40 minutes.

Directly after conditioning, participants had to perform the same SRC task as before the conditioning phase. At the end of the experiment participants were fully debriefed and received a $€ 15$ euro voucher for compensation.

\section{Results}

\section{DATA REDUCTION AND ANALYSES}

The results are reported separately for the two different outcome measures, that is, the self-reported urge to smoke as assessed during the conditioning task and the SRC task. For all analyses, a rejection criterion of .05 was used. In the case of multiple comparisons, the rejection criterion was Bonferroni corrected. Huyn-Feldt epsilon corrections and the corresponding adjustments of the degrees of freedom are reported for all repeated-measures analyses in which the assumption of sphericity was violated.

\section{SELF-REPORTED URGE TO SMOKE}

Participants repeatedly rated their urge to smoke on 11point Likert scales before and after exposure to the smoking cues, while they were exposed to either the availability or the unavailabil- 
ity cue (i.e. the screen colours predicting whether participants would be either allowed or not allowed to smoke after exposure to the smoking cues). Half of the participants had received instructions to pay special attention to predictors of being allowed to smoke; the other half did not receive such instructions. The urge data were analyzed using a 2 (availability cues: availability versus unavailability) x 2 (smoking cues: absent versus present) x 4 (trial: 1, 2, 3, or 4) x 2 (group: no instructions versus instructions) mixed model analysis of variance (ANOVA). Mean self-reported urge to smoke for the availability cues and the smoking cues as measured during the conditioning task for the 'no instructions and the 'instructions group' are depicted in Figure 1.

The analyses confirmed that there was a main effect of smoking cues, $\mathrm{F}(1,37)=18.77, \mathrm{p}<.001$. When exposed to the smoking cues, participants reported higher urge scores than in the absence of the smoking cues. There was no significant main effect of availability cues, $\mathrm{F}(1,37)=.69$, ns, implying that conditioning of differential urge responding to these cues had not occurred. In other words, participants did not seem to have learned the association between the availability cue (i.e. CS) and smoke intake (i.e. US).

No significant main effect of trial was revealed, F(1.99, $70.45)=1.99$, ns. However, there was a significant interaction between smoking cues and trial, $\mathrm{F}(3,111)=7.58, \mathrm{p}<.001$, indicating that the effect of the smoking cues changed over the course of the trials. To explore this interaction further, separate post hoc tests were conducted with trial as the independent variable and urge responding in the presence or absence of smoking cues as the dependent variable, using a Bonferroni-corrected rejection criterion of $\alpha=$ .025. Initially, higher urges were reported in the presence of smoking cues compared to their absence, but this difference diminished over trials due to a significant increase in urge to smoke in the absence of smoking cues $(\mathrm{F}[2.03,77.29]=4.67, \mathrm{p}<.02)$, whereas 
urge responding to the presence of smoking cues remained at the same level over trials $(F[1.97,74.79]<1)$. No other effects were found significant, all Fs $<1$.
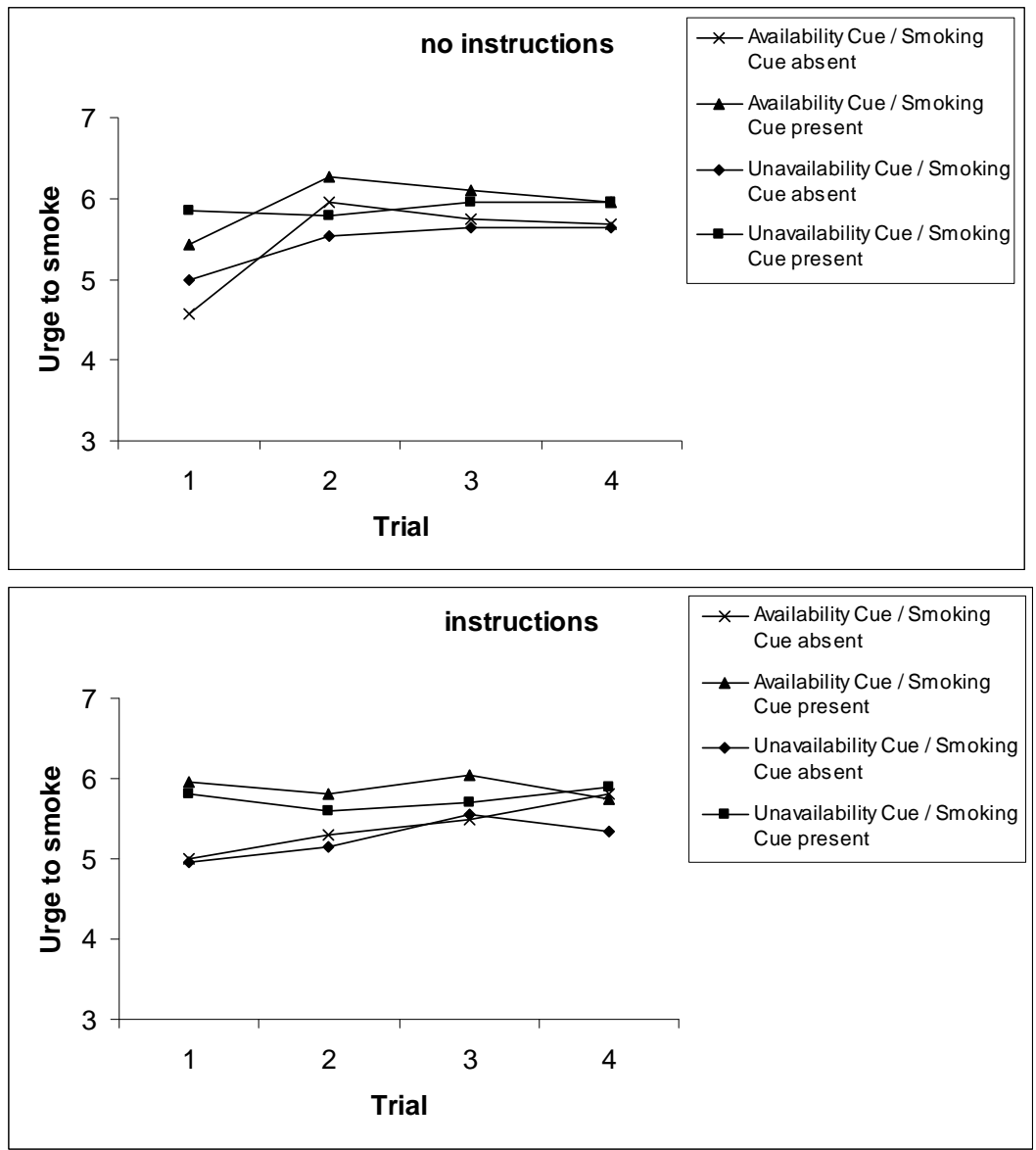

Figure 1. Effect of availability cues and smoking cues on self-reported urge to smoke at trial 1-4 of the conditioning task for the 'no instruction group' $(n=19)$ and the 'instruction group' $(n=20)$. 


\section{STIMULUS-RESPONSE COMPATIBILITY TASK}

Due to technical failure, reaction time data from one participant in the no instruction group was not recorded. To remove outliers, reaction times were excluded per participant and per trial type if they were smaller than $200 \mathrm{~ms}$ or larger than 2.5 SD above the mean (11\% of the data) (see also Mogg et al., 2003).

Participants performed the stimulus-response compatibility task twice, once before and once after the conditioning procedure. It was expected that participants (all smokers) would be faster to approach smoking-related pictures than to avoid them and that this particular response tendency would be larger than for the control pictures. Furthermore, it was expected that at the post-test the magnitude of this effect would be more pronounced in the presence of the availability cue (i.e., the screen color predictive of being allowed to smoke; the $\mathrm{CS}+$ ) than in the presence of the unavailability cue (the CS-).

The data were analyzed using a 2 (test: pre-test versus posttest) x 2 (stimulus: smoke picture versus control picture) x 2 (CS: $\mathrm{CS}+$ versus CS-) x 2 (group: no instructions versus instructions) mixed model ANOVA.

The dependent variable was the response tendency calculated per participant and per picture class (smoke and control) as the difference in RT between the avoidance response and the approach response. A positive response tendency for smoke pictures would thus reflect relatively more rapid approach than avoidance of smoking-related pictures. Figure 2 displays the mean response tendency towards both the control pictures and the smoking-related pictures at pre-test and the post-test for each separate group. 


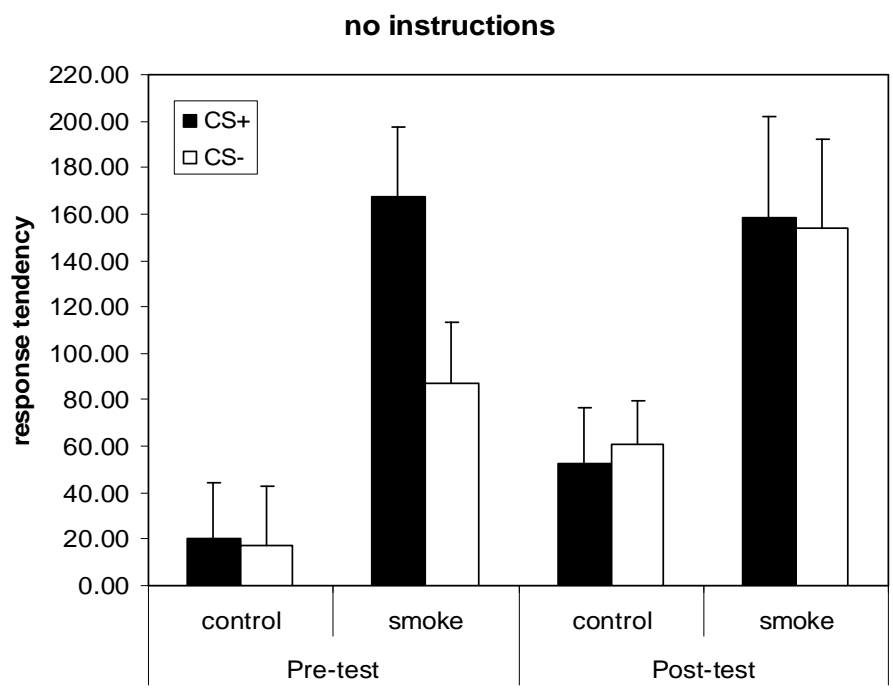

instructions

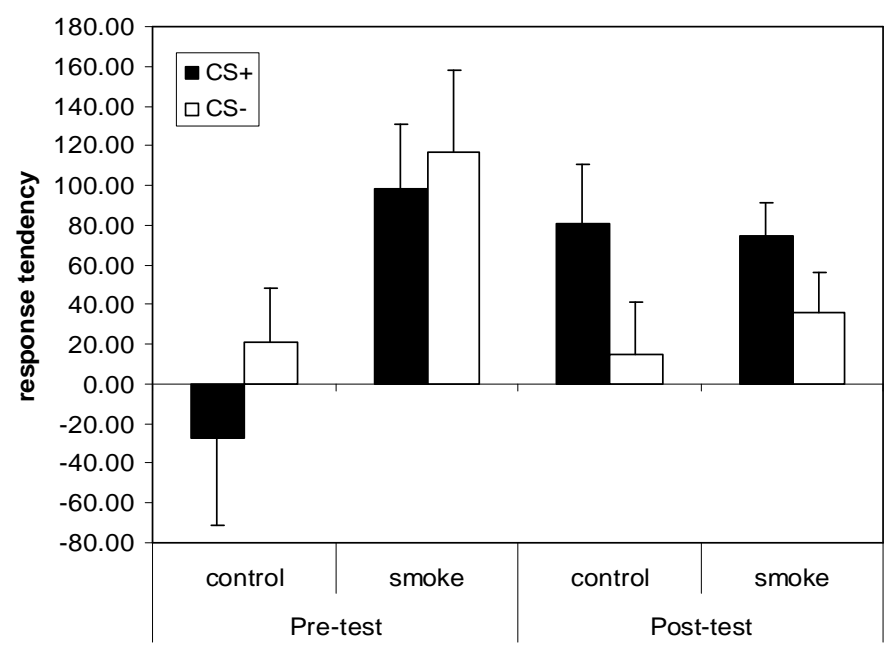

Figure 2. Mean response tendency (avoid RT minus approach RT) plus standard errors of the mean towards both the control pictures and the smoking-related pictures at pre-test and the post-test for the 'no instruction group' $(n=19)$ and the 'instruction group' $(n=20)$. 
There was a main effect of stimulus, $F(1,37)=9.72, p<.01$. As expected, participants had a more positive response tendency towards smoking-related pictures than towards the control pictures. Further, we found a significant main effect of group $\mathrm{F}(1,37)=4.89$, $\mathrm{p}<.05$, which is qualified by a significant test $\mathrm{x}$ CS $\mathrm{x}$ group threeway interaction, $\mathrm{F}(1,37)=11.42, \mathrm{p}<.01$. Post hoc analyses were conducted separately for each group to test for a potential test x CS interaction. No such an interaction was found for group 'no instructions', $\mathrm{F}(1,18)=3.50$, ns, but a clear test $\mathrm{x} C \mathrm{CS}$ interaction was found in group 'instructions', $F(1,19)=8.15, \mathrm{p}<.01$. This interaction reflects a CS specific shift in response tendency; that is, at posttest, the participants in the 'instructions' group demonstrated a more positive response tendency towards both the smoking-related and control pictures when presented against the CS+ background as compared to the response tendencies for these pictures when presented against the CS- background. In other words, after the conditioning procedure the approach tendency was stronger for the CS+ than for CS-, as can also be inferred from Figure 2. Further, a test $x$ stimulus $x$ CS three-way interaction effect was found, $F(1,37)=$ $4.17, \mathrm{p}<.05$. At pre-test, the response tendency for the control pictures was smaller when presented with the CS+ than when presented with the CS-, whereas at post-test this difference in response tendency toward the control pictures was reversed for the CSs. No other effects were found, all ps $>.12$.

\section{Discussion}

As hypothesized, the present experiment replicated the earlier finding reported by other researchers that smokers are faster to approach smoking-related pictures than to avoid them and this particular approach tendency is larger than for control pictures (Mogg et al., 2003; Bradley et al., 2004; Mogg et al., 2005). More importantly, 
this study demonstrated a differentially conditioned incentive motivation in low-dependent smokers as revealed by a stronger approach tendency when the availability cue (CS+) was presented than when the unavailability cue (CS-) was presented. This effect, though, was only apparent in the group who received instructions to actively determine the specific availability cues-smoking contingencies. It was hypothesized that the smokers would demonstrate an increase in approach tendency for smoking-related cues when presented in compound with the CS+. However, the CS+ came to elicit a stronger approach tendency than the CS- irrespective of the smoke relevance of the simultaneously presented picture. In other words, low-dependent smokers exhibit a greater approach tendency towards a stimulus predicting the availability of smoking, but only when they are prompted to seek out the contingency between the (availability) cues and smoking. This effect of instructions is in line with the current opinion that contingency knowledge is necessary for learned motivation in humans (see Hogarth, et al., 2006).

Although the data suggests that prompting subjects to be contingency-aware is necessary to promote conditioned incentive motivation as indexed by an approach tendency for smoking-related cues, prompting contingency awareness in this sample was not sufficient to demonstrate differential urge responding to the availability cues. It is possible that differential urge responding would have appeared with more learning trials as this should lead to more contingency awareness. Similarly, more frequent prompting of the contingency might also induce more contingency awareness. For example, Hogarth et al. (2005) prompted participants several times during training by presenting them the different stimuli and asking them to indicate which outcome would be followed by the stimuli. Indeed, explicit instructions regarding the contingency between availability cues and smoking does lead to differential urge responding (see e.g., Thewissen, et al., 2005). Nonetheless, the present results corrobo- 
rate the incentive sensitization theory of addiction that states that cue-induced incentive motivation to seek and use drugs is not necessarily expressed as subjectively experienced urges (Robinson \& Berridge, 1993; 2003). Moreover, the SRC task employed in the present experiment to assess approach bias may be regarded as a more sensitive measure of cue-elicited motivation to use drugs.

Taken together the results of the present study builds upon the existing literature of the role that conditioning mechanisms in addictions plays by demonstrating that incentive motivation can be conditioned in low-dependent smokers. That is, low-dependent smokers have a greater approach tendency for smoking-related cues than for control cues when presented with a cue signaling the availability of smoking. Though this effect was only evident in a group of smokers that was prompted about the contingency between the availability cues and smoking outcome. It would be interesting to examine whether the present pattern of results can be replicated comparing high- with low-dependent smokers. As it can be assumed that neural sensitization due to smoking is stronger in heavy smokers, the incentive sensitization model would predict a more rapid acquisition of a conditioned approach bias in high-dependent smokers. Further, with regard to clinical practice, it would be interesting to investigate whether or under which circumstances the degree of a smoking cue approach bias is a better predictor of smoking and the probability of relapse of smoking than cue-elicited urge to smoke. 


\section{CONDITIONING INCENTIVE MOTIVATION IN SMOKERS}

\section{References}

Bradley, B. P., Field, M., Mogg, K., \& De Houwer, J. (2004). Attentional and evaluative biases for smoking cues in nicotine dependence: component processes of biases in visual orientating. Behavioural Pharmacology, 15, 29-36.

De Houwer, J. (2003). A structural analysis of indirect measures of attitudes. In J. Musch \& K. C. Klauer (Eds). The Psychology of Evaluation: Affective Processes in Cognition and Emotion, pp. 219-244. Mahwah, NJ: Lawrence Erlbaum.

Di Chiara, G. (2000). Role of dopamine in the behavioural actions of nicotine related to addiction. European Journal of Pharmacology, 393, 295-314.

Di Chiara, G. (2002). Nucleus accumbens shell and core dopamine: differential role in behavior and addiction. Behavioural Brain Research, 137, 75-114.

Drummond, D. C. (2000). What does cue-reactivity have to offer clinical research. Addiction, 95, (suppl. 2), S129-144.

Drummond, D. C., Litten, R. Z., Lowman, C. \& Hunt, W. A. (2000). Craving research: future directions. Addiction, 95, (suppl. 2), S247-255.

Everitt, B. J., Dickinson, A., \& Robbins, T. W. (2001). The neuropsychological basis of addictive behaviour. Brain Research and Review, 36, 129-138.

Heatherton, T. F., Kozlowski, L. T., Frecker, R. C. \& Fagerström, K. (1991). The Fagerström Test for Nicotine Dependence: A revision of the Fagerström Tolerance Questionnaire. British Journal of Addiction, 86, 1119-1127.

Hogarth, L., Dickinson, A., \& Duka, T. (2003). Discriminative stimuli that control instrumental tobacco-seeking by human smokers also command selective attention. Psychopharmacology, 168, 435-445.

Hogarth, L. Dickinson, A., \& Duka, T. (2005). Explicit knowledge of stimulus-outcome contingencies and stimulus control of selective attention and instrumental action in human smoking behaviour. Psychopharmacology, 177, 428-437.

Hogarth, L., Mogg, K., Bradley, B. P., Duka, T., \& Dickinson, A. (2003). Attentional orientating towards smoking related stimuli. Behavioural Pharmacology, 14, 153-160.

Hogarth, L., Dickinson, A., Hutton, S. B., Bamborough, H., \& Duka, T. (2006). Contingency knowledge is necessary for learned motivated behaviour in humans: relevance for addictive behaviour. Addiction, 101, 1153-1166.

Killen, J. D. \& Fortmann, S. P. (1997). Craving is associated with smoking relapse: Findings from three prospective studies. Experimental and Clinical Psychopharmacology, 5, $137-142$

Lavez, A. B., Herzog, T. A., \& Brandon, T. H. (1999). Classical conditioning of environmental cues to cigarette smoking. Experimental and Clinical Psychopharmacology, 7, 56-63.

Mogg, K., Bradley, B. P., Field, M. \& De Houwer, J. (2003). Eye movement to smokingrelated pictures in smokers: relationship between attentional biases and implicit and explicit measures of stimulus valence. Addiction, 98, 825-836. 


\section{SMOKING IN CONTEXT}

Mogg, K. Field, M. \& Bradley, B. P. (2005). Attentional and approach biases for smoking cues in smokers: an investigation of competing theoretical views of addiction. Psychopharmacology, 180, 333-341.

Robinson, T. E., \& Berridge, K. C. (1993). The neural basis of drug craving: an incentive sensitization theory of addiction. Brain Research and Review, 18, 247-291.

Robinson, T. E., \& Berridge, K. C. (2003). Addiction. Annual Review of Psychology, 54, 25 53.

Shiffman, S., Engberg, J., Paty, J. A., Perz, W. G., Gnys, M., Kassel, J.D., \& Hickcox, M. (1997). A day at a time: Predicting smoking lapse from daily urge. Journal of Abnormal Psychology, 106, 104-116.

Shiffman, S., Paty, J. A., Gnys, M., Kassel, J. A., \& Hickcox, M. (1996). First lapses to smoking: Within-subjects analysis of real-time reports. Journal of Consulting and Clinical Psychology, 64, 366-379.

Shiffman, S., Read, L., Maltese, J., Rapkin, D., \& Jarvik, M. E. (1985). Preventing relapse in exsmokers: A self-management approach. In G. A. Marlatt \& J. R. Gordon (Eds.), Relapse Prevention: Maintenance strategies in treatment of addictive behaviours, pp. 472-520. New York: Guilford Press.

Siegel, S. (1975). Evidence from rats that morphine tolerance is a learned response. Journal of Comparative and Physiological Psychology, 89, 498-506.

Siegel, S. (1989). Pharmacological conditioning and drug effects. In A.J. Goudie and M.W. Emmett-Oglesby (Eds), Psychoactive Drugs: Tolerance and Sensitization, pp. 115180. Clifton, NJ: Humana Press.

Thewissen, R., Van den Hout, M., Havermans, R. C., \& Jansen, A. (2005). Contextdependency of cue-elicited urge to smoke. Addiction, 100, 387-396.

Tiffany, S. T. (1990). A cognitive model of drug urges and drug-use behavior: Role of automatic and nonautomatic processes. Psychological Review, 97, 147-168.

Walters, A. J. \& Sayette, M. A. (2006). Implicit cognition and tobacco addiction. In R. W. Wiers \& A. W. Stacy (Eds.), Handbook of Implicit Cognition and Addiction, pp. 309338. California: Sage Publications. 
CONDITIONING INCENTIVE MOTIVATION IN SMOKERS 
SMOKING IN CONTEXT 


\section{Chapter 3}

ConteXT-DEPENDENCY of Cue-elicited URGe to SMOKE

Roy THewissen, MARCEL VAN DEN Hout, REMCo C. HAVERMANS, ANITA JANSEN 


\section{ABSTRACT}

Aims: Earlier studies (Dols, Willems, et al., 2000; Dols, van den Hout, et al., 2002) have suggested that the cue-induced urge to smoke depends on the expectation of the availability of smoking. The present study investigated whether a 'room context' change could undo the learned discrimination between two stimuli respectively predicting smoking availability or smoking unavailability.

Design: A 2 (smoking cue) x 2 (availability context cue) x 6 (trial) x 2 (room context change) within-subjects design was used. Participants were repeatedly presented with a context cue predicting smoking availability (blue serving tray) and a context cue predicting unavailability (yellow serving tray) in one room and tested for an effect of context change in a different room.

Setting: Two distinct rooms located in different department buildings of Maastricht University.

Participants: Seventeen daily smokers who had smoked at least five cigarettes a day for at least two years.

Measurements Self-reported urge to smoke using a visual analogue scale (VAS).

Findings and conclusions: Results replicated the finding that a context cue that predicted smoking elicited greater urges to smoke than a context cue that predicted no smoking, irrespective of the presence of smoking cues. In addition, this study showed that this differential effect on the urge to smoke was generalized to a context other than the context in which learning took place. These findings are discussed in relation to the significance of a context change regarding the predictive value of smoking availability. 


\section{INTRODUCTION}

In general, the urge to use a drug is conceptualized as an emotional state in which the individual is motivated to seek and use the drug (see Baker, Morse, \& Sherman, 1987; Tiffany, 1990; Drummond, Litten, Lowman, \& Hunt, 2000). There is considerable interest in the urge (or craving) phenomenon from a theoretical and clinical perspective, as drug urges play an important role in the maintenance and relapse of addictive behaviour (Drummond, et al., 2000). The cue reactivity paradigm has proven useful in studying the relevance of urges in explaining maintenance and relapse of drug use (see e.g. Niaura, Rohsenow, Binkoff, Monti, Pedraza \& Abrams, 1988; Drummond, Cooper \& Glautier, 1990; Drummond, 2000). The theory of Pavlovian conditioning suggests that stimuli or cues (Conditioned Stimuli, CS) can be associated with drug intake (e.g. smoking behaviour) (Unconditioned Stimuli, US) and as a result these cues will elicit conditioned responses (CRs), or cue reactivity (physiological and psychological). These conditioned responses can be experienced subjectively as an urge to use a given drug (Lavez, Herzog, \& Brandon, 1999). (For a critical discussion about the nature of these conditioned responses, see Niaura, et al. 1988; Carter \& Tiffany, 1999).

Clinical implications derived from this theoretical position led to the application of an exposure-based treatment for addiction, comparable with the treatment of anxiety disorders (e.g. Lee, \& Oei, 1993). Cue exposure with response prevention is a therapeutic strategy especially designed to deal with the aspect of urge. For example, a smoker is repeatedly exposed to smoking cues (e.g. cigarettes, lighters, ashtrays), but is not allowed to smoke (response prevention). This procedure then should lead to the elimination of the previously learned association between smoking cues and smoking. As a result, the smoking cue reactivity should be extinguished at the 
end of the treatment. Furthermore, by eliminating an important motivation for continued drug use the probability of a (re)lapse should be limited. Cue exposure therapy has been extensively used in the clinical domain and research into its effectiveness has shown that it can indeed lead to the extinction of drug urges (see e.g. Drummond \& Glautier, 1994; Monti, et al., 1993; Niaura, et al., 1999; Powell, Gray, \& Bradley, 1993; Franken, de Haan, van der Meer, Haffmans, \& Hendriks, 1999; O’Brien, Childress, McLellan, \& Ehrman, 1990). However, relapse after 'successful' treatment is still a matter of great concern for clinicians and their clients and cue exposure does not tend to reduce relapse rates (Conklin \& Tiffany, 2002; Havermans \& Jansen, 2003).

Contemporary learning theory provides an explanation for the apparent limited effectiveness of cue exposure therapy. Bouton and colleagues (Bouton, 1988; 2000; Bouton \& Bolles, 1979; Bouton \& Swartzentruber, 1991) have repeatedly shown that extinction does not entail the 'unlearning' of the CS - US association, but instead the learning of a new inhibitory association (CS - No US). This newly learned association during extinction is controlled by the context in which the extinction treatment took place. The client learns that, given the extinction context, the US will no longer follow the CS. As a consequence, an extinguished CR is renewed when the client is exposed to the CS outside the extinction context. In other words, cue-elicited urges can be extinguished, but when the client is exposed to drug-related cues outside the environment in which exposure took place, these urges may reappear, rendering cue exposure therapy ineffective (Conklin \& Tiffany, 2002; Havermans $\&$ Jansen, 2003). Indeed, some evidence for such a renewal of drug cue reactivity after cue exposure treatment has been found in social drinkers (Collins \& Brandon, 2002; but see Staiger, Greeley, \& Wallace, 1999).

The renewal of extinguished cue reactivity demonstrates the 
importance of contextual variables in cue-elicited responding. Contexts appear to control the meaning of more punctuated cues, that is, drug cues predict drug use within the drug use environment, but predict the absence of drug taking behaviour in a treatment setting. Translating this notion to addiction to smoking, Dols, Willems, van den Hout and Bittoun (2000) investigated the influence of context on cue-elicited urge to smoke. Smokers were exposed to two contexts: one context (signalled by a yellow card) predicted no smoking and the other context (signalled by a blue card) predicted smoking. In each context, the urge to smoke was rated before and after the presentation of smoking cues (favourite brand of cigarettes, ashtray, and lighter). Results showed that smoking cues elicited less urge in the non-smoking context than in the smoking context. In addition, the contexts appeared better predictors of smoking or non-smoking than the smoking cues. Germane smoking cues elicited a stronger urge to smoke when presented in the smoking context than when presented in the non-smoking context. This study was replicated under more stringent conditions and the results were essentially similar (see Dols, van den Hout, Kindt, \& Willems, 2002). It was concluded that smoking cues elicit urges mainly due to the expectation of smoking or non-smoking and less due to a long history of associative learning. The perceived availability of smoking seems to be more crucial for eliciting the urge to smoke (e.g. Droungas, Ehrman, Childress \& O'Brien, 1995; Juliano \& Brandon, 1998; Powell, 1995; Carter \& Tiffany, 2001). Recently, a review of the collected studies (so far) that directly or indirectly addressed drug availability, consistently reported stronger self-reported urges when clients perceive their drug available for use than when not (Wertz \& Sayette, 2001).

Dols et al. (Dols, Willems, et al. 2000; Dols, Hout van den, et al. 2002) showed that the cue-induced urge to smoke could be influenced by manipulating the expectation of smoking. This ex- 
periment was designed to investigate whether the learned control over cue-elicited urges by context cues (i.e., blue versus yellow card) generalizes across more naturalistic environmental contexts. If so, it could be argued that the experimental manipulation of the expectation of smoking provides a potentially effective alternative to cue exposure treatment of smoking dependency.

The experimental procedure used in this experiment was similar to the procedure used by Dols and colleagues (Dols, Willems, et al. 2000; Dols, Hout van den, et al. 2002) and is a discriminative classical conditioning task in which 'cue-availability' (Carter \& Tiffany, 2001) or 'perceived drug use opportunity' (Wertz \& Sayette, 2001) is manipulated. This design was implemented in a more naturalistic environmental context to investigate the influence of a particular setting on the learned expectations regarding the availability of smoking. That is, the aim was to examine whether a context change from one room to a new room would undo the learned discrimination between two stimuli predicting smoking or no smoking respectively. In this study, three types of stimuli were presented: smoking cues (favourite brand of cigarettes, lighter and ashtray; SC), context cues (blue or yellow serving trays; CC), and two different rooms that served as the naturalistic environmental contexts. The smoking cues were stimuli presumed to elicit conditioned craving responses as a result of smoking history. The coloured serving trays served as context cues explicitly signalling smoking availability, that is to say, in the blue situation the presentation of the smoking cues would be followed by smoking (taking one puff), whereas in the yellow situation the presentation of the smoking cues would not be followed by smoking (smoking is not allowed). The rooms may be seen as more incidental contextual variables in which the experimental manipulation is embedded. The physical elements or characteristics of the rooms referred to a distinct semantic whole, categorized as an "office" and a "therapy 
room". However, these two rooms were equivalent in terms of their limited smoking-relevant characteristics, that is, participants were likely to evaluate these rooms as places where they would not expect to be allowed to smoke, which did not remind them of places where they have smoked before (reference to a smoking context), in which they experienced low levels of the urge to smoke, in which they were able to refuse a cigarette (control of smoking), in which they felt positive or pleasant (valence of the room), and in which they were relaxed (subjective arousal). These data were derived from an unpublished pilot study $(\mathrm{n}=22)$ in which 5 different rooms were evaluated by smokers on the above characteristics.

Similar to the procedure of Dols and colleagues (Dols, Willems, et al., 2000; Dols, van den Hout, et al., 2002), smokers were exposed to their smoking cues in either an availability or an unavailability context (signalled by a blue versus a yellow serving tray). After this, smokers were tested in the same room and in a different room. As in the two previous studies by Dols and colleagues (Dols, Willems, et al., 2000; Dols, van den Hout, et al., 2002), it was expected that (a) the context cue (i.e. serving tray) associated with smoking (US) would come to function as a conditioned stimulus (CS+) predicting the occurrence of smoking, hence eliciting a conditioned urge response, whereas the other context cue not associated with smoking (no US) would come to function as a conditioned inhibitory stimulus (CS-) predicting smoking abstinence, hence extinguishing or diminishing conditioned urge responding; (b) urge responses would be stronger when smoking cues were presented than when not, irrespective of the context cue; (c) urge responses to the smoking cues would be stronger if the 'availability context cue' was given than if the 'unavailability context cue' was given; (d) after a room context change the difference in conditioned urge response between the 'unavailability context cue' and the 'availability context cue' would be reduced (loss of generalization). 


\section{METHOD}

\section{PARTICIPANTS}

Seventeen smokers $(10$ females, 7 males; $\mathrm{M}$ age $=23.8$ years, $\mathrm{SD}=4.9)$ participated in the present study. All but three participants ( 2 males and 1 female) were students at Maastricht University and responded to posted advertisements. All participants had been smoking for at least two years, with a minimum of five cigarettes a day. The average score on the revised Fagerström Test for Nicotine Dependence (FTND; Heatherton, Kozlowski, Frecker, \& Fagerström, 1991) was 2.9 ( $\mathrm{SD}=2.5)$. Participants were not allowed to smoke for 2 hours prior to the experiment. An abstinent period of 2 hours was chosen to ensure that the desire to smoke would not be too low or too high, preventing a floor and ceiling effect of urge during the conditioning task.

\section{SETTING}

The experiment took place in two especially designed rooms at Maastricht University. Both rooms were made distinctive in their physical characteristics. One room was arranged as a typical office with two desks, two computers, office materials (e.g. pens, papers, phones, and covers), a red carpet and red office chairs, and had a window. The other room was a therapy setting with a desk, books, plants and 'nature' posters, a flip-over, and blue chairs, which had no window. The two rooms were located in two different department buildings on the university campus. Additionally, the rooms were made distinctive by spreading two different odours ('Vanilla \& Lily' and 'After Tobacco air'; Ambi Pur, Veenendaal/the Netherlands). Both rooms had an exhaust tube connected to a ventilator in the ceiling to remove smoke instantly, though the tubes were of different material and colour. 


\section{MEASURES}

Pre-acquisition phase: A 100-mm visual analogue scale (VAS) was used to measure the valence of the room (question: "In this room, I feel", range: 0 "very unpleasant/negative" - 100 "very pleasant/positive"); subjective arousal (question: "At this moment, I feel", range: 0 "very relaxed" - 100 "very tense"); urge to smoke (question: "At this moment, I feel", range: 0 "no urge to smoke at all" - 100 "an almost irresistible urge to smoke"); reference to a smoking context (question: "This room makes me think of a room in which I smoked", range: 0 "very little to not at all" - 100 "very much"); perceived control of smoking (question: "If at this moment I were offered a cigarette, I would be able to refuse", range: 0 "definitely not" - 100 "definitely"); and expectation of availability to smoke (question: "In this room I expect to be allowed to smoke", range: 0 "definitely not" - 100 "definitely"). Another VAS was used to measure the extent to which participants evaluated the two rooms as being different (question: "The first room differs from the second room", range: 0 "to a small extent" - 100 "to a large extent").

Acquisition and Test phase: A VAS was used to measure urge to smoke (question: "At this moment, I feel", range: 0 "No urge to smoke at all" - 100 "a nearly irresistible urge to smoke").

Post-experimental questionnaire: Four VASs were used retrospectively to measure pre-experimental expectations about the participants' urge to smoke when presented with the serving trays and the smoking cues (question: "To what extent - prior to the experiment - did you expect that your urge to smoke would increase, decrease or stay at the same level when presented with the yellow (or blue) serving tray", range: 0 "decrease" - 50 "same level" - 100 "increase"); (question: "To what extent - prior to the experiment did you expect that your urge to smoke would increase, decrease or stay at the same level, when presented with the yellow (or blue) 
serving tray and the cigarettes, lighter and ashtray", range: 0 "decrease" - 50 "same level" - 100 "increase").

\section{Procedure}

Participants were asked to refrain from smoking for 2 hours prior to the experiment. On arrival, participants received an introduction to the study and completed an informed consent form in the waiting room. After the introduction their expired air carbon monoxide (CO in ppm) content was measured and they completed the FTND questionnaire. Next, they were guided to two rooms for a pre-acquisition session. They were instructed to relax for 1 minute and to pay attention to the features of the room and to note what they felt and experienced at that moment. Then they completed a VAS questionnaire in which they rated 'expectation of availability to smoke'; 'reference to a smoking context'; 'urge to smoke'; 'control of smoking'; 'valence of the room'; and 'subjective arousal'. After a 5-minute break the same was done for the other room. Another VAS was used to measure the extent to which participants evaluated the two rooms as being different. Again after a short break of 3 minutes participants were taken to the room where the acquisition phase would take place.

The procedure for the acquisition phase was modelled after the study by Dols, Hout van den, et al. (2002). At the start of the acquisition phase, participants were explicitly informed about the meaning of the blue and yellow situation in which they would be exposed to their smoking cues. Seated at a table, participants were then presented with the serving tray (blue or yellow) and instructed to pay attention to the colour of the serving tray and to note their feelings and thoughts during that time. After approximately $30 \mathrm{sec}-$ onds the experimenter presented the participant with a VAS on which s/he was instructed to rate his/her urge to smoke. Then the participant was exposed to smoking cues (favourite brand of ciga- 
rettes, ashtray and lighter). The participant was instructed to handle the cues for approximately 30 seconds. The participant was instructed to touch the cigarette, smell it, place it between the lips (without being allowed to sham smoke), and hold a burning lighter near the cigarette (without being allowed to light it). Then the second VAS assessment of urge took place, followed by the occurrence or non-occurrence of smoking. If the participants were allowed to smoke, they were instructed to take one puff and exhale the smoke through a respiratory tube, followed by a reading break. In the unavailability situation participants were instructed to take the cigarette between their lips and hold a burning lighter to the cigarette, but were not allowed to light it and smoke. This was also followed by a reading break. Each participant was put in six smoking and unavailability situations that were presented in a pseudo-random order, with no more than three of the same types of situation in succession. The duration of the reading break between trials for both situations was approximately 3 minutes. The total duration of the acquisition phase was approximately 60 minutes.

The testing phase took place after a 5 minute break, in the same or the other room. There the participants were again presented with both situations (blue and yellow serving tray; 1 trial each, order counterbalanced between participants) and completed the urge VAS, followed by additional exposure to the smoking cues and again the urge VAS. After a 5-minute break participants were again tested in the other room in a similar manner. At the end of the experiment, participants filled in a post-experimental questionnaire and were debriefed. 


\section{RESULTS}

\section{DATA REDUCTION AND ANALYSES}

Results will be reported for the three main phases of the experiment: pre-acquisition, acquisition and test. During the preacquisition 'perceived expectation of availability to smoke'; 'reference to a smoking context'; 'urge to smoke'; 'control of smoking'; 'valence of the room'; and 'subjective arousal' were rated on a 100mm VAS. This was done for the two rooms: the 'office' and the 'therapy room'. In addition, a 100-mm VAS was used to measure the extent to which participants felt the two rooms to be different. To test a potential context change effect, the rooms used in this experiment had to be physically different but equivalent in terms of their smoking-relevant characteristics. That is, both contexts had to produce the same response pattern for all these measures. Pairedsample t-tests were used to test this hypothesis.

During acquisition and testing, every presentation of the coloured serving tray (context cue) and every presentation of the smoking cues (cue) was followed by a VAS (urge to smoke). During the acquisition phase, there were 6 trials of each context cue (yellow and blue serving tray) and during every trial context cues were presented alone and with smoking cues. Thus during acquisition there were 24 measurements of urge to smoke. A $2 \times 2 \times 6$ (smoking cue $\mathrm{x}$ context cue $\mathrm{x}$ trial) repeated measures analysis of variance (ANOVA) was performed for the acquisition phase with the self-reported urge to smoke. During the test phase, each context cue was presented alone and with smoking cues. Thus the urge was measured 4 times during the test. For the test phase a $2 \times 2 \times 2$ (context change $\mathrm{x}$ context cue $\mathrm{x}$ smoking cue) repeated measures ANOVA was conducted.

The post-experimental questionnaire, using VASs, retrospectively measured pre-experimental expectations about the urge to 
smoke when presented with serving trays and smoking cues. Pairedsample t-tests were used to test differences.

\section{PRE-ACQUISITION}

Table 1 displays mean scores for the two contexts on all the indices. There were no significant differences measured between 'office' context and 'therapy-room' context on all the indices (-1.04 $<$ ts < 1.01; ps > .32). However, participants did evaluate these rooms as being perceptually distinct, which is demonstrated by the average score on the VAS measure 'difference between rooms' (M $=62.4 ; \mathrm{SD}=21.1 ; \mathrm{t}=12.23 ; \mathrm{df}=16 ; \mathrm{p}<.01)$. Thus, the 'office' context and the 'therapy-room' context were equivalent in terms of their limited smoking-relevant characteristics, yet distinct in terms of their physical characteristics.

Table 1. Mean scores on smoking-related measures for the two contexts/rooms.

\begin{tabular}{lllllll}
\hline & $\begin{array}{l}\text { Arousal } \\
\text { M (SD) }\end{array}$ & $\begin{array}{l}\text { Valence } \\
\text { M (SD) }\end{array}$ & $\begin{array}{l}\text { Urge } \\
\text { M } \\
(\mathrm{SD})\end{array}$ & $\begin{array}{l}\text { Reference } \\
\text { M (SD) }\end{array}$ & $\begin{array}{l}\text { Control } \\
\text { M (SD) }\end{array}$ & $\begin{array}{l}\text { Expectancy } \\
\text { M (SD) }\end{array}$ \\
\hline 'The & 34.0 & 55.2 & 34.5 & $36.7(30.2)$ & 58.8 & 32.5 \\
office' & $(19.1)$ & $(20.7)$ & $(16.7)$ & & $(28.1)$ & $(25.1)$ \\
'The & 32.4 & 62.9 & 30.5 & $26.1(25.2)$ & 61.8 & 33.7 \\
therapy & $(15.5)$ & $(15.6)$ & $(18.1)$ & & $(28.4)$ & $(28.6)$ \\
room' & & & & & & \\
\hline
\end{tabular}

\section{ACQUISITION}

Hypothesis (a): urges to smoke are stronger if the availability context cue is given than if the unavailability context cue is given.

The mean urges to smoke scores in all four conditions as measured during the acquisition phase are shown in table 2 . The effects of context cues and smoking cues on urge to smoke during 


\section{SMOKING IN CONTEXT}

the acquisition phase are depicted in figure 1. As predicted, participants who expected smoking to occur after exposure reported a stronger urge compared to participants who expected that smoking would not occur. This was revealed by a significant main effect of context cue $(F(1,16)=10.47 ; p<.01)$. In general, smokers experienced higher levels of urge when exposed to a context cue that predicted smoking than when exposed to a context cue that predicted no smoking. Thus, the context cues acquired the capacity to differentially elicit urge responding.

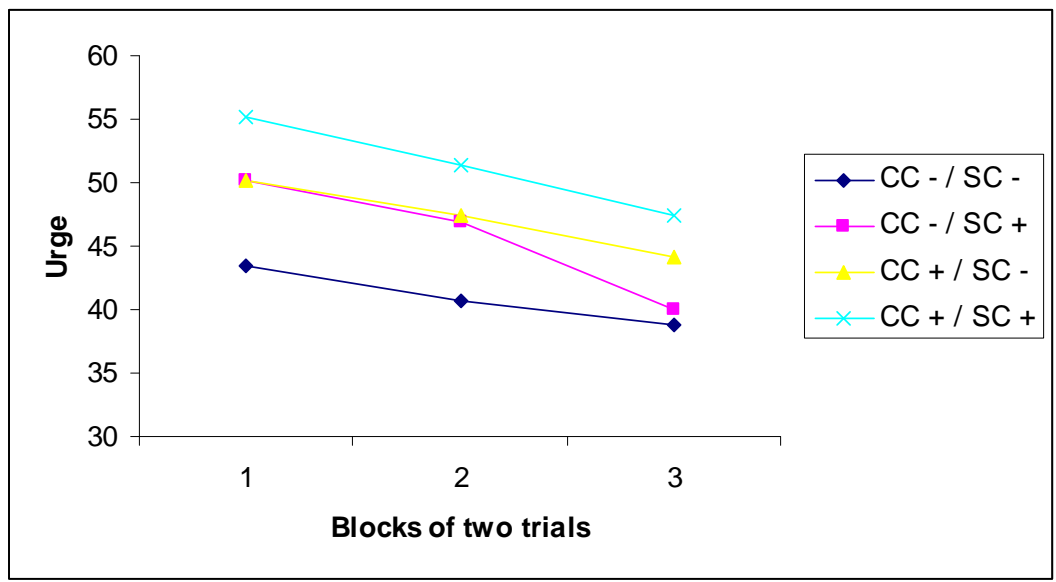

Figure 1. Effects of context cues and smoking cues during the acquisition phase. $(C C-)=$ unavailability context cue; $(C C+)=$ availability context cue; $(S C-)=$ smoking cues absent $;(S C+)=$ smoking cues present .

Hypothesis (b): urges to smoke are stronger when smoking cues are presented than when not, irrespective of the context cues.

A significant main effect of smoking cues confirmed the hypothesis that participants report stronger urges when exposed to their smoking cues than when not, irrespective of the context cues $(\mathrm{F}(1,16)=8.21 ; \mathrm{p}<.05)$. As depicted in figure 1, the lines repre- 
senting the presence of smoking cues $(\mathrm{SC}+)$ are higher than the lines representing the absence of smoking cues (SC -) on all three trials, with the exception of CC - / SC + on trial 3.

Hypothesis (c): urges to smoke in response to smoking cues are stronger if the availability context cue is given than if the unavailability context cue is given.

The prediction that urge responding to the smoking cues should be stronger if the availability context cue is given than if the unavailability context cue is given could not be confirmed by a significant context cues $\mathrm{x}$ smoking cues interaction $(\mathrm{F}(1,16)=0.18 ; \mathrm{p}$ $=.69$ ). Thus, the urge-inducing effects of the smoking cues were the same for both context cues.

Table 2 Mean urge to smoke scores in all four conditions $(n=17)$ in blocks of two trials (blocks 1-3) of the acquisition phase.

\begin{tabular}{lllll}
\hline & $\begin{array}{l}\mathrm{CC}-/ \mathrm{SC}- \\
\mathrm{M}(\mathrm{SD})\end{array}$ & $\begin{array}{l}\mathrm{CC}-/ \mathrm{SC}+ \\
\mathrm{M}(\mathrm{SD})\end{array}$ & $\begin{array}{l}\mathrm{CC}+/ \mathrm{SC}- \\
\mathrm{M}(\mathrm{SD})\end{array}$ & $\begin{array}{l}\mathrm{CC}+/ \mathrm{SC}+ \\
\mathrm{M}(\mathrm{SD})\end{array}$ \\
\hline Block 1 & $43.4(21.0)$ & $50.1(22.2)$ & $50.2(18.4)$ & $55.2(19.1)$ \\
Block 2 & $40.7(22.0)$ & $46.9(19.6)$ & $47.4(25.4)$ & $51.4(24.0)$ \\
Block 3 & $38.8(23.2)$ & $40.0(21.4)$ & $44.1(24.9)$ & $47.4(24.2)$ \\
& & & & \\
\hline
\end{tabular}

Note. $(C C-)=$ non-smoking context cue; $(C C+)=$ availability context cue; $(S C-)=$ smoking cues absent; $(S C+)=$ smoking cues present .

\section{EFFECT OF THE TRIAL}

An overall effect of the trial was found, indicating a significant decrease of urge over trials for all four conditions (lines) in figure $1(\mathrm{~F}(5,80)=3.14 ; \mathrm{p}<.05)$. More specifically, results showed a significant smoking cues $\mathrm{x}$ trial interaction $(\mathrm{F}(5,80)=4.35$; $\mathrm{p}<$ $.01)$. No significant context cue $\mathrm{x}$ smoking cue $\mathrm{x}$ trial interaction was revealed $(F(5,80)=0.74 ; p>.59)$. To further examine this in- 
teraction, separate post hoc tests were conducted with trial as the independent variable and urge responding in the presence or absence of smoking cues as the dependent variable, using a Bonferroni-corrected rejection criterion of $\alpha=.025$. Urge responding to the presence of the smoking cues significantly decreased from the first to the last trial $(\mathrm{F}(5,80)=5.77 ; \mathrm{p}<.01)$, whereas urge responding to the absence of the smoking cues remained the same from the first to the last trial $(F(5,80)=1.20 ; p>.30)$. This suggests an overall extinction of urge responding when participants are repeatedly exposed to their smoking cues.

\section{TEST}

The results of the acquisition phase showed differential learning in the case of the context cues. That is, the availability context cue that confirmed the association between smoking cues and smoking behaviour elicited an urge response, whereas the unavailability context cue that weakened the association between smoking cues and smoking behaviour became a conditioned stimulus inhibiting urge responding. The data therefore allowed a test for hypothesis (d):

Hypothesis (d): after a room context change the difference in conditioned urge response between the 'unavailability context cue' and the 'availability context cue' will be reduced (loss of generalization).

The mean urges to smoke scores in all four conditions as measured during the test phase are shown in table 3. The effects of context cues and smoking cues on the urge to smoke during the test phase are shown in figure 2. A significant main effect of context cue was found $(\mathrm{F}(1,16)=7.87 ; \mathrm{p}<.05)$ indicating a higher urge score for the availability context cue than for the unavailability context cue. As can be seen in figure 2, the lines representing the condition 
of the availability context cue $(\mathrm{CC}+)$ are higher than the lines representing the condition of the unavailability context cue (CC -). Thus a room context change did not change differential urge responding to the context cues. The availability context cue kept its ability to elicit conditioned urge responding, whereas the unavailability context cue kept its ability to reduce urge responding, as learned during the acquisition phase of this experiment. In other words, the acquired discriminative ability of the context cues generalized after a context switch. There was also a significant main effect of context change $(F(1,16)=6.33 ; p<.05)$, which indicates that urge scores were significantly lower if a context change did occur than if not. Analyses did not reveal any other significant interactions or main effects.

Table 3. Mean urge to smoke scores in all four conditions $(n=17)$ during the test phase.

\begin{tabular}{lllll}
\hline Context change & $\begin{array}{l}\mathrm{CC}-/ \mathrm{SC}- \\
\mathrm{M}(\mathrm{SD})\end{array}$ & $\begin{array}{l}\mathrm{CC}-/ \mathrm{SC}+ \\
\mathrm{M}(\mathrm{SD})\end{array}$ & $\begin{array}{l}\mathrm{CC}+/ \mathrm{SC}- \\
\mathrm{M}(\mathrm{SD})\end{array}$ & $\begin{array}{l}\mathrm{CC}+/ \mathrm{SC}+ \\
\mathrm{M}(\mathrm{SD})\end{array}$ \\
\hline Yes & $29.6(25.5)$ & $30.1(26.1)$ & $37.2(24.3)$ & $37.9(25.5)$ \\
No & $35.9(26.2)$ & $37.7(26.2)$ & $39.2(23.7)$ & $43.2(24.0)$ \\
& & & & \\
\hline
\end{tabular}

Note. $(C C-)=$ unavailability context cue $;(C C+)=$ availability context cue; $(S C-)=$ smoking cues absent $;(S C+)=$ smoking cues present . 


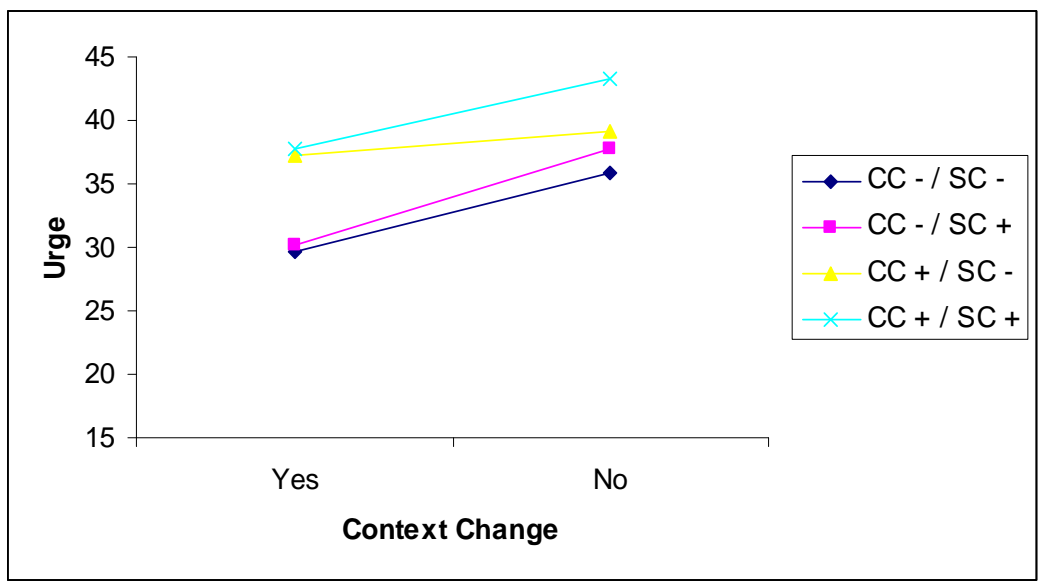

Figure 2. Effects of context change on context cues and smoking cues during the test phase. $(C C-)=$ unavailability context cue; $(C C+)=$ availability context cue; $(S C-)=$ smoking cues absent; $(S C+)=$ smoking cues present.

\section{PoST-EXPERIMENTAL QUESTIONNAIRE}

Paired-sample t-analyses revealed that participants have a significantly higher expectation that the addition of the smoking cues would increase their urge to smoke in comparison with the mere presentation of the context cues (serving trays), both in case of the unavailability context cue $(\mathrm{t}=4.71$, df $=16, \mathrm{p}<.01)$ and the availability context cue $(\mathrm{t}=5.53, \mathrm{df}=16, \mathrm{p}<.01)$.

\section{DISCUSSION}

The main finding of the studies by Dols and colleagues (Dols, Willems, et al., 2000; Dols, van den Hout, et al., 2002) was replicated by this experiment. Smokers reliably report higher levels of the urge to smoke when exposed to a context cue predicting the occurrence of smoking than when exposed to a context cue predicting absti- 
nence from smoking. However, on the basis of the present study the hypothesis that urges induced by smoking cues (lighter, cigarettes, and ashtray) are stronger if the availability context cue is given than if the unavailability context cue is given could not be confirmed. Rather, it was found that smoking cues still elicited urge responding irrespective of the context cues. Dols and colleagues (Dols, van den Hout, et al., 2002), however, did find an interaction between context cues and smoking cues, indicating that in case the availability context cue that predicts smoking was given, the smoking cues elicited an additional urge to smoke in comparison with the unavailability context cue that predicted no smoking. This interaction was only observed in the group that did not receive a belief neutralization manipulation (by reading a statement at the beginning of the experiment informing the subjects that research has found contradicting results with regard to the urge-eliciting capacity of smoking contexts and non-smoking contexts). The authors suggested that this difference was due to a demand effect, that is, participants could have held pre-experimental expectations of what the outcome of the study should be. In the present study no belief neutralization was conducted. Therefore it is suggested that there was a general expectation that smoking cues would elicit an urge to smoke regardless of a given context cue. A post-experimental check (the questions asked referred to pre-experimental expectations) of expectations revealed that participants did have a significantly higher expectation that the addition of the smoking cues would increase their levels of urge in comparison with the mere presentation of the context cues (serving trays), both in case of the unavailability context cue and the availability context cue being given. Thus, these pre-experimental expectations generally could have generated the stronger urge scores after presentation of the smoking cues, irrespective of the given context cues. Nevertheless, the context cues that were previously not associated with smoking immediately acquired the potential of elicited 
differential conditioned urge response depending on their predictive value for smoking. The smoking expectancy, in this case signalled by environmental cues (coloured serving trays), seems to be crucial for these cues to acquire the ability to control urge reactivity. This finding is in line with the growing body of literature on the effect of perceived drug use availability on the capacity of drug-related cues to elicit the urge to use (for a review see Wertz \& Sayette, 2001). For example, Carter and Tiffany (2001) repeatedly exposed smokers to either a lit cigarette in an ashtray or a glass of water. On each trial participants were informed about the probability $(0 \%, 50 \%$ or 100 $\%$ ) of being able to either take a puff of the cigarette or take a sip of the water. In this way they manipulated cigarette availability and found that urge ratings increased on cigarette trials with increased availability to smoke, whereas no effect was observed on urge with increased availability on the water trials.

One could argue that the present results are the result of experimental demand as the participants were instructed beforehand about the predictive value of the coloured serving trays instead of learning these contingencies through experience. In other words, participants would behave according to received instructions rather than demonstrate conditioned urge responding. However, the participants were not explicitly informed about the specific hypotheses regarding urge responding and thus can be said to behave according to the acquired contingencies between the coloured trays and smoking availability. Contemporary human learning research has repeatedly demonstrated that conditioned responding (both subjective and psychophysiological responding) is based on such acquired associations and that these associations can be acquired through both instructions and trial-by-trial experience (see for instance Dawson \& Shell, 1987; Davey, 1992; Lovibond, 2003). Furthermore, by giving information about the CS-US contingency before the conditioning task, conscious awareness of this association is raised and therefore 
conditioning effects could be facilitated, as suggested and studied by Dawson and colleagues (e.g. Dawson, 1973; Dawson \& Shell, 1987; see also Field and Duka, 2001, for an application of these principles in a discriminative classical conditioning task with smokers). As such, the urge responses elicited by the coloured serving trays can be described as conditioned urge responding. Note that the issue of possible experimental demand in an experimental preparation of the present type was explicitly and empirically addressed by Dols, Hout van den, et al. (2002). Dols, Hout van den, et al. (2002) controlled for this effect by conducting a belief-neutralization procedure for half of the subjects prior to participation in the experiment (by reading a statement at the beginning of the experiment informing the subjects that research has found contradicting results with regard to the urge-eliciting capacity of smoking contexts and non-smoking contexts). A post experimental questionnaire tested the effect of the belief neutralization on personal and research beliefs regarding effect of cues and context on urge to smoke. No differences were found on personal and research beliefs except for the non-smoking context without smoking cues condition (CC- / SC-). The expected urge to smoke was significantly lower than all the other conditions of the researcher's beliefs. If only the CC- / SCcondition differed the belief neutralization group this difference would have an effect on the depended variable urge to smoke and thus the two groups would have differed on urge scores in the CC- / $\mathrm{SC}$ - condition. Despite the fact that the group differed in expectation, there was no effect on urge scores in the CC- / SC- condition between the two groups, indicating that experimental demand was minimal. Furthermore, they found that this procedure did not fundamentally affect results, that is, irrespective of belief-neutralization participants reported stronger urges when exposed to the availability context cue than when exposed to the unavailability context cue. In other words, beliefs about the outcome of the experiment did not 
appear to affect results at all. As the present experimental procedure is similar to the procedure used by Dols and colleagues (2002) it is unlikely that experimental demand effects have played an important role in the present findings.

The present results further showed that changing room contexts did not lead to the reduction of differential urge responding controlled by the availability and the unavailability context cue. Urge responses were stronger if the availability context cue was given than if the unavailability context cue was given and this generalized to a room context different from the context in which the acquisition phase took place. It could be argued that the context change in the present study was hardly a challenge, as both rooms only differed in their physical characteristics and not in their smoking-relevant characteristics. It is feasible that a context change has to be of sufficient significance with regard to the prediction of smoking availability, in other words the prediction of the occurrence of smoking (i.e. US), before context can modulate previous learned expectancies. The context change therefore has to be meaningful in relation to the availability of smoking. For example, changing the context from a 'low smoking-relevant' to a 'high smoking-relevant' context (for instance a bar) could be meaningful enough to alter the expectancy relation of the context cues and/or smoking cues, hence causing a reduction of differential conditioned urge responding between the context cues. This would demonstrate that there is a more complex relationship between cues, context cues and broader contexts in the human classical conditioning phenomenon. Whether the generalization of learned differential urge responding across environmental contexts depends on the relevance for smoking of the contexts requires further research.

The finding that the urge to smoke can be controlled by expectations regarding the occurrence of smoking provides support for a cognitive perspective on cue exposure treatment. As Dols, Hout 
van den, et al. (2002) proposed, smokers can learn to control or even master their urge to smoke by controlling their expectancies regarding smoking. Therapists, using a similar procedure as Dols and colleagues (Dols, Willems, et al. 2000; Dols, Hout van den, et al. 2002), can teach smokers that their urge to smoke is not an uncontrollable phenomenon, triggered by environmental stimuli, but is something that (partly) depends on their own expectations regarding the occurrence of smoking. Smokers who take the decision to quit smoking but are confronted with strong levels of urge can hold ineffective beliefs and ideas concerning the consequences of their urge experiences. They could for instance hold the belief that urge automatically has to lead to smoking; that one loses control over smoking behaviour; that one turns mad if one does not smoke; etcetera. Although a wide range of cues, context cues, contexts and the urge itself can lead to high levels of urge, cue exposure can be taken as a (final) behavioural experiment, during which the client can discover and experience that urge does not have to lead to smoking and that early cognitions (i.e. expectations, beliefs, etc.) can be modified. The results of this study, although preliminary, also point to the importance, for therapists and clients, of the role of the wider context in which cue exposure takes place, and this in relation to the smoking-related contexts outside the exposure context. The finding that no context change effect became apparent after changing room contexts - which are different in terms of their physical characteristics but are equivalent as regards their low smoking-relevant characteristics - points to the possibility of generalizing learned expectations concerning smoking from these kinds of contexts. Although in this study participants were not attempting to quit and thus were not at risk of relapsing, an analogue can be drawn for determinants of maintaining drug use behaviour. Following Marlatt \& Gordon's (1985) theoretical framework of determinants of relapse, the two rooms/contexts used in this study can be defined as 'low risk situa- 
tions' as opposed to 'high risk situations'. That is, these rooms/contexts possess a low risk for relapse because of their low smoking-relevant characteristics. It should be noted, though, that the present sample size was small and comprised mainly light smokers (FTND $=2.9)$ who were not attempting to quit smoking at the time of testing. Although the population of Dols, Hout van den, et al. (2002) had an average FTND of 2.13 while smoking at least 10 cigarettes a day. Therefore, whether learning to control cue-elicited urges truly constitutes a valuable treatment component requires further empirical validation.

To recapitulate, this study replicated the main finding of context dependency of cue-elicited urge to smoke using a procedure similar to that of Dols and colleagues (Dols, Willems, et al., 2000; Dols, van den Hout, et al., 2002). The expectancy of smoking availability increases urge responding in comparison with the expectation of smoking unavailability. Smokers can thus be taught to exert control over their urge by manipulating their expectancies regarding cue-elicited urge and smoking behaviour. This supports a more cognitive approach in deploying cue exposure strategies in the treatment of addiction. In addition, this study provides preliminary support for generalization of the effect of learned expectations of availability to smoke on the urge to smoke. As such, the present results warrant further research to examine the degree to which learning to control one's urge to smoke will be beneficial for the treatment of smoking addiction. 


\section{CONTEXT-DEPENDENCY OF CUE-ELICITED URGE TO SMOKE}

\section{REFERENCES}

Baker, T.B., Morse, E. \& Sherman, J. E. (1987) The motivation to use drugs: A psychobiological analysis of urges. In C. Rivers (Ed.), The Nebraska Symposium on Motivation: Alcohol use and abuse (pp. 257-323) Lincoln: University of Nebraska Press.

Bouton, M. E. (1988) Context and ambiguity in the extinction of emotional learning: implications for exposure therapy. Behavior Research and Therapy, 26, 137-149.

Bouton, M. E. (2000) A learning theory perspective on lapse, relapse, and the maintenance of behavior change. Health Psychology, 19, 57-63.

Bouton, M. E. \& Bolles, R. C. (1979) Contextual control of the extinction of conditioned fear. Learning and motivation, 10, 445-466.

Bouton, M. E. \& Swartzentruber, D. (1991) Sources of relapse after extinction in Pavlovian and instrumental learning. Clinical Psychology Review, 11, 123-140.

Carter, B. L. \& Tiffany, S. T. (1999) Meta-analysis of cue reactivity in addiction research. Addiction, 94, 327-340.

Carter, B. L. \& Tiffany, S. T. (2001) The cue-availability paradigm: the effects of cigarette availability on cue reactivity in smokers. Experimental and Clinical Psychopharmacology, 9, 183-190.

Conklin, C. A. \& Tiffany, S. T. (2002) Applying extinction research and theory to cueexposure addiction treatments. Addiction, 97, 155-167.

Collins, B. N. \& Brandon, T. H. (2002) Effects of extinction context and retrieval cues on alcohol cue reactivity among nonalcoholic drinkers. Journal of Consulting and Clinical Psychology, 70, 390-397.

Davey, G. C. L. (1992) Classical conditioning and the acquisition of human fears and phobias: A review and synthesis of the literature. Advances in Behaviour Research and Therapy, 14, 29-66.

Dawson, M. E. (1973) Can classical conditioning occur without contingency learning? A review and evaluation of the evidence. Psychophysiology, 10, 82-86.

Dawson, M. E. \& Schell, A. M. (1987) The role of 'controlled' and 'automatic' cognitive processes in human autonomic classical conditioning. In G. C. L. Davey (Ed.), Cognitive processes and Pavlovian conditioning in humans. Chichester: John Wiley.

Dols, M., Willems, B. W., van den Hout, M. \& Bittoun, R. (2000) Smokers can learn to influence their urge to smoke. Addictive Behaviors, 25, 103-108.

Dols, M., van den Hout, M., Kindt, M. \& Willems, B. (2002) The urge to smoke depends on the expectation of smoking. Addiction, 97, 87-93.

Droungas, A., Ehrman, R. N., Childress, A. R. \& O’Brien, C. P. (1995) Effect of smoking cues and cigarette availability on craving and smoking behavior. Addictive Behaviors, 20, 657-673.

Drummond, D. C. (2000) What does cue-reactivity have to offer clinical research. Addiction, 95, (suppl. 2), S129-144.

Drummond, D. C. \& Glautier, S. (1994) A controlled trial of cue exposure treatment in alcohol dependence. Journal of Consulting and Clinical Psychology, 62, 809-817. 


\section{SMOKING IN CONTEXT}

Drummond, D. C., Cooper, T. \& Glautier, S. P. (1990) Conditioned learning in alcohol dependence: implications for cue exposure treatment. British Journal of Addiction, 85, 725-743.

Drummond, D. C., Litten, R. Z., Lowman, C. \& Hunt, W. A. (2000) Craving research: future directions. Addiction, 95, (suppl. 2), S247-255.

Field, M. \& Duka, T. (2001) Smoking expectancy mediates the conditioned responses to arbitrary smoking cues. Behavioural Pharmacology, 12, 183-194.

Franken, I. H. A., de Haan, H. A., van der Meer, C. W., Haffmans, P. M. J. \& Hendriks, V. M. (1999) Cue reactivitity and effects of cue exposure in abstinent posttreatment drug users. Journal of Substance Abuse Treatment, 16, 81-85.

Havermans, R. C. \& Jansen, A. T. M. (2003). Increasing the efficacy of cue exposure treatment in preventing relapse of addictive behavior. Addictive Behaviors, 28, 989-994.

Heatherton, T. F., Kozlowski, L. T., Frecker, R. C. \& Fagerström, K. (1991) The Fagerström Test for Nicotine Dependence: A revision of the Fagerström Tolerance Questionnaire. British Journal of Addiction, 86, 1119-1127.

Juliano, L. M. \& Brandon, T. H. (1998) Reactivity to instructed smoking availability and environmental cues: evidence with urge and reaction time. Experimental and Clinical Psychopharmacology, 6, 45-53.

Lavez, A. B., Herzog, T. A., \& Brandon, T. H. (1999) Classical conditioning of environmental cues to cigarette smoking. Experimental and Clinical Psychopharmacology, 7, 56-63.

Lee, N. K. \& Oei, T. P. S. (1993) Exposure and response prevention in anxiety disorders: implication for treatment and relapse prevention in problem drinkers. Clinical Psychological Review, 13, 619-632.

Marlatt, G. A. (1985) Situational determinants of relapse and skill-training interventions. In G. A. Marlatt \& J. R. Gordon, (Eds.). Relapse prevention (pp. 71-127). New York: Guilford Press.

Monti, P. M., Rohsenow, D. J., Rubonis, A. V., Niaura, R. S., Sirota, A. D., Colby, S. M., Goddard, P. \& Abrams, D. B. (1993) Cue Exposure with coping skill treatment for male alcoholics: A preliminary investigation. Journal of Consulting and Clinical Psychology, 61, 1011-1019.

Niaura, R., Rohsenow, D. J., Binnkoff, J. A., Monti, P. M., Pedrazza, M. \& Abrams, D. B. (1988) Relevance of cue reactivity to understanding alcohol and smoking relapse. Journal of Abnormal Psychology, 97, 133-152.

Niaura, R., Abrams, D. B., Shadel, W. G., Rohsenow, D. J., Monti, P. M. \& Sirota, A. D. (1999) Cue exposure treatment for smoking relapse prevention: a controlled clinical trial. Addiction, 94, 685-695.

O’Brien, C. P., Childress, A. R., McLellan, T. \& Ehrman, R. (1990) Integrating systematic cue exposure with standard treatment in recovering drug dependent patients. Addictive Behaviors, 15, 355-365.

Powell, J., Gray, J., \& Bradley, B. P. (1993) Subjective craving for opiates: Evaluation of a cue exposure protocol for use with detoxified opiate addicts. British Journal of Clinical Psychology, 32, 39-53. 


\section{CONTEXT-DEPENDENCY OF CUE-ELICITED URGE TO SMOKE}

Staiger, P. K., Greeley, J. D. \& Wallace, S. D. (1999) Alcohol exposure therapy: generalization and changes in responsivity. Drug and Alcohol Dependence, 57, 29-40.

Tiffany, S. T. (1990) A cognitive model of urges and drug-use behavior: Role of automatic and non-automatic processes. Psychological Review, 97, 147-168.

Wertz, J. M. \& Sayette, M. A. (2001) A review of the effects of perceived drug use opportunity on self-reported urge. Experimental and Clinical Psychopharmacology, 9, 3-13. 
SMOKING IN CONTEXT 


\section{Chapter 4}

From the OfFICE TO THE PUB:

The Role OF SMOKE RELEVANT CONTEXTS ON CUE-ELICITED URGE TO SMOKE

Roy THEWISSEN, VALERIE A. F. VAN DER MEIJDEN, REMCO C. HAVERMANS, MARCEl VAN DEN Hout, ANITA JANSEN 


\begin{abstract}
In the present study it was investigated how environmental context can affect cue-elicited urges to smoke. A total of 33 smokers were repeatedly presented with a cue predicting smoking and a cue predicting no smoking in one room and tested for an effect of context change in a different room. Results replicated earlier findings that a cue predicting smoking availability elicited greater urges to smoke than a cue predicting smoking unavailability. Furthermore, this study showed that a context switch from a low smoke relevant room to a high smoke relevant room reduces the learned differential urge responding between the two availability cues. These findings are discussed in relation to the role that smoke relevant contexts play in generalization of differential urge responding after a context switch.
\end{abstract}

Keywords: availability, context, cue exposure, differential conditioning, urge to smoke, generalisation, smoke relevance 
Smokers consistently report higher levels of urge to smoke when exposed to smoking-related cues (Carter \& Tiffany, 1999; Niaura et al., 1988). This phenomenon of cue-elicited urge to smoke has been studied with the cue reactivity paradigm that is based on the theoretical framework of Pavlovian conditioning (Lavez, Herzog, \& Brandon, 1999). According to this theory, stimuli or cues become associated with smoking and come to act as conditioned stimuli (CSs) predicting the occurrence of smoking (the unconditioned stimulus; US) and eliciting both conditioned physiological and psychological responses (conditioned responses, CRs), termed cue reactivity. Although a wide variety of measurements to asses cue reactivity has been conducted in the addiction research field, self reported urge to use a drug has been found to be a more robust and cue specific measure than psychophysiological responses (see Carter \& Tiffany, 1999). Furthermore, subjectively experienced urge to smoke is a prominent aspect of smoking-related cue reactivity that plays an important role in the maintenance and (re)lapse of smoking addiction (e.g. Killen \& Fortmann, 1997; Shiffman, Paty, Gnys, Kassel \& Hickcox, 1996; Shiffman, et al. 1997).

The cue reactivity paradigm has been adopted by many researchers to study different aspects of cue-induced processes and responses in addicts. One factor that could influence cue-elicited urge to use a drug is drug use availability. The influence of perceived availability of drug use as a moderator of urges or craving has been studied by several researchers. In their review of these studies Wertz and Sayette (2001) conclude that nicotine, alcohol, cocaine and opiate dependent persons consistently report stronger urges when they perceive their drug available for use than when not. Carter and Tiffany (2001) argue that a cue-availability paradigm extends the classical procedure of cue reactivity by taking into account the effect of drug availability on cue reactivity.

But when does one perceive drug use availability? Of 
course, direct drug-related cues may function as such a signal for drug use, but within certain contexts prohibiting drug use these drug-related cues are less meaningful. For example, smoking is prohibited at the cinema. Looking at an actor (or actress) smoking a cigarette will probably not elicit much urge in a smoker, but observing someone else smoking a cigarette inside a pub will almost certainly elicit strong urges to smoke. Carter and Tiffany (2001), and Wertz and Sayette (2001) have argued that such contextual control of urges depends on their function signalling drug use opportunity or not. It is likely that such a signalling function is acquired through Pavlovian conditioning; that is, learning an association between environmental context and smoking. Indeed, Conklin (in press) demonstrated that distal smoking cues such as a smoking-related environment elicit smoking urges just as well as more proximal smoking cues such as cigarettes, a lighter or an ashtray. Likewise, certain contexts being associated with the absence of smoking might function as conditioned inhibitors, thus inhibiting any urge to smoke.

Dols, Willems, van den Hout and Bittoun (2000) investigated whether cue-elicited urges to smoke depends on a long history of associative learning, or rather on the conscious expectation to be able to smoke or not. Smokers were exposed to two different availability cues: a yellow card predicting no smoking and a blue card predicting the opportunity to smoke. For each availability cue, urge to smoke was rated before and after the presentation of explicit smoking cues (i.e., favourite brand of cigarettes, ashtray, and lighter). Results showed that smoking cues elicit less urge when exposed to the non-availability cue than when exposed to the smoking availability cue (see also Dols, van den Hout, Kindt, \& Willems, 2002). Moreover, the urge to smoke came under the complete control of the availability cues. These results were successfully replicated under more stringent conditions (see Dols, van den Hout, Kindt, \& Willems, 2002). It was concluded that smoking availabil- 
ity cues elicit urges as a result of the expectation of smoking rather than a long history of associative learning. However, this finding could not be confirmed in subsequent studies using a similar discriminative conditioning procedure (Thewissen, van den Hout, Havermans, \& Jansen, 2005; see also Thewissen, et al., in press). Smoking cues remained able to elicit smoking urges in these particular studies. It thus seems that not only the expectation of smoking, signalled by higher order (availability) cues, is responsible for smoking cue reactivity, but also depends to some extent on a history of associative learning.

Dols et al. (2002) speculated on a more cognitive approach in conducting cue exposure treatment in addiction. They argued that: "Therapists would have a powerful tool to teach smokers that their urge to smoke is not an uncontrollable phenomenon, triggered by stimuli, but something that depends strongly on their personal expectations regarding the occurrence of smoking" (p. 92 in Dols et al. 2002). Thus, learning that the urge to smoke depends on one's expectations might prove to be beneficial in the treatment of addictive smoking behaviour. However, such learning will only be a beneficial treatment tool if what one learns generalizes from the treatment setting to other environmental contexts. Whether this is the case was investigated by Thewissen and colleagues (2005). They used a discriminative classical conditioning paradigm similar as Dols and colleagues (2002) and again found that urge to smoke was higher following the availability cue than following the unavailability cue. Thewissen, et al. (2005) also investigated whether an environmental context change would reduce such differential urge responding to the availability cues. It was found that the availability cues did not lose their predictive value in another environment; that is, urge to smoke was still higher following the availability cue than following the unavailability cue. Thus, the meaning of the availability cues that was learned in one environmental setting, 
as indexed by the differential urge responding, generalized fairly well to another setting. However, the environmental contexts that were used differed on their physical characteristics, but were equivalent on their (low) smoke relevant characteristics, that is, participants evaluated the rooms as environments where they did not expect to be allowed to smoke, that did not remind them of places where they generally smoke, in which they experienced low levels of urge to smoke, in which they felt able to refuse a cigarette, in which they felt positive or pleasant and in which they were relaxed. One may argue that a change from one low smoke relevant environment to another may not be meaningful enough regarding the availability of smoking and, thus, did not attenuate differential urge responding to the availability cues. Therefore, it is conceivable that a context change from a low to particularly a high smoke relevant setting will reduce the differential urge responding between availability cues (i.e. loss of generalization). This possible complex relationship between environmental contexts, availability cues and smoking cues in eliciting urge to smoke was investigated in the present experiment. In other words, the importance of the smokerelevance of a change of environmental contexts on learned differential urge responding between availability cues was manipulated in this study. Similar to Thewissen, et al. (2005) a discriminative classical conditioning procedure was used in which 'cue availability' (Carter \& Tiffany, 2001) or 'perceived drug use opportunity' (Wertz $\&$ Sayette, 2001) is manipulated. The aim of the present experiment was to determine whether an environmental context change reduces the differential urge responding between availability cues.

Similar to the procedure of Thewissen, et al. (2005), smokers were exposed to their smoking cues after presentation of either an availability or an unavailability cue (signalled by a blue versus a yellow serving tray) in either a low or high smoke relevant environment. After this acquisition phase, smokers were tested both in a 
low and a high smoke relevant setting. It was expected that (a) the availability cue (i.e. serving tray) associated with smoking (US) would come to function as a conditioned stimulus (CS+) predicting the occurrence of smoking, hence eliciting a conditioned urge response, whereas the unavailability cue associated with no smoking (no US) would come to function as a conditioned inhibitory stimulus (CS-) predicting smoking abstinence, hence extinguishing or diminishing conditioned urge responding; (b) urge responses would be stronger when smoking cues were presented than when not, irrespective of the availability cue; (c) urge responses to the smoking cues would be stronger if the 'availability cue' was given than if the 'unavailability cue' was given; (d) after an environmental context change the difference in conditioned urge response between the 'unavailability cue' and the 'availability cue' is reduced (loss of generalization), and significantly more so after a switch from a low to a high smoke relevant setting than after a switch from a high to a low smoke relevant setting.

\section{Method}

\section{Participants}

Participants were 33 (23 females, 10 males; mean age $=$ 21.70; $\mathrm{SD}=2.57$; range $=18-27$ ) smokers who were recruited personally or responded to posted advertisements at Maastricht University. Only subjects who had smoked for at least two years, with a minimum of five cigarettes a day, were allowed to participate in the present study. Participants were generally light dependent smokers as indicated by the average score of $2.94(\mathrm{SD}=1.93)$ on the revised Fagerstrom Test for Nicotine Dependence (FTND, Heatherton, Kozlowski, Frecker, \& Fagerstrom, 1991). Nine participants (27\%) reported smoking 10 or less cigarettes a day, twenty-two (67\%) between 11 and 20 cigarettes, one (3\%) between 21 and 30 ciga- 
rettes, and one (3\%) more than 31 cigarettes. Participants had to abstain from smoking two hours prior to testing. This abstinence period was chosen in order to prevent floor or ceiling effects of urge to smoke during the experiment.

\section{SETTING}

The experiment was carried out in two specially designed rooms at Maastricht University. Both rooms were located in two different department buildings and made distinct on their physical characteristics. One room was arranged to look like a typical office while the other room was arranged in such a way that it resembled a typical pub setting. The office room was provided with two desks, two computers, office materials (e.g., pens, paper, phones, covers), a red carpet, red office chairs, a plant and a window. The other room, the pub environment, was equipped with a counter/bar with a tap, three bar stools, six wooden tables with each two or more chairs, typical pub supply (e.g., beer glasses, ashtrays, beer mats, serving trays, stereo hi-fi), shaded orange-coloured lights, alcohol advertisement posters, and no window. Both rooms were further differentiated by the spreading of different odours: the pub was scented after alcohol and tobacco, while the office room was scented with a perfume 'After Tobacco Air' (Ambi Pur, Veenendaal, the Netherlands). Respiratory tubes were connected to a ventilator in the ceiling of the rooms in order to instantly remove the smell of fresh cigarette smoke from the experimental room.

\section{MEASURES}

Pre-acquisition phase. A self-assessment bipolar visual analogue scale (VAS) with a $0-100 \mathrm{~mm}$ range was used to measure each of the six smoke relevant characteristics in both rooms, namely valence of the room ("In this room, I feel ..." ranging from 0 
“...very unpleasant/negative" to 10 "...very pleasant/positive"); subjective arousal ("At this moment, I feel..." ranging from 0 "...very relaxed" to 100 "...very tense"); urge to smoke ("At this moment, I feel..." ranging from 0 "...no urge to smoke at all" to 100 "... an almost irresistible urge to smoke"); reference to a smoking context ("This room makes me think ...of a room in which I smoked" ranging from 0 "...very little to not at all" to 100 “...very much"); perceived control of smoking ("If at this moment I would be offered a cigarette, I would be ...able to refuse" ranging from 0 "...definitely not" to 100 "...definitely"); and expectation of availability to smoke ("In this room I expect to be ... allowed to smoke" ranging from 0 "definitely not" to 100 “... definitely").

Finally, another VAS was used to rate to which extent participants found the two rooms different from each other ("The first room differs ... from the second room" ranging from 0 "...to a small extent" to 100 "...to a large extent").

Acquisition and test phase. A $100 \mathrm{~mm}$ VAS was used to measure the subjective craving to smoke in each room before and during the presentation of the smoking cues. This VAS was accompanied by the statement "At this moment, I feel..." ranging from 0 "...no urge to smoke at all" to 100 "....an almost irresistible urge to smoke".

\section{Procedure}

Participants were asked to refrain from smoking for 2 hours prior to the experiment. On arrival, participants received an introduction to the study and completed an informed consent form in the waiting room. After the introduction their end-expired air was measured on the content of carbon monoxide ( $\mathrm{CO}$ in ppm) and they completed the FTND questionnaire. Next, they were guided to two rooms for a pre-acquisition session. They were instructed to relax for 1 minute and to pay attention to the features of the room and to 
note what they felt and experienced at that moment. Then they completed a questionnaire in which they rated 'expectation of availability to smoke'; 'reference to a smoking context'; 'urge to smoke'; 'control of smoking'; 'valence of the room'; and 'subjective arousal'. After a 5-minute break, the same was done for the other room. Another VAS was used to measure the extent to which participants evaluated the two rooms as being different. Again, after a short break of 5 minutes participants were taken to the room where the acquisition phase would take place.

The procedure for the acquisition phase was modelled after the study by Thewissen et al. (2005). Participants were randomly assigned to either the 'pub' or the 'office' for acquisition. At the start of the acquisition phase, participants were informed about the meaning of the blue and yellow situation in which they would be exposed to their smoking cues. As in Dols, et al. (2002) a belief neutralisation was given with the instructions of the meaning of blue and the yellow serving tray. The participants were read a statement informing them that research has found contradicting results with regard to the urge-eliciting capacity of smoking contexts and nonsmoking contexts: "Some research has found that contexts in which one is allowed to smoke generates more urge to smoke because of the expectation to smoke in the near future. And other research has found that contexts in which one is not allowed to smoke elicits more urge to smoke because of the fact that smoking restrictions make it more appealing to smoke". This was done for all the participants of this experiment (for a more detailed description of the belief neutralisation procedure we refer to Dols, et al., 2002).

Seated at a table, participants were then presented with the serving tray (blue or yellow) and instructed to pay attention to the colour of the serving tray and to note their feelings and thoughts during that time. After approximately 30 seconds the experimenter presented the participant with a VAS on which s/he was instructed 
to rate his/her urge to smoke. Then the participant was exposed to smoking cues (favourite brand of cigarettes, ashtray and lighter). These smoking cues were presented onto the serving tray. The participant was instructed to handle the cues for approximately $30 \mathrm{sec}-$ onds. The participant was instructed to touch the cigarette, smell it, place it between the lips (without being allowed to sham smoke), and hold a burning lighter near the cigarette (without being allowed to light it). Then the second VAS assessment of urge took place, followed by the occurrence or non-occurrence of smoking. If the participants were allowed to smoke (availability situation), they were instructed to take one puff and exhale the smoke through a respiratory tube. In the unavailability situation, participants were instructed to take the cigarette between their lips and hold a burning lighter to the cigarette, but were not allowed to smoke it. Each participant was put in three availability and three unavailability situations that were presented in a pseudo-random order with no more than two of the same types of situation in succession. The intertrial interval was set at approximately 3 minutes during which the participants were allowed to read a magazine.

The testing phase took place after a 5 minute break, in the same and the other room. There the participants were again presented with both availability cues (blue and yellow serving tray; 1 trial each, order counterbalanced between participants) and completed the urge VAS, followed by additional exposure to the smoking cues and again the urge VAS. After a 5 minute break participants were again tested in the other room in a similar manner (counterbalanced between participants). Upon completion of the experiment, participants were fully debriefed and received money (15 euro) or course credits. 


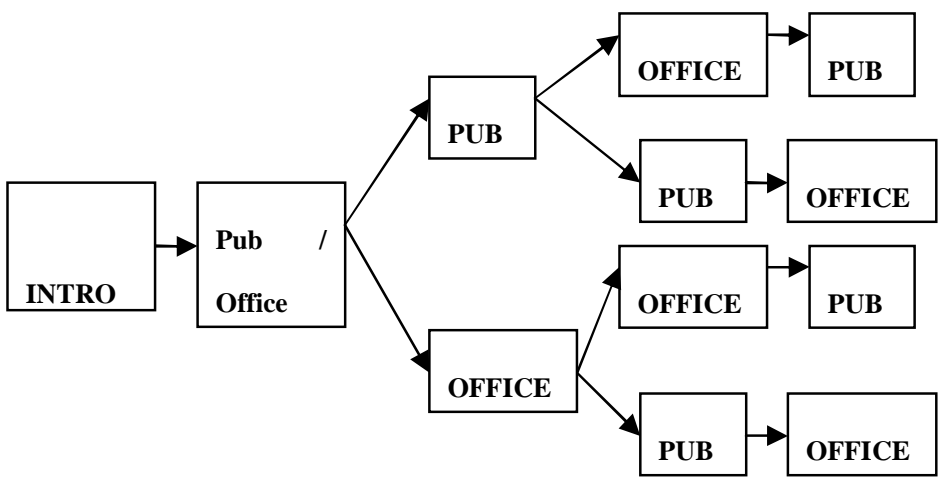

Figure 1. Design representing the 3 main phases of the experiment: preacquisition, acquisition, and test. Pre-acquisition took place in 'pub' as well as 'office' (counterbalanced across participants). Acquisition took place in 'pub' for one half of the participants $(n=16)$ and in the 'office' for the other half $(n=17)$. During test participants were further divided over two counterbalanced groups: one group were tested firstly in the 'office' and subsequently in the 'pub', while the other group was tested firstly in the 'pub' and subsequently in the 'office'.

\section{Results}

For all analyses, a rejection criterion of .05 was used, unless indicated otherwise. Huynh-Feldt epsilon corrections and corresponding adjustments to the degrees of freedom are reported for all the following analyses of variance (ANOVAs) in which the assumption of sphericity was violated.

\section{PRE-ACQUISITION}

The two room contexts differed significantly on all measures of smoke relevant characteristics. That is, the 'pub' context was 
evaluated by the participants as more positive, less arousing, eliciting more urge to smoke, referring to a higher extent to a smoking context, bringing about less control over smoking, and generating a much higher expectation of availability of smoking than the 'office' context $(5.24<$ ts $<15.17$; df $=32 ;$ ps < .05). Furthermore, participants indicated that these environmental contexts differed to a large extent ('difference between rooms': $\mathrm{M}$ difference $=85.49$; $\mathrm{SD}=$ $10.04 ; \mathrm{t}=48.91$; $\mathrm{df}=32 ; \mathrm{p}<.01$ ). Thus, the 'pub' can be considered as a context with high smoke relevant characteristics, whereas the 'office' can be considered as a context with low smoke relevant characteristics. Table 1 displays the mean scores for the two contexts on all the measured indices of smoke relevance.

Table 1. Mean scores on smoke relevant measures for the two room contexts.

\begin{tabular}{l|llllll}
\hline & Valence & Arousal & Urge & Reference & Control & Expectancy \\
& $\mathrm{M}(\mathrm{SD})$ & $\mathrm{M}(\mathrm{SD})$ & $\mathrm{M}(\mathrm{SD})$ & $\mathrm{M}(\mathrm{SD})$ & $\mathrm{M}(\mathrm{SD})$ & $\mathrm{M}(\mathrm{SD})$ \\
\hline The & 76.45 & 24.39 & 57.24 & 81.18 & 45.42 & 81.90 \\
'Pub' & $(12.79)$ & $(15.61)$ & $(15.90)$ & $(20.39)$ & $(28.88)$ & $(17.53)$ \\
& & & & & & \\
The & 59.00 & 34.76 & 38.67 & 20.33 & 61.94 & 19.18 \\
'office' & $(14.54)$ & $(15.27)$ & $(15.57)$ & $(17.08)$ & $(26.26)$ & $(19.48)$ \\
& & & & & & \\
\hline
\end{tabular}

\section{ACQUISITION}

During the acquisition phase, there were 3 trials of each availability cue (yellow and blue serving tray) and during each trial, availability cues were presented alone and with smoking cues. Thus, during acquisition there were 12 measurements of urge. A smoking cue (present vs. absent) $\mathrm{x}$ availability cue (availability cue vs. unavailability cue) $\mathrm{x}$ trial $(1,2$, or 3 ) analysis of variance (ANOVA) was performed for the acquisition phase. 
Hypothesis (a): urges to smoke are higher given the availability cue than given the unavailability cue. The effects of availability cues and smoking cues during the acquisition phase are depicted in Figure 2. As hypothesized, participants exposed to a serving tray predicting the occurrence of smoking (i.e., the availability cue) reported a stronger urge to smoke than when exposed to a serving tray predicting the omission of smoking (i.e. the unavailability cue), $\mathrm{F}(1,32)=29.67, \mathrm{p}<.01$. Thus, the availability cues acquired the ability to differentially elicit urge responding.

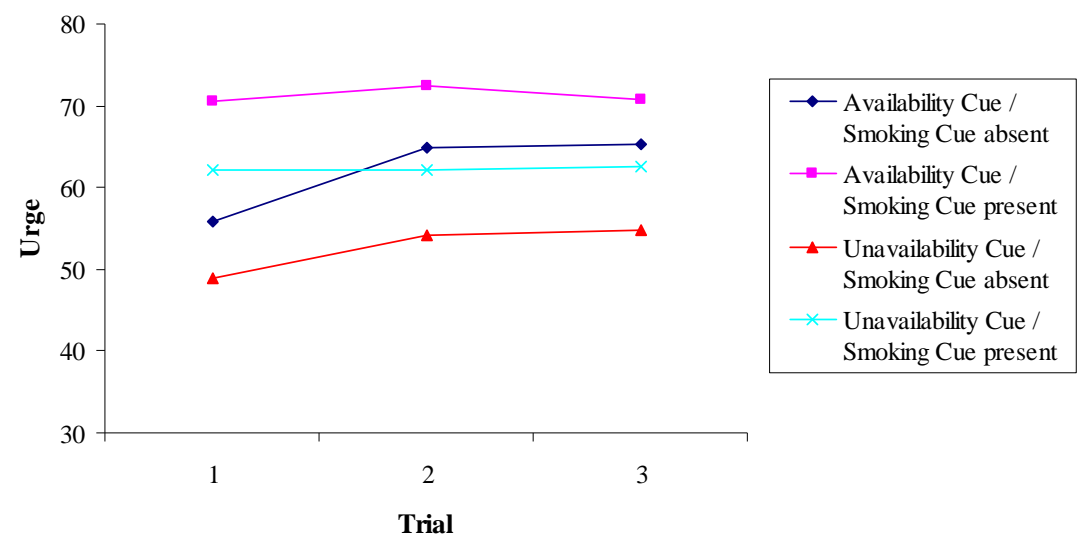

Figure 2. Effects of availability cues and smoking cues on urge to smoke during the acquisition phase.

Hypothesis (b): urges to smoke are higher when smoking cues are presented than when not, irrespective of the availability cues. The overall test revealed a significant main effect of smoking cues, $\mathrm{F}(1,32)=58.87, \mathrm{p}<.01$. Smokers reported higher urges when exposed to their smoking cues than when not, irrespective of avail- 
ability cues.

Hypothesis (c): urges to smoke to smoking cues are higher given the availability cue than given the unavailability cue. No availability cue $\mathrm{x}$ smoking cue interaction was revealed by the overall test, $F(1,32)<1$. The urge-inducing effect of the smoking cues was the same for the availability cue as well as for the unavailability cue.

Effect of trial. A main effect of trial was found indicating an overall increase of urge over trials, $\mathrm{F}(2,64)=4.02$, $\mathrm{p}<.05$. More specifically, analyses revealed a significant interaction effect of smoking cue $\mathrm{x}$ trial $\mathrm{F}(2,64)=10.67, \mathrm{p}<.01$. To further examine this interaction, separate post hoc tests were conducted with trial as the independent variable and urge responding in the presence or absence of smoking cues as the dependent variable, using a Bonferroni-corrected rejection criterion of $\alpha=.025$. Urge responding to the presence of the smoking cues stayed at the same level from the first to the last trial $F(2,64)<1$, while urge responding in the absence of the smoking cues increased from the first to the last trial, $\mathrm{F}(1.73,55.34)=9.51, \mathrm{p}<.01$.

\section{TEST}

The results of the acquisition phase showed differential learning regarding the availability cues. That is, in Pavlovian terms, the availability cue $(\mathrm{CS}+)$, predicting the occurrence of smoking behaviour (US), became a conditioned stimulus eliciting a conditioned urge response (CR), while the unavailability cue (CS-), predicting the absence of smoking behaviour (no US), became a CS inhibiting urge responding. Thus, the data allowed for a test of generalization of acquired differential urge responding.

During the test phase, each availability cue was presented alone and with smoking cues in either the low and high smoke rele- 
vant context. Thus during test there were 8 measurements of urge to smoke. For the test phase an availability cue (availability cue vs. unavailability cue) $\mathrm{x}$ smoking cue (present vs. absent) $\mathrm{x}$ test setting (same vs. different) $\mathrm{x}$ smoke relevance (high smoke relevant context vs. low smoke relevant context) ANOVA was performed with availability cue, smoking cue and test setting as within-subjects factors and smoke relevance as between-subjects factor.

Hypothesis (d): after an environmental context change the difference in conditioned urge response between the 'unavailability cue' and the 'availability cue' is reduced (loss of generalization), significantly more so after a switch from a low to a high smoke relevant setting ('office' to 'pub') than after a switch from a high to a low smoke relevant setting ('pub' to 'office'). Effect of test setting (same versus different from the acquisition setting) and smoke relevance (tested in high or low smoke relevant context) on urges to smoke in all four conditions of the test phase is depicted in Figure 3. Analyses revealed a significant main effect of availability cues $[\mathrm{F}(1,31)=18.87 ; \mathrm{p}<.01]$, indicating that - regardless of any environmental context switch - the availability cue still elicited a higher urge response than the unavailability cue at test. However, as expected, a significant interaction between availability cues and test setting $[\mathrm{F}(1,31)=4.95 ; \mathrm{p}<.05]$ revealed that the differential urge responding to the availability cues was larger in case of no environmental context change. No three-way availability cue $\mathrm{x}$ test setting $\mathrm{x}$ smoke relevance interaction effect was found, $\mathrm{F}(1,31)<1$. However, given the a priori hypothesis that loss of generalization of urge responding to the availability cues is particularly strong when testing in a high smoke relevant environment post-hoc analyses 
were conducted with test setting and smoke relevance as independent variables and urge to smoke in case of the availability and the unavailability cue as dependent variable, using a Bonferonnicorrected rejection criterion of $\alpha=.025$. Differential urge responding between the availability cues decreased significantly $[\mathrm{F}(1,16)=$ 6.64; $\mathrm{p}<.025$ ] when a context change occurred from a low to a high smoke relevant context, whereas this differential urge responding remained on the same level $[\mathrm{F}(1,15)=0.82 ; \mathrm{p}=.37]$ when a context change occurred from a high to a low smoke relevant context. Thus, these results confirm the hypothesis that switching contexts from a low to a high smoke relevant context induces a larger loss of generalization than when switching from a high to a low smoke relevant context.

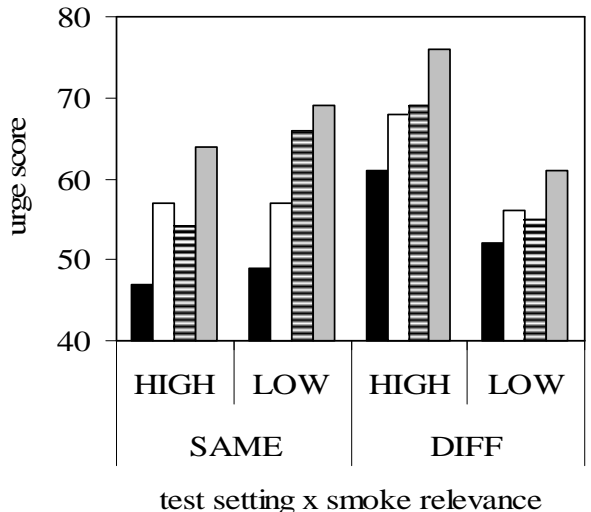

Unavailability Cue / Smoking Cue absent $\square$ Unavailability Cue / Smoking Cue present 目 Availability Cue / Smoking Cue absent $\square$ Availability Cue / Smoking Cue present

Figure 3. Effect of test setting (same versus different from the acquisition setting) and smoke relevance (tested in high or low smoke relevant context) on urges to smoke in the presence or absence of the smoking cues and in the presence of the availability cues. 
Further, analyses showed a significant main effect of smoking cues $[\mathrm{F}(1,31)=35.38 ; \mathrm{p}<.01]$ indicating a higher urge score when smoking cues were presented than when not. A smoking cue $\mathrm{x}$ test setting interaction effect was marginally significant $[\mathrm{F}(1,31)=$ $4.13 ; \mathrm{p}<.06]$, but the smoking cue $\mathrm{x}$ test setting $\mathrm{x}$ smoke relevance interaction clearly reached significance, $\mathrm{F}(1,31)=7.91, \mathrm{p}<.01$. This interaction reflects a larger effect of smoking cue exposure on smoking urges when exposed to smoking cues in a high smoke relevant environment during test when no context change was done (same test setting), as can be inferred from Figure 3. No other main or interaction effects were found, all ps > .10.

\section{Discussion}

As found in the studies of Dols and colleagues (Dols, et al., 2000; 2002) and Thewissen and colleagues (Thewissen, et al., 2005; Thewissen, Snijders, Havermans, van den Hout, \& Jansen, in press), a cue predicting smoking availability reliably elicited higher urges to smoke than a cue predicting the unavailability of smoking. As Thewissen, et al. (2005) found, smoking cues kept their ability to elicit urge responding both in case of the availability as well as the unavailability cue, although this effect of smoking cues seemed to be reduced at the last acquisition trial. The urge-inducing effect of smoking cues thus demonstrates that urge responding to these cues was not completely modulated by the availability cues. More importantly though, it was found that the availability cues differentially elicited smoking urges depending on their signalling either smoking opportunity or not, and that this acquired differential urge responding was lost with a switch to a highly smoke relevant environment. The present results thus confirm the hypothesis that a context switch from a low smoke relevant context to a high smoke relevant context 
reduces the learned differential urge responding between the two availability cues respectively predicting the availability and unavailability of smoking.

The present results raise the question what role smoke relevant contexts play in generalization of differentially conditioned urge responding after a context switch. As suggested by Thewissen et al. (2005) a context change may have to be meaningful in relation to the signalling value of availability of smoking of the availability cues. Indeed, contexts do not appear to function as simple conditioned excitors or inhibitors as learning to differentiate between availability cues predicting the occurrence and non-occurrence of smoking did not seem to depend on context. Such differentiation was rapidly acquired in both a low and high smoke relevant context. Further, what is learned in a high smoke relevant context generalizes well to a different low smoke relevant context. However, when one learns this discrimination between availability cues in a low smoke relevant context (e.g. 'office' context) and then switches to a high smoke relevant context, in which one expects to be allowed to smoke (i.e. 'pub' context), this context switch seems to be more meaningful, hence attenuating generalization. The high smoke relevant context appears to be a (semantic) complex stimulus providing information about smoking behaviour: smokers feel relaxed, experience higher urges to smoke and less control to refrain from smoking, and expect to be allowed to smoke. In other words, the expectation of being allowed to smoke in the high smoke relevant context is particularly salient after a context switch from a low to high smoke relevant context. Thus, when one switches from a low to a high smoke relevant context the expectation of being allowed to smoke overrides the previously acquired inhibitory association between the unavailability cue and smoking behaviour.

One could argue that participants may have had certain preexperimental beliefs concerning the outcome of the experiment that 


\section{SMOKING IN CONTEXT}

led to experimental demand and subsequently to the present pattern of results. However, the belief neutralization procedure adopted in the present experiment was intended to limit the probability of experimental demand. Furthermore, empirical evidence indicates that the differential conditioning procedure as applied in the present study is relatively insensitive to such demand (Dols et al., 2002; for an extended discussion see Thewissen, et al., 2005). Further, it should be noted that the participants in the present experiment were mainly smokers with a low to moderate level of smoking dependence, and who were not intending to quit smoking at the time of testing. Future research should investigate whether the findings of the present experiment also apply to more dependent smokers. 


\section{References}

Carter, B. L., \& Tiffany, S. T. (1999). Meta-analysis of cue reactivity in addiction research. Addiction, 94, 327-340.

Carter, B. L., \& Tiffany, S. T. (2001). The cue-availability paradigm: the effects of cigarette availability on cue reactivity in smokers. Experimental and Clinical Psychopharmacology, 9, 183-190.

Conklin, C. A. (in press). Environments as cues to smoke: Implications for human extinctionbased research and treatment. Experimental and Clinical Psychopharmacology.

Dols, M., Willems, B. W., van den Hout, M., \& Bittoun, R. (2000). Smokers can learn to influence their urge to smoke. Addictive Behaviors, 25, 103-108.

Dols, M., van den Hout, M., Kindt, M., \& Willems, B. (2002). The urge to smoke depends on the expectation of smoking. Addiction, 97, 87-93.

Heatherton, T. F., Kozlowski, L. T., Frecker, R. C., \& Fagerström, K. (1991). The Fagerström Test for Nicotine Dependence: A revision of the Fagerström Tolerance Questionnaire. British Journal of Addiction, 86, 1119-1127.

Killen, J. D., \& Fortmann, S. P. (1997). Craving is associated with smoking relapse: findings from three prospective studies. Experimental and Clinical Psychopharmacology, 5, $137-142$.

Lavez, A. B., Herzog, T. A., \& Brandon, T. H. (1999). Classical conditioning of environmental cues to cigarette smoking. Experimental and Clinical Psychopharmacology, 7, 56-63.

Niaura, R., Rohsenow, D. J., Binnkoff, J. A., Monti, P. M., Pedrazza, M., \& Abrams, D. B. (1988). Relevance of cue reactivity to understanding alcohol and smoking relapse. Journal of Abnormal Psychology, 97, 133-152.

Shiffman, S., Engberg, J., Paty, J. A., Perz, W. G., Gnys, M., Kassel, J.D., \& Hickcox, M. (1997). A day at a time: Predicting smoking lapse from daily urge. Journal of Abnormal Psychology, 106, 104-116.

Shiffman, S., Paty, J. A., Gnys, M., Kassel, J. A., \& Hickcox, M. (1996). First lapses to smoking: Within-subjects analysis of real-time reports. Journal of Consulting and Clinical Psychology, 64, 366-379.

Thewissen, R., Hout van den, M., Havermans, R. C., \& Jansen, A. (2005). Contextdependency of cue-elicited urge to smoke. Addiction, 100, 387-396.

Thewissen, R., Snijders, S. J. B. D., Havermans, R. C., Hout van den, M., \& Jansen, A. (in press). Renewal of cue-elicited urge to smoke: Implications for cue exposure treatment. Behaviour Research and Therapy.

Wertz, J. M., \& Sayette, M. A. (2001). A review of the effects of perceived drug use opportunity on self-reported urge. Experimental and Clinical Psychopharmacology, 9, 3-13. 
SMOKING IN CONTEXT 


\section{Chapter 5}

RENEWAL OF CUE-ELICITED URGE TO SMOKE: IMPLICATIONS FOR CUE EXPOSURE TREATMENT

Roy Thewissen, StefFie J. B. D. SNiJders, REMCo C. Havermans, Marcel VAN DEN Hout, ANITA JANSEN 


\begin{abstract}
The effects of cue exposure therapy are limited, because renewal after extinction is an important source of relapse. In this study, 33 smokers were exposed to a cue predicting smoking availability and a cue predicting smoking unavailability in one context (acquisition context A). Following extinction in another context (extinction context B), a test for renewal took place in the original acquisition context A (i.e. ABA renewal). Urge to smoke was measured using a Visual Analogue Scale. Renewal of differential conditioned urge responding occurred when participants were tested in the acquisition context, while differential urge responding remained extinguished when tested in the extinction context. This experiment provides evidence that ABA renewal occurred in smokers. Clinical implications are discussed.
\end{abstract}

Keywords: context, cue exposure, renewal, smoking urges 


\section{Introduction}

Exposure-based therapies are based on Pavlovian conditioning principles and are widely practiced in the treatment of a variety of psychopathology such as anxiety disorders, eating disorders as well as addictive behaviours (e.g. Öst, 1997; Jansen, 1998; Drummond, Tiffany, Glautier \& Remington, 1995). Cue exposure with response prevention was developed to reduce the urge to use a drug (Brandon, Piasecki, Quinn \& Baker, 1995). In case of smoking addiction, a smoker is repeatedly exposed to smoking cues (e.g. cigarettes, lighters, ashtrays), but is not allowed to smoke (response prevention). This procedure then should lead to the elimination of the previously learned association between smoking-related cues (conditioned stimuli, CSs) and the intake of smoke (unconditioned stimulus, US), because the smoking-related stimuli no longer predict smoke intake. As a result, cue-elicited urge to smoke (i.e., the conditioned response, CR) should be extinguished. Furthermore, by eliminating an important motivation for smoking the probability of a (re)lapse should be reduced.

Although outcome studies of cue exposure in the realm of addiction yielded some promising results, there is still room for improvement (Conklin \& Tiffany, 2002). More fundamental learning research has shed some light on the limitations of exposure-based treatments and suggested possible ways to overcome these limitations. During cue exposure, the individual is exposed to the CS (e.g. smoking cues) without the drug (US) being presented. Under these conditions, 'extinction' is held to occur. Traditionally, extinction is conceptualised as the unlearning of the association between CS and US. The work of Bouton (Bouton, 1988, 2000) however indicates that this is fundamentally incorrect. Extinction is not 'unlearning' the CS - US association, but instead learning that in the context in which extinction takes place the CS will not be followed by a US. 
Strong support for this position is the fact that extinguished conditioned responding is "renewed" when the CS is presented in a context other than the extinction context.

For addiction, some evidence for renewal has been found within heavy drinkers. Collins and Brandon (2002) conducted a clinical analogue experiment with moderate to heavy social drinkers and found a significant renewal of extinguished alcohol cue reactivity. Recently, fundamental research into human learning mechanisms done by Vansteenwegen and colleagues (2005) found evidence for renewal using a differential fear conditioning paradigm (see also Havermans, Keuker, Lataster, \& Jansen, 2005).

Renewal may thus contribute to the limited effect of cue exposure in the treatment of addiction. However, in the studies described above, it is assumed that cue-elicited urges are the result of prior conditioning. This is not necessarily the case. Field and Duka (2001) for instance argue that cue reactivity measured in the laboratory could reflect non-specific arousal or might be due to perceived demands of the experiment. An obvious advantage of clinical analogue experiments is the control one has over the learning phases of acquisition and extinction. Collins and Brandon (2002) for example did not have any control over the acquisition of cue reactivity of their participants and the context in which acquisition could have taken place. Therefore, the present experiment was specially designed to establish such control. The experimental procedure used in this experiment was similar to the procedure used by Thewissen et al. (2005) and was a discriminative classical conditioning task in which 'cue-availability' (Carter \& Tiffany, 2001) or 'perceived drug use opportunity' (Wertz \& Sayette, 2001) was manipulated; that is, participants were exposed to their smoking cues following either an availability or an unavailability cue (signalled by a blue versus a yellow serving tray). After smoking cues were presented with the availability cue participants were instructed to smoke, but when pre- 
sented with the unavailability cue they had to refrain from smoking. The primary aim of the present study was to investigate whether an association between cue and smoking acquired in a context $\mathrm{A}$ can be extinguished in another context B and if so, whether extinguished urge responding can be renewed when presented with the cue in context A (i.e. ABA renewal).

\section{Method}

\subsection{PARTICIPANTS}

Thirty-three smokers $(8$ males, 25 females; $\mathrm{M}$ age $=21.3$ years; $\mathrm{SD}=1.72$ ) who smoked a minimum of five cigarettes a day for at least two years were recruited at Maastricht University. All participants completed the Fagerström test for nicotine dependence (FTND; Heatherton, Kozlowski, Frecker, \& Fagerstrom, 1991). The average score on the FTND was 2.70 (SD = 2.07), which indicates that participants, on average, had a low level of 'nicotine dependence'. Fourteen participants smoked less than 10 cigarettes a day, fourteen participants smoked between 11 and 20 cigarettes a day, four participants smoked between 21 and 30 cigarettes a day and one participant smoked more than 30 cigarettes a day. Participants had to abstain from smoking for two hours prior to the experiment. An abstinence period of two hours was chosen to avoid floor or ceiling effects of urge during the conditioning task.

\subsection{INDEPENDENT VARIABLES}

Smoking cues. The smoking cues were stimuli presumed to elicit conditioned urge responses as a result of smoking history. The participant's favourite brand of cigarettes, a lighter, and an ashtray were used as smoking cues. 
Availability cues. A blue or a yellow colour of a serving tray signalled the occurrence or non-occurrence of smoking. For half of the participants, a blue serving tray indicated that smoking after presentation of the smoking cues - was allowed, and a yellow serving tray indicated that smoking was not allowed. For the other half, the meaning of the colours of the serving trays was reversed. These availability cues served as CSs respectively predicting the occurrence of smoking (CS+) and absence of smoking (CS-). The US consisted of one puff of a cigarette.

Contexts. Two rooms (an 'office' and a 'therapy room') represented contexts that differed on their physical characteristics, but both had low smoke-relevant characteristics. The 'office' consisted of two desks, two computers, office materials (e.g. phones, pens, papers, and covers), a red carpet and red office chairs. The 'therapy room' had one desk, books, pens, writing papers, plants, 'nature posters', a flip-over, and blue chairs. Further, the 'office' had a window and 'After Tobacco Air' (Ambi Pur, Veenendaal/ The Netherlands) was spread in this room, while the 'therapy room' had no window and had a 'Vanilla \& Lily' (Ambi Pur, Veenendaal/ The Netherlands) odour. The 'office' and the 'therapy room' were located in two different department buildings at Maastricht University and both had a respiratory tube connected to a ventilator in the ceiling. The respiratory tubes in the 'office' and the 'therapy room' were of different material and colour. 


\subsection{DEPENDENT VARIABLES}

Smoke-relevant characteristics. In the pre-acquisition phase, in each room, $100 \mathrm{~mm}$ Visual Analogue Scales (VASs) were used to measure 'valence of the room' ("In this room, I feel": 0 "very unpleasant/ negative"- 100 "very pleasant/ positive"), 'subjective arousal' ("In this room, I feel”: 0 "very relaxed"- 100 "very tense"), "urge to smoke' ("At this moment, I feel": 0 "no urge to smoke at all"- 100 "an almost irresistible urge to smoke"), 'reference to a smoking context' ("This room makes me think of a room in which I smoked": 0 "very little to not at all"- 100 "very much"), 'perceived control of smoking' ("If at this moment I would be offered a cigarette, I would be": 0 "definitely not able to refuse"- 100 "definitely able to refuse"), and "expectation of availability to smoke' ("In this room, in general, I expect to be allowed to smoke": 0 "definitely not"- 100 "definitely"), respectively. These VASs were used to test the smoke-relevant characteristics of both contexts. Additionally, a $100 \mathrm{~mm}$ VAS ("The first room differs from the second room": 0 "to a small extent" - 100 "to a large extent") was used to measure the extent to which subjects considered the two rooms as being physically different.

Urge to smoke. During the acquisition phase, as well as in the extinction phase and the test phase, $100 \mathrm{~mm}$ VASs ("At this moment, I feel": 0 "no urge to smoke at all"- 100 "an almost irresistible urge to smoke") were used to measure urge to smoke.

\subsection{PROCEDURE}

The experiment started with an introduction in which par- 


\section{SMOKING IN CONTEXT}

ticipants were told what the meaning was of the blue and the yellow serving tray (i.e., signalling smoking availability or unavailability). After this introduction, participants gave informed consent. In addition, participants completed a general smoking questionnaire and the FTND. All of this took place in a waiting room.

Pre-acquisition phase. Participants moved to the 'office' or the 'therapy-room' for a pre-acquisition session. After being seated at a desk, subjects were told to relax for one minute while concentrating on the features of the room and taking notice of their feelings at that moment. Next, subjects rated 'valence of the room', 'subjective arousal', 'urge to smoke', 'reference to a smoking context', 'perceived control of smoking' and 'expectation of availability to smoke' on VASs. After this, subjects moved to the other context in which the same procedure was followed as in the first preacquisition session. In the second pre-acquisition session subjects completed the six VASs and an additional VAS that measured to what extent participants evaluated the two rooms as being physically different. Next, participants had a five minute reading break and were escorted to the acquisition context that was the same context as the room in which the second pre-acquisition session had taken place (the 'office' or the 'therapy-room').

Acquisition phase. After being seated at a desk, participants were again instructed about the meaning of the blue and the yellow serving tray (i.e., signalling smoking availability or unavailability). The acquisition phase started with the presentation of a blue or a yellow serving tray for approximately 25 seconds. Participants were instructed to concentrate on the serving tray and to focus on their urge to smoke, after which they rated their urge to smoke on a VAS. 
Next, a participant's favourite brand of cigarettes, a lighter and an ashtray were placed on the serving tray. Participants were instructed to take a cigarette out of the cigarette box and handle the cigarette (touch it, place it between their lips, holding it) without lighting the cigarette. After approximately 25 seconds, subjects rated their urge to smoke on a second VAS. Following the second craving assessment, participants took one puff of a cigarette when the colour of the serving tray indicated that smoking was allowed and exhaled the smoke through a respiratory tube. If the colour of the serving tray indicated that smoking was not allowed, participants held the cigarette between their lips and a burning lighter next to it, but did not light the cigarette. After the occurrence or non-occurrence of smoking, subjects read for three minutes. Each participant completed six trials: three trials with a blue serving tray and three trials with a yellow serving tray in a random order with the restriction of no more than two consecutive trials of the same type. In total, the acquisition phase had a duration of approximately 30 minutes. Following the last trial, participants were taken to the other room in which extinction would take place.

Extinction phase. The procedure for the extinction phase was the same as with the acquisition phase except smokers were not allowed to smoke at all. After being seated at a desk, participants were instructed about the new meaning of the blue and the yellow serving tray (i.e., both signalling smoking unavailability). Following the last trial, half the participants relaxed and read in a waiting room for five minutes and the other half was escorted to the other context. Renewal test phase 1. In the first renewal test phase, participants were presented with a blue or a yellow serving tray, after which they completed a VAS of urge to smoke. Next, they were exposed to 
their smoking cues, followed by a second urge VAS. After a three minute reading break, a serving tray of the other colour was presented to the subjects, followed by an urge VAS. After this, exposure to smoking cues occurred and a second urge VAS was completed. In both trials, participants were not allowed to smoke. After this, subjects moved to the other context (the 'office' or the 'therapy-room').

Renewal test phase 2. In the second renewal test phase, the same procedure was followed as in the first renewal test phase. The only difference between the two test phases was that they took place in two different contexts (counterbalanced). At the end of the second renewal test phase, participants were paid and debriefed in a waiting room.

\section{Results}

\section{DATA REDUCTION AND ANALYSES}

Results will be reported for the four main phases of the experiments: pre-acquisition, acquisition, extinction and test. For all analyses, a rejection criterion of .05 was used. Huynh-Feldt epsilon corrections and corresponding adjustments to the degrees of freedom are reported for all repeated measures analyses of variance (ANOVAs) in which the assumption of sphericity was violated.

\subsection{PRE-ACQUISITION}

During the pre-acquisition phase self-report measures of 'perceived expectation of availability to smoke', 'reference to a smoking context', 'urge to smoke', 'control of smoking', 'valence of the room', and 'subjective arousal' were scored on a $100-\mathrm{mm}$ VAS. This was done for the two rooms. Additionally, a 100-mm VAS was used to measure the extent to which participants evaluated 
the two rooms as being different. To test for renewed cue-elicited smoking urges, the contexts used in this experiment had to be physically different but equivalent on their smoke relevant characteristics; that is, both contexts had to produce the same response pattern on all the aforementioned measures.

The two contexts, 'office' context and 'therapy-room' context, were equal on all indices $(-0.56<\mathrm{ts}<2.02$; $\mathrm{df}=32$; all ps $>$ $.05)$, except on the measurement of 'valence of the room' $[\mathrm{t}(32)=$ $3.18 ; \mathrm{p}<.001$ ], indicating that the 'therapy-room' context was more positively labelled than the 'office' context. Further, participants evaluated these rooms as being distinct, $\mathrm{t}(32)=28.16$; $\mathrm{p}<.001$.

\subsection{ACQUISITION AND EXTINCTION}

To be able to test for renewed cue-elicited urges to smoke, initial acquisition of cue-elicited urge responding and subsequent extinction of such responding had to be ascertained. The mean urges to smoke scores in all four conditions as measured during the acquisition phase are shown in Figure 1.

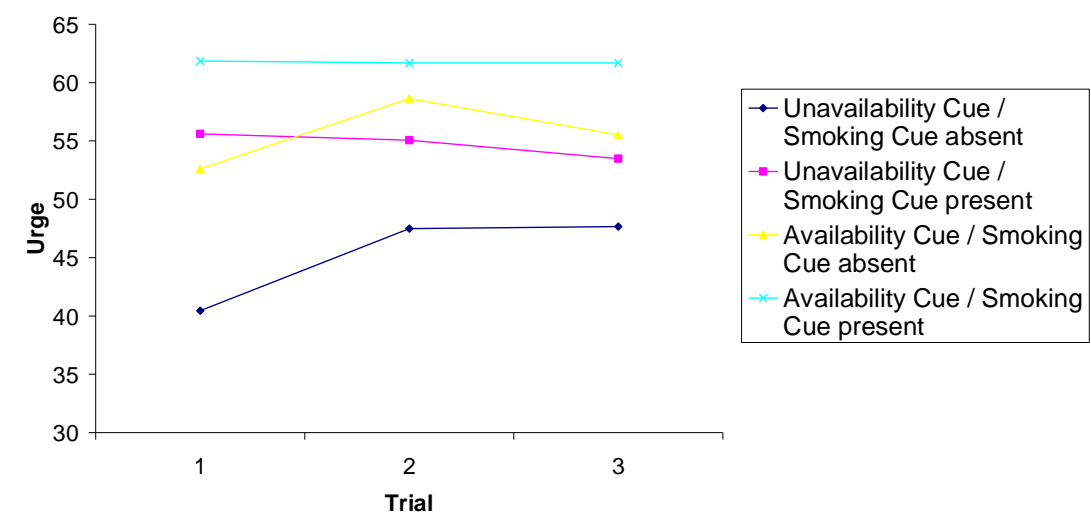

Figure 1. Effect of availability cues and smoking cues on the urge to smoke at trial $1-3$ of the acquisition phase $(n=33)$. 
During acquisition, extinction and test, every presentation of the coloured serving tray (availability cues) and every presentation of the smoking cues (cue) were followed by a 100-mm VAS (urge to smoke). During the acquisition and extinction phase, there were 3 trials of each availability or unavailability cue (yellow and blue serving tray) and during every trial, availability cues were presented alone and with smoking cues. Separate 2 x 2 x 3 (smoking cue $x$ availability cues $\mathrm{x}$ trial) within-subjects ANOVAs were performed for the acquisition and extinction phase.

For acquisition, the analyses confirmed that urges to smoke are higher given the availability cue than given the unavailability cue, $\mathrm{F}(1,32)=28.41, \mathrm{p}<.001$. Thus, the availability cues acquired the conditional potency to differentially elicit urge responding. The availability cue (CS+) associated with the occurrence of smoking behavior (US) elicited higher urge responses (CR) than the unavailability cue (CS -) associated with the absence of smoking behavior (no US), irrespective of the presentation of the smoking cues.

Further, a significant main effect of smoking cues was revealed, $\mathrm{F}(1,32)=52.04, \mathrm{p}<.001$. When exposed to their smoking cues participants reported higher urge scores than when not. The analyses also revealed a significant interaction effect of availability cues $x$ smoking cue, $\mathrm{F}(1,32)=4.17, \mathrm{p}<.05$, and a significant availability cues $x$ smoking cue $x$ trial $[F(1.64,52.51)=3.53, p<.05]$ interaction. The latter three-way interaction indicates that the urgeinducing effects of smoking cues was larger given the unavailability cue than the availability cue, particularly on the first acquisition trial as can be inferred from Figure 1.

No significant main effect of trial was revealed, $\mathrm{F}(1.58$, $50.66)=1.25$, ns. However, there was a significant interaction between smoking cues and trial, $\mathrm{F}(2,64)=15.41, \mathrm{p}<.001$, indicating that the urge scores differed for the presence or absence of smoking 
cues over trials. As can be inferred from Figure 1, the urge to smoke increased somewhat after the first trial in the absence of smoking cues, whereas in the presence of these smoking cues the urge to smoke remained relatively constant across the trials.

Extinction (or renewal) can only take place if learning has occurred. For this reason the analyses of the extinction and renewal phase are presented for the 25 out of the 33 participants showing successful acquisition (i.e., differential urge responding to the availability cues).

The overall effect of availability cues on urge to smoke as measured on the last acquisition trial and during the subsequent extinction phase is depicted in Figure 2.

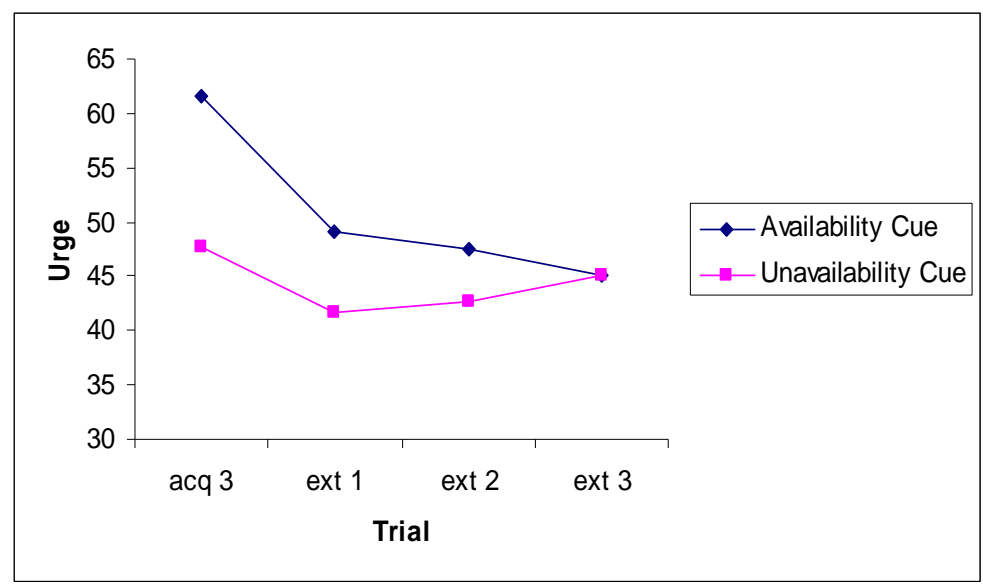

Figure 2. Overall effect of availability cues on the urge to smoke as measured on the third and last acquisition trial (acq 3) and during the subsequent extinction phase (trials ext 1,2, and 3) for the participants who had shown successful acquisition of differential urge responding to the availability cues $(n=25)$.

The availability cues (availability versus unavailability) x smoking 
cues (present versus absent) $\mathrm{x}$ trial (extinction trials 1,2 , or 3 ) ANOVA revealed a significant main effect of availability cues, F(1, $24)=5.39, \mathrm{p}<.05$, showing that on average urge to smoke was higher given the availability cue than given the unavailability cue. Moreover, an availability cues $\mathrm{x}$ trial interaction was found, $\mathrm{F}(2,48)$ $=4.89, \mathrm{p}<.05$, demonstrating extinction of differential urge responding to the availability and the unavailability cue. Further posthoc analyses revealed that for the availability cue there was a significant decrease in reported urge to smoke from the last acquisition trial to the last extinction trial, $\mathrm{F}(2.33,55.93)=10.64, \mathrm{p}<.01$, whereas urge responding to the unavailability cue did not increase significantly from the last acquisition trial to the last extinction trial, $\mathrm{F}(2.46,58.98)=2.27$, ns. This implies that the loss of differential urge responding to the availability cues can be largely attributed to the decrease in the urge to smoke in the presence of the availability cue.

Further results indicated that smokers reported higher levels of urge to smoke when exposed to their smoking cues than when not, $F(1,24)=19.90, p<.001$. No main effect of trial was revealed by the analysis, $\mathrm{F}(2,48)<1$, ns.

A significant interaction of availability cues $\mathrm{x}$ smoking cues, $F(1,24)=14.46, p<.01$, showed that the urge inducing effect of the smoking cues was larger given the unavailability than given the availability cue. No availability cues $\mathrm{x}$ smoking cues $\mathrm{x}$ trial interaction was revealed, $\mathrm{F}(2,48)=2.70$, ns.

\subsection{RENEWAL TEST}

Since the results of the extinction phase clearly demonstrated an extinction of differential urge responding to the availability cues, in particular reflected by the decrease in urge to smoke in the presence of the availability cue, a test for renewal after a room context change was warranted. For the test phase, a 2 x 2 x 2 (con- 
text change $\mathrm{x}$ availability cues $\mathrm{x}$ smoking cue) repeated measures ANOVA was performed.

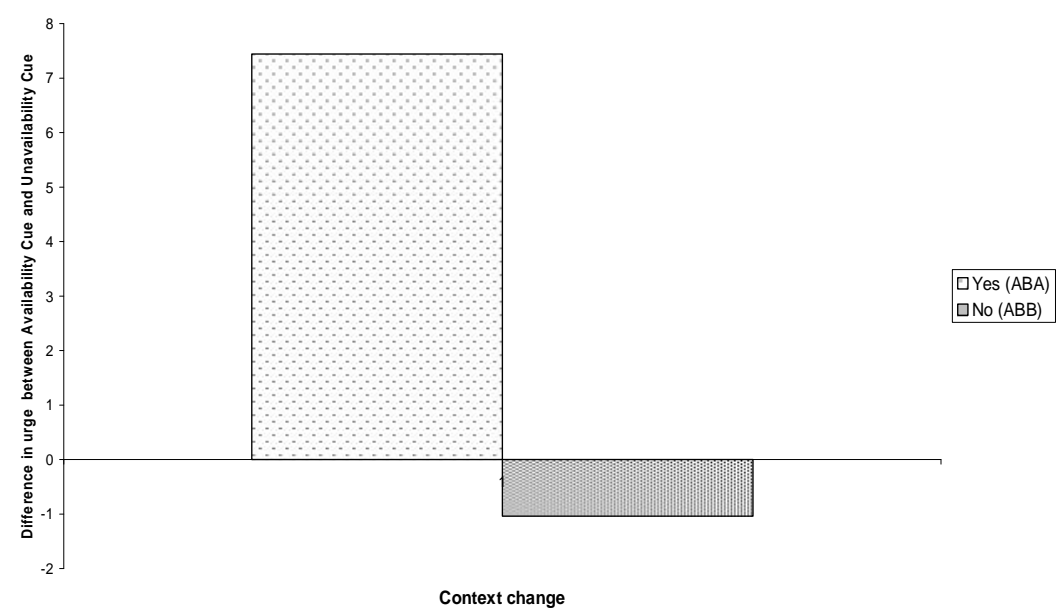

Figure 3. Effect of a context change on differential urge responding to the availability cues at test. The $Y$ axis represents the mean difference in urge to smoke between the unavailability cue and the availability cue.

Figure 3 depicts the effect of a context change on differential urge responding to the availability cues during the test phase. The ANOVA revealed a significant main effect of context change, $\mathrm{F}(1$, $24)=5.27, p<.05$, showing that urge to smoke is higher given a context change at test than when not. More specifically, a significant interaction effect of context change $x$ availability cues, $F(1,24)$ $=4.34, \mathrm{p}<.05$, revealed that the availability cue elicited more urge to smoke than the unavailability cue when the test occurred in the acquisition context (i.e. ABA renewal), than when tested in the extinction context (i.e. ABB control). Planned comparisons confirmed this renewal effect by revealing that the differential effect of availability cues was significant in case of a context change [ABA; $t(24)$ $=3.03, \mathrm{p}<.01]$, but not significant in case of no context change 
$[\mathrm{ABB} ; \mathrm{t}(24)=.36, \mathrm{~ns}]$.

Further results revealed a significant main effect of smoking cue, $\mathrm{F}(1,24)=16.16, \mathrm{p}<.01$, again reflecting smokers reporting a higher urge to smoke when exposed to their smoking cues.

\section{Discussion}

It was hypothesized that extinguished cue-elicited urge to smoke can be renewed. The results clearly demonstrate renewal of extinguished differential urge responding to the availability cues when tested in the room context in which acquisition took place (ABA renewal). Apparently, extinguished cue-elicited urge to smoke is context-dependent and tends to be renewed when individuals find themselves outside the context where extinction treatment took place.

As the bulk of evidence regarding the phenomenon of renewal in human learning in general and specifically in human psychopathology grows, the call for improvement of exposure-based treatment strategies gets more and more pronounced (see Bouton, 2002; Conklin \& Tiffany, 2002; Havermans \& Jansen, 2003). In general, the results of this study points to the importance of the role of the broader context in which cue exposure takes place. In that respect it should be noted that following Marlatt and Gordon's 1985 theoretical framework of determinants of relapse of addictive behaviour, the two room contexts used in the present study can be defined as 'low risk situations' as opposed to 'high risk situations'. That is, these room contexts possess a relatively low risk for relapse because of their low smoke relevant characteristics. Therefore, it is conceivable that situational contexts with high smoking relevant characteristics hold a greater risk for relapse that would be evidenced by an even more pronounced renewal effect after a context change from a low smoke relevant treatment context to a high risk 
situation. Further research should illuminate this matter.

The results of the present study again replicate the main finding of the studies by Dols, Willems, et al. (2000), Dols, van den Hout, et al. (2002) and Thewissen et al. (2005) that smokers report higher levels of urge to smoke when exposed to a cue signalling the availability of smoking than when exposed to a cue signalling the unavailability of smoking. Hence, the availability cues acquired the capacity to differentially elicit urge responding. Dols and colleagues (2002) state that cue reactivity does not necessarily depend on a long history of associative learning between smoking-related cues and smoking behaviour, but that the predictive value regarding the availability of smoking is crucial in evoking urge responses to smoking-related cues. The repeated finding in these studies as well as the present study that availability cues that were not previously associated with smoking behaviour can nearly instantaneously acquire the capacity to differentially elicit urge responding provides support for this argument. One could argue, though, that this finding is the result of experimental demand as the participants are instructed beforehand about the predictive meaning of the availability cues and that, hence, they behave according to received instructions rather than learning these contingencies through experience. However, according to contemporary learning theory, human conditioned responding - both subjective and autonomic psychophysiological responding - is based on stimulus-outcome associations that can be acquired through both explicit instructions and trial-by-trial experience (see e.g., Dawson \& Shell, 1987; Davey, 1992; Lovibond, 2003). Furthermore, providing information of the CS-US contingency before the conditioning task elevates conscious awareness of the association between the color of the serving tray and the (un)availability of smoking hence facilitating conditioning (see e.g., Dawson \& Shell, 1987; Field \& Duka, 2001). Nevertheless, one could still argue that participants may have had certain pre- 
experimental beliefs concerning the outcome of the experiment that led to experimental demand. However, experimental evidence indicates that the present procedure is not sensitive to such demand. Dols et al. (2002) found that a belief-neutralization procedure (given to half of the subjects prior to participation in the experiment) did not fundamentally affect results, that is, irrespective of beliefneutralization participants reported stronger urges when exposed to the availability cue than when exposed to the unavailability cue. As the present experimental procedure is similar to the procedure employed by Dols and colleagues (2002) it is unlikely that experimental demand played an important role in the present findings.

It should be noted though that the participants in the present experiment were mainly smokers with a low level of smoking dependence and who had no intention to quit smoking at the time of testing. This raises the question whether more dependent smokers would respond to contextual cues in the same manner. Therefore, the data of the five more heavy dependent smokers (i.e., smoking more than 20 cigarettes/day) of this sample were examined more closely. They showed differential urge responding to the availability cues (acquisition; mean difference urge scores $=6.9$ ) and a decrease in urge responding to the availability cue (mean urge on last acquisition trial $=61$; mean urge on last extinction trial $=43.2$ ). At test they still showed differential urge responding to the availability cues (mean difference $=8.5$ ), but only in the acquisition context suggesting renewal.

Summarized, the data presented here suggest that cueelicited urges to smoke, which are subsequently extinguished in another context, are renewed when participants are exposed to cues in the context in which they had initially learned the association between these cues and smoking. Future research should investigate whether the found renewal of cue-elicited smoking urges generalizes to individuals who receive cue exposure treatment for their 
smoking addiction, and whether the findings of the present experiment also apply to a sample of more heavy smokers. Nonetheless, the present results do offer support for the context-dependency of extinction that might explain the limited efficacy of cue exposure therapy. 


\section{SMOKING IN CONTEXT}

\section{References}

Bouton, M.E. (1988). Context and ambiguity in the extinction of emotional learning: implications for exposure therapy. Behaviour Research and Therapy, 26, 137-149.

Bouton, M.E. (2000). A learning theory perspective on lapse, relapse, and the maintenance of behavior change. Health Psychology, 19, (Suppl. 1), 57-63.

Brandon, T.H., Piasecki, T.M., Quinn, E.P., \& Baker, T.B. (1995). Cue exposure treatment in nicotine dependence. In D.C. Drummond, S.T. Tiffany, S. Glautier, \& B. Remington (Eds.), Addictive Behaviour: Cue Exposure Theory and Practice (pp.211-227). New York: John Wiley \& Sons.

Carter, B.L., \& Tiffany, S.T. (2001). The cue-availability paradigm: the effects of cigarette availability on cue reactivity in smokers. Experimental and Clinical Psychopharmacology, 9, 183-190.

Collins, B.N., \& Brandon, T.H. (2002). Effects of extinction context and retrieval cues on alcohol cue reactivity among non-alcoholic drinkers. Journal of Consulting and Clinical Psychology, 70, 390-397.

Conklin, C.A., \& Tiffany, S.T. (2002). Applying extinction research and theory to cueexposure addiction treatments. Addiction, 97, 155-167.

Davey, G.C.L. (1992). Classical conditioning and the acquisition of human fears and phobias: a review and synthesis of the literature. Advances in Behaviour Research and Therapy, 14, 29-66.

Dawson, M.E., \& Schell, A.M. (1987). Human autonomic and skeletal classical conditioning: The role of conscious cognitive factors. In G.C.L. Davey (Ed.), Cognitive processes and Pavlovian conditioning in humans, (pp. 27-55). Chichester: Wiley.

Dols, M., Willems, B., Van den Hout, M., \& Bittoun, R. (2000). Smokers can learn to influence their urge to smoke. Addictive Behaviors, 25, 103-108.

Dols, M., Van den Hout, M., Kindt, M., \& Willems, B. (2002). The urge to smoke depends on the expectation of smoking. Addiction, 97, 87-93.

Drummond, D. C., Tiffany, S.T., Glautier, S., \& Remington, B. (1995). Addictive Behaviour: Cue Exposure Theory and Practice. New York: John Wiley \& Sons.

Field, M., \& Duka, T. (2001). Smoking expectancy mediates the conditioned responses to arbitrary smoking cues. Behavioural Pharmacology, 12, 183-194.

Havermans, R.C., \& Jansen, A.T.M. (2003). Increasing the efficacy of cue exposure treatment in preventing relapse of addictive behavior. Addictive Behaviors, 28, 989-994.

Havermans, R.C., Keuker, J., Lataster, T., \& Jansen, A. (2005). Contextual control of extinguished conditioned performance in humans. Learning and Motivation, 36, 1-19.

Heatherton, T.F., Kozlowski, L.T., Frecker, R.C., \& Fagerström, K.O. (1991). The Fagerström Test for Nicotine Dependence: A revision of the Fagerström Tolerance Questionnaire. British Journal of Addiction, 86, 1119-1127.

Jansen, A. (1998). A learning model of binge eating: Cue reactivity and cue exposure. Behaviour Research and Therapy, 36, 257-272.

Lazev, A.B., Herzog, T.A., \& Brandon, T.H. (1999). Classical conditioning of environmental cues to cigarette smoking. Experimental and Clinical Psychopharmacology, 7, 56-63. 


\section{RENEWAL OF CUE-Elicited URGE TO SMOKE}

Lovibond, P.F. (2003). Causal beliefs and conditioned responses: retrospective revaluation induced by experience and instruction. Journal of Experimental Psychology: Learning, Memory, and Cognition, 29, 97-106.

Marlatt, G. A., \& Gordon, J. R. (1985). Relapse Prevention: Maintenance Strategies in the Treatment of Addictive Behaviors. New York: Guilford Press.

Öst, L.G. (1997). Rapid treatment of specific phobias. In G. Davey (Ed.). Phobias: A handbook of theory, research and treatment (pp. 227-246). Chichester: Wiley.

Thewissen, R., Van den Hout, M., Havermans, R.C., \& Jansen, A. (2005). Contextdependency of cue-elicited urge to smoke. Addiction, 100, 387-396.

Vansteenwegen, D., Hermans, D., Vervliet, B., Francken, G., Beckers, T., Baeyens, F., \& Eelen, P. (2005). Return of fear in a human differential conditioning paradigm caused by a return to the original acquisition context. Behaviour Research and Therapy, 43, 323-336.

Wertz, J.M., \& Sayette, M.A. (2001). A review of the effects of perceived drug use opportunity on self-reported urge. Experimental and Clinical Psychopharmacology, 9, 3-13. 
SMOKING IN CONTEXT

116 


\section{Chapter 6}

From the Clinic to the Pub: THE EFFECT OF SMOKE ReLEVANT CONTEXTS ON URGE TO SMOKE

Roy THEWISSEN, REMCO C. HAVERMANS, MARCEL VAN DEN HOUT, ANITA JANSEN 


\begin{abstract}
Renewal of previously extinguished conditioned responding is a well established phenomenon. It has repeatedly been demonstrated in both animals and humans. More importantly, renewal helps to explain relapse of addictive behaviour after extinction-based treatments such as cue exposure therapy. In the present study, the possible impact of smoke relevant contexts on renewal of extinguished urges to smoke was investigated. Results show that after establishing acquisition and extinction of differential urge responding no renewal could be observed when using an ABC-renewal design. However, an overall effect of smoke relevant contexts on urge to smoke was found indicating that smoke relevant contexts serve as conditioned stimuli directly eliciting urge to smoke. The validity of explaining relapse of addictive behaviour in terms of renewal as well as clinical implications regarding extinction-based treatments are discussed.
\end{abstract}

Keywords: smoke relevance, context, cue exposure, renewal, smoking urges 


\section{Introduction}

Renewal of previously extinguished conditioned responding is a well established phenomenon within the animal literature (see Bouton, 1988; 2002). It concerns the return of previously acquired and subsequently extinguished conditioned responding to a conditioned stimulus (CS) when this CS is presented in a context different from the extinction context. Renewal can occur when conditioned responding is extinguished in a context $\mathrm{B}$ and subsequently the CS is presented in the original learning context A (i.e. ABA renewal; e.g. Bouton \& Bolles, 1979; Bouton \& King, 1983; Rosas \& Bouton, 1997; Bouton \& Peck, 1989), or when tested in a completely new context (ABC renewal; e.g. Bouton \& Brooks, 1993; Bouton \& Swartzentruber, 1986). Similarly, when both acquisition and extinction of conditioned responding take place in the same context A presenting the CS in a novel context $\mathrm{B}$ at test will lead to renewed conditioned responding ( $\mathrm{AAB}$ renewal; see e.g. Bouton \& Ricker, 1994).

In humans, the renewal effect has also been demonstrated, however, not as extensively as in animals. For example, Vansteenwegen and colleagues (2005) found evidence for ABA renewal using a differential fear conditioning paradigm. Havermans, Keuker, Lataster, and Jansen (2005) also found evidence for ABA renewal in human subjects. Using a conditioned suppression task they found that extinguished conditioned responses could be renewed when the $\mathrm{CS}$ was presented in the original learning context. The renewal effect demonstrates that extinguished conditioned responding is context specific; that is, what is learned during extinction is not the 'unlearning' of the original excitatory association between the CS and the unconditioned stimulus (the US), but the learning of a new inhibitory association in which the CS acquires an ambiguous meaning regarding the occurrence or absence of the US (Bouton, 1988; 
2002). The meaning of the CS is disambiguated by the environmental context in which extinction takes place. The extinction context becomes endowed with a modulatory property, thus controlling the CS - no US association. So when the CS is presented in the extinction context the inhibitory CS - no US association is retrieved, whereas in all other contexts the original CS - US association will be retrieved leading to renewed responding to the CS.

The renewal effect poses important implications for extinction-based treatments of various instances of psychopathology (Conklin \& Tiffany, 2002). Exposure therapy is based on the principle of extinction and is one of the most widely applied forms of behaviour therapy, particularly in the treatment of specific phobias such as spider phobia (e.g. Öst, 1997). Repeated exposure to spiders or spider-related stimuli will lead to the extinction of cue-elicited fear in spider phobics. However, after a context switch, some of this extinguished conditioned fear appears to be renewed (see e.g., Mineka, Mystkowski, Hladek, \& Rodriguez, 1999; Rodriguez, Craske, Mineka, \& Hladek, 1999; Rowe \& Craske, 1998; Lang \& Craske, 2000). Within the field of addiction research a similar renewal effect has been demonstrated. Collins and Brandon (2002) conducted a clinical analogue experiment with moderate to heavy social drinkers and found a significant renewal of extinguished cueelicited urges to drink alcohol (but see Staiger, Greeley, \& Wallace, 1999). Additionally, they demonstrated that renewal was attenuated when a retrieval cue was present during the extinction and test phase. The use of retrieval cues as a possible mean to handle the problem of renewal was already suggested in the animal literature (e.g. Brooks \& Bouton, 1994), has been favoured by some researchers in the addiction field (Havermans \& Jansen, 2003) and its potential was demonstrated in humans (Vansteenwegen, Vervliet, Hermans, Beckers, Baeyens, \& Eelen, 2006; Mystowski, Echiverri, Labus, \& Craske, 2006). However, one drawback of the study of 
Collins and Brandon (2002) is that the researchers cannot be certain that the observed renewal of alcohol urges constitutes the return of a previously conditioned response as the observed cue-elicited urges to drink in their participants was merely presumed to be the result of an associative learning history.

More recently, Thewissen, Snijders, Havermans, van den Hout and Jansen (2006) investigated whether renewal can be demonstrated in smokers using a Pavlovian discrimination learning task in which the researchers did have complete control over the acquisition and extinction of cue-elicited urges to smoke. It was found that smokers learned to differentially respond to a coloured serving tray predicting the occurrence of smoking with a higher self-reported urge to smoke in comparison with a coloured serving tray predicting the absence of smoking. This differential urge responding was subsequently extinguished. At test, cue-elicited urges were renewed after a context switch. However, as was noted by Thewissen, Snijders, et al. (2006), the contexts used in this study can be defined as 'low risk situations' as opposed to 'high risk situations' (see Marlatt \& Gordon, 1985). That is, these low smoke relevant contexts environmental possess a relatively low risk for relapse because of their low smoke relevant characteristics. Participants evaluated the contexts as environments where they did not expect to be allowed to smoke, that did not remind them of places where they generally smoke, and in which they experienced low levels of urge to smoke. Of course, these are not the type of contexts that form the typical smokers' habitat. Thewissen, Snijders, et al. (2006) thus suggested that contexts with high smoke relevant characteristics hold a greater risk for relapse that would be evident in an even more pronounced renewal effect after a context switch from a low to a high smoke relevant context. This general hypothesis was tested in the present experiment. Related to the concept of high smoke relevant contexts, Conklin (2006) already demonstrated that environments or contexts 
associated with smoking can elicit an urge to smoke, even more so if these contexts are personalised.

The present experiment was designed to further tailor the experimental design to the clinical reality, thus enhancing the ecological validity of the study. In real life every context or environment of the smoker's personal living environment becomes high smoke relevant due to the smoker's history of smoking. When seeking out treatment to quit smoking, the smoker will enter a novel clinical setting that by definition is a low smoke relevant context. That is, evidently smoking at some time during therapy will be stopped. Note that although it is common to give the client homework assignments, the client is still 'in-treatment' and under the supervision of the therapist, hence, 'being-in-treatment' can also be viewed as a clinical context. After 'successful' treatment the ex-smoker will then reenter his or her personal living environment that still bears high smoke relevant characteristics. Such an environment is bound to elicit strong urges to smoke, hence increasing the probability of a lapse.

The following experimental design aimed to investigate the role of smoke relevant contexts on renewal of cue-elicited urge to smoke and a possible way to overcome the limited effect of extinction-based treatments after a context switch. Similar to the procedure used by Thewissen, Snijders, et al. (2006) four groups of smokers were repeatedly exposed to their smoking cues after presentation of either an availability cue or an unavailability cue in a high smoke relevant context (A), using a differential conditioning paradigm (acquisition of differential urge responding to the availability cues). Subsequently, the acquired differential urge responding was intended to be extinguished in a low smoke relevant context (B). Test for renewal took place in either a novel low or high smoke relevant context $(\mathrm{C})$. It was expected that renewal would be more pronounced for the group of smokers tested in a high smoke rele- 
vant context than the group tested in a low smoke relevant context. An additional control group received the renewal test in the same low smoke relevant context as the extinction context B. A fourth group did not only receive acquisition in a high smoke relevant context $\mathrm{A}$, but also extinction and renewal test were conducted in a high smoke relevant context ( $\mathrm{A}$ and $\mathrm{C}$ respectively). For this group it was expected that renewal would be attenuated in comparison with the group receiving the renewal test in a high smoke relevant context but extinction in a low smoke relevant context.

\section{Acquisition Extinction Renewal test}

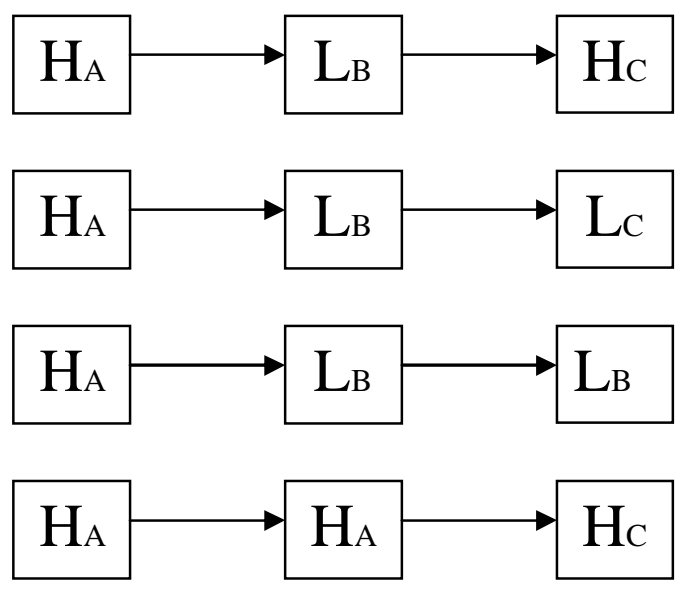

Figure 1. Experimental design of the study: four groups during three phases of the experiment: acquisition, extinction and renewal test. The preacquisition phase, pre-exposure to all the contexts, took place before these three phases and for all the participants. $H$ high smoke relevant context = 'living room' or 'pub'; L low smoke relevant context = 'office' or 'lab'; $A$ $B C=A B C$ renewal group; $A B B=A B B$ control for renewal group; $A A$ $C=A A C$ protection from renewal through resemblance in smoke relevance. 


\section{Method}

\subsection{PARTICIPANTS}

Fifty-five smokers (22 males, 33 females; $\mathrm{M}$ age $=24.13$ years; $\mathrm{SD}=7.45$ ) who smoked a minimum of five cigarettes a day for at least two years were recruited at different departments of Maastricht University. All participants completed the Fagerström Test for Nicotine Dependence (FTND; Heatherton, Kozlowski, Frecker, \& Fagerstrom, 1991). The average score on the FTND was 2.79 (SD = 2.19). Twenty-two participants smoked less than 10 cigarettes a day, twenty-four participants smoked between 11 and 20 cigarettes a day, six participants smoked between 21 and 30 cigarettes a day and three participants smoked more than 30 cigarettes a day.

Participants had to refrain from smoking for two hours prior to the experiment. An abstinence period of two hours was chosen to avoid floor or ceiling effects of urge responding during the experiment.

\subsection{INDEPENDENT VARIABLES}

Smoking cues. The smoking cues were stimuli presumed to elicit conditioned urge responses as a result of smoking history. The participant's favourite brand of cigarettes, a lighter, and an ashtray were used as smoking cues.

Availability cues. A blue or a yellow colour of a serving tray signalled the availability or unavailability of smoking. For half of the participants, a blue serving tray indicated that smoking - after presentation of the smoking cues - was allowed, and a yellow serving tray indicated that smoking was not allowed. For the other half, the meaning of the colours of the serving trays was reversed. These availability cues served as CSs respectively predicting the occur- 
rence of smoking (CS+) and absence of smoking (CS-). The US consisted of one puff of a cigarette.

Contexts. Four rooms were especially designed for the purpose of this experiment: an 'office' and a 'lab' represented contexts that differ on their physical characteristics, but both have low smoke-relevant characteristics. The 'pub' and 'living room' represented contexts that also differ on their physical characteristics, but both have high smoke-relevant characteristics.

The 'office' contained two desks, two desktop computers, office materials (e.g., phones, pens, papers, and covers), a red carpet and red office chairs. Furthermore, the 'office' had a window and was scented with 'After Tobacco Air' (Ambi Pur, Veenendaal/ The Netherlands). The 'lab' was a small laboratory room furnished with only a small table, one chair, a computer screen, and an electric plug board. The room had no windows and was unscented. The 'living room' was furnished with a set table, two dining chairs, three couches, a television set and a coffee table. The walls had posters of animals and plants. The 'living room' had no windows and was scented with 'Vanilla \& Lily' odour (Ambi Pur, Veenendaal/ The Netherlands) and with cigarette smoke. The 'pub' was designed as a typical pub setting containing a bar with tap and three wooden stools, six small wooden tables each surrounded by two or three wooden chairs. On these tables were placed empty ashtrays, beer bottles and some candles. The walls had posters of beer commercials. The room itself was dimly lit and was scented of alcohol and cigarettes.

The 'office' and the 'lab' were located in a different department building at Maastricht University than the 'pub' and the 'living room'. All four contexts were equipped with a respiratory tube connected to a ventilator in the ceiling. The respiratory tubes were made of different material and had a distinct colour. 


\subsection{DEPENDENT VARIABLES}

Smoke-relevant characteristics. In the pre-acquisition phase, in each room, $100 \mathrm{~mm}$ Visual Analogue Scales (VASs) were used to measure 'valence of the room' ("In this room, I feel": 0 "very unpleasant/ negative"- 100 "very pleasant/ positive"), 'subjective arousal' ("In this room, I feel": 0 "very relaxed"- 100 "very tense"), 'urge to smoke' ("At this moment, I feel": 0 "no urge to smoke at all"- 100 "an almost irresistible urge to smoke"), "reference to a smoking context' ("This room makes me think of a room in which I smoke": 0 "very little or not at all"- 100 "very much"), 'perceived control of smoking' ("If at this moment I would be offered a cigarette, I would be": 0 "definitely not able to refuse"- 100 "definitely able to refuse"), and "expectation of availability to smoke' ("In this room, in general, I expect to be allowed to smoke": 0 "definitely not"- 100 "definitely"), respectively. These VASs were used to assess the smoke-relevant characteristics of both contexts. Additionally, six $100 \mathrm{~mm}$ VASs ("The first/second/third/fourth room differs from the first/second/third/fourth room": 0 "to a small extent" - 100 "to a large extent") were used to measure the extent to which participants considered the four rooms as being physically different.

Urge to smoke. During the acquisition phase, as well as in the extinction phase and the test phase, $100 \mathrm{~mm}$ VASs ("At this moment, I feel": 0 "no urge to smoke at all"- 100 "an almost irresistible urge to smoke") were used to measure momentary subjective urge to smoke.

\subsection{PROCEDURE}

Prior to their participation in the experiment, all participants provided informed consent. The experiment started with an introduction in which participants were told the meaning of the blue and the yellow serving tray (i.e., signalling smoking availability or un- 
availability). Next, end-expired air carbon monoxide [Smokerlyzer, Bedfont Scientific, Ltd, CO in parts per million (ppm)] was assessed . In addition, participants completed a general smoking questionnaire and the FTND. All of this took place in a separate waiting room.

Pre-acquisition phase. Participants were exposed to each of the four rooms for a pre-acquisition session. After being seated at a desk, participants were told to relax for one minute while concentrating on the features of the room and taking notice of their feelings at that moment. Next, participants rated 'valence of the room', 'subjective arousal', 'urge to smoke', 'reference to a smoking context', 'perceived control of smoking' and 'expectation of availability to smoke' on VASs. After this, participants moved to another room in which the same procedure was followed as in the first preacquisition session. During the following pre-acquisition sessions participants completed an additional VAS that measured to what extent participants evaluated the last visited rooms as being physically different. Next, participants had a five minute reading break and were escorted to the acquisition context.

Acquisition phase. After being seated at a desk, participants again received instructions concerning the meaning of the blue and the yellow serving tray (i.e., signalling smoking availability or unavailability). The acquisition phase started with the presentation of a blue or a yellow serving tray for approximately 25 seconds. Participants were instructed to concentrate on the serving tray and to focus on their urge to smoke, after which they rated their urge to smoke on a VAS. Next, a participant's favourite brand of cigarettes, a lighter and an ashtray were placed on the serving tray. Participants 


\section{SMOKING IN CONTEXT}

were instructed to take a cigarette out of the cigarette box and handle the cigarette (touch it, place it between their lips, holding it) without lighting the cigarette. After approximately 25 seconds, subjects rated their urge to smoke on a second VAS. Following the second urge assessment, participants took one puff of the cigarette when the colour of the serving tray indicated that smoking was allowed and exhaled the smoke through a respiratory tube. If the colour of the serving tray indicated that smoking was not allowed, participants held the cigarette between their lips and a burning lighter next to it, but did not light the cigarette. Each participant completed six of such trials: three trials with a blue serving tray and three trials with a yellow serving tray in a random order with the restriction of no more than two consecutive trials of the same type. Between trials, the participants were allowed to read in one of the available magazines for approximately two minutes. In total, the acquisition

phase had a duration of approximately 30 minutes. Following the last trial, participants were taken to the room in which extinction would take place.

Extinction phase. The procedure for the extinction phase was the same as for the acquisition phase except smokers were not allowed to smoke at all and there were 4 trials of each serving tray, for a total of 8 trials. After being seated at a desk, participants were instructed about the new meaning of the blue and the yellow serving tray (i.e., both signalling smoking unavailability). In total, the extinction phase had a duration of approximately 40 minutes. Following the last trial, participants were seated in a separate waiting room for about five minutes before being escorted to the renewal test con- 
text.

Renewal test phase. During the renewal test phase, participants were again presented with a blue or a yellow serving tray, after which they completed a VAS to assess the urge to smoke. Next, they were exposed to their smoking cues, followed by a second urge VAS. After a two minute reading break, a serving tray of the other colour was presented to the subjects, followed by an urge VAS. After this, exposure to smoking cues occurred and again the urge to smoke was assessed. During both trials, participants were not allowed to smoke, but were not informed about this beforehand. After the renewal test phase, participants were debriefed in the waiting room and were paid a $€ 30$ voucher for compensation.

\section{Results}

\section{DATA REDUCTION AND ANALYSES}

Results are reported for the four main phases of the experiments: pre-acquisition, acquisition, extinction and renewal test. For all analyses, a rejection criterion of .05 was used. Huynh-Feldt epsilon corrections and corresponding adjustments to the degrees of freedom are reported for all repeated measures analyses of variance (ANOVAs) in which the assumption of sphericity was violated.

\subsection{PRE-ACQUISITION}

During the pre-acquisition phase, self-report measures of 'perceived expectation of availability to smoke', 'reference to a smoking context', 'urge to smoke', 'control of smoking', 'valence of the room', and 'subjective arousal' were scored on a $100-\mathrm{mm}$ VAS. This was done for all four rooms. Additionally, a 100-mm 
VAS was used to measure the extent to which participants evaluated the four rooms as being different. To test for renewed cue-elicited smoking urges and the influence of smoke-relevant contexts, the contexts used in this experiment had to be physically different and the low versus the high smoke relevant contexts should be different on their smoke relevant characteristics.

Table 1. Mean scores on smoking relevant characteristics for all four contexts/rooms.

\begin{tabular}{lllllll}
\hline & $\begin{array}{l}\text { Arousal } \\
\text { M (SD) }\end{array}$ & $\begin{array}{l}\text { Valence } \\
\text { M (SD) }\end{array}$ & $\begin{array}{l}\text { Urge } \\
\mathrm{M}(\mathrm{SD})\end{array}$ & $\begin{array}{l}\text { Refer- } \\
\text { ence } \\
\mathrm{M}(\mathrm{SD})\end{array}$ & $\begin{array}{l}\text { Control } \\
\mathrm{M}(\mathrm{SD})\end{array}$ & $\begin{array}{l}\text { Expectancy } \\
\mathrm{M}(\mathrm{SD})\end{array}$ \\
\hline 'Office' & 45.4 & 55.3 & 45.4 & 39.1 & 53.1 & 22.8 \\
& $(21.4)$ & $(19.3)$ & $(22.2)$ & $(26.4)$ & $(27.6)$ & $(22.8)$ \\
\hline 'Lab' & 55.3 & 33.8 & 33.0 & 14.6 & 58.3 & 15.9 \\
& $(17.1)$ & $(16.2)$ & $(22.1)$ & $(15.8)$ & $(29.7)$ & $(22.8)$ \\
\hline 'Living room' & 26.3 & 72.4 & 55.8 & 76.6 & 45.7 & 78.5 \\
& $(19.0)$ & $(17.0)$ & $(22.1)$ & $(18.8)$ & $(32.1)$ & $(24.2)$ \\
\hline 'Pub' & 25.5 & 75.5 & 63.9 & 88.2 & 34.4 & 91.5 \\
& $(17.5)$ & $(15.4)$ & $(18.0)$ & $(15.8)$ & $(28.9)$ & $(13.0)$ \\
\hline
\end{tabular}

Table 1 displays mean scores for all four contexts on all the indices. The data confirmed that the low smoke relevant contexts, the 'office' and the 'lab', had lower scores on 'valence of the room', 'urge to smoke', 'reference to a smoking context' and 'perceived expectation of availability to smoke' $(2.65<$ ts $<25.50$; $\mathrm{df}=54$, all ps < $.02)$; and higher scores on 'subjective arousal' and 'control of smoking' $(-8.60<$ ts $<-1.60$; $\mathrm{df}=54$, all ps $<.01$; except for 'control of smoking' between the 'living-room' and the 'office' $p=.12$ ). Additionally, the 'pub' was being perceived as being even more a high smoke relevant context than the 'living-room' on the indices 'urge to smoke', 'reference to a smoking context' and 'perceived expectation of availability to smoke' $(-4.60<\mathrm{ts}<-3.01$; $\mathrm{df}=54$, all ps <.01) and on 'control to smoke' $(\mathrm{t}=3.30 ; \mathrm{df}=54 ; \mathrm{p}<.01)$. Also, the 'lab' was perceived as being more of a low smoke relevant con- 
text than the 'office' on the indices 'valence of the room', 'urge to smoke' and 'reference to a smoking context' $(3.83<\mathrm{ts}<7.06$; $\mathrm{df}=$ 54 , all ps <.001) and on 'subjective arousal' $(\mathrm{t}=-2.86$; $\mathrm{df}=54 ; \mathrm{p}$ $<.01)$. Further, participants evaluated these rooms as being distinct from each other $(15.17<$ ts $<109.65 ; \mathrm{df}=54$, all ps $<.001)$.

\subsection{ACQUISITION AND EXTINCTION}

To be able to test for renewed cue-elicited urges to smoke, initial acquisition of cue-elicited urge responding and subsequent extinction of such responding had to be ascertained (see Thewissen, Snijders, et al., 2006). The mean urges to smoke scores in all four conditions as measured during the acquisition phase are depicted in Figure 2.

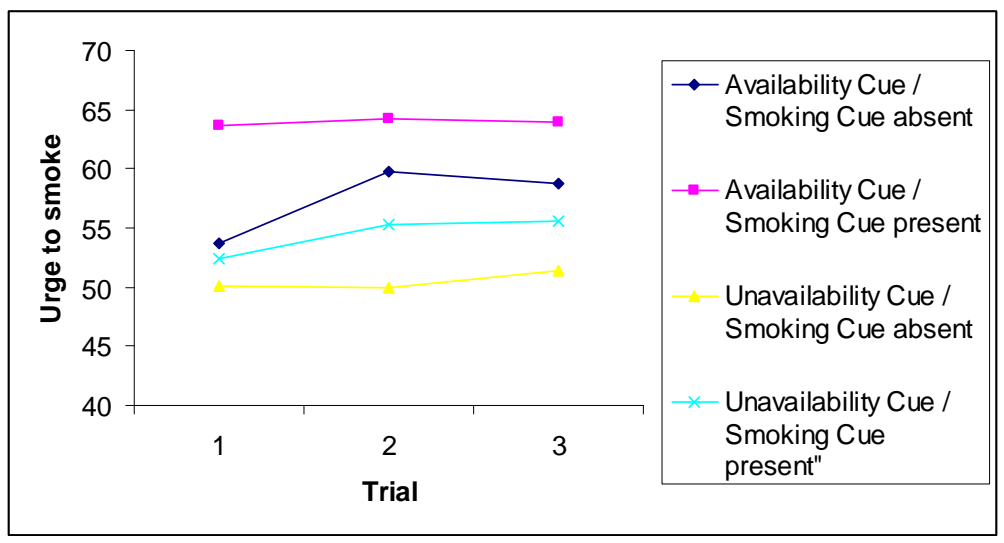

Figure 2. Effect of availability cues and smoking cues on the urge to smoke at triall-3 of the acquisition phase $(n=55)$.

During acquisition, extinction and test, every presentation of the coloured serving tray (availability cues) and every presentation of the smoking cues (cue) were followed by a $100-\mathrm{mm}$ VAS to assess subjective urge to smoke. During the acquisition phase, there were 3 
trials of each availability or unavailability cue (yellow and blue serving tray) and during every trial, availability cues were presented alone and with smoking cues. The extinction phase consisted of 4 trials. Separate (smoking cue $\mathrm{x}$ availability cues $\mathrm{x}$ trial) repeated measures ANOVAs were performed for the acquisition and extinction phase.

For acquisition, the analyses confirmed that urge responding was higher given the availability cue than given the unavailability cue, $\mathrm{F}(1,54)=30.75, \mathrm{p}<.001$. Thus, the availability cues acquired the capacity to differentially elicit urge to smoke. The availability cue (CS+) associated with the occurrence of smoke intake (US) elicited higher urge responses (CR) than the unavailability cue (CS-) associated with the omission of smoke intake (no US), irrespective of the presentation of the smoking cues.

Further, analyses revealed a significant main effect of smoking cues, $\mathrm{F}(1,54)=37.47, \mathrm{p}<.001$. When exposed to their smoking cues participants reported higher urge scores than when not, irrespective of the availability cues. Furthermore, analyses revealed a significant interaction effect of availability cues $x$ smoking cue, $\mathrm{F}(1,54)=4.77, \mathrm{p}<.05$, and a significant availability cues $\mathrm{x}$ smoking cue $x$ trial $[F(1.57,84.70)=3.80, p<.05]$ interaction. The latter three-way interaction indicates that the urge-inducing effects of smoking cues increases over trials given the unavailability cue, whereas given the availability cue the urge-inducing effects of smoking cues decreases, as can be inferred from Figure 2.

Extinction (or renewal) can only take place if learning has occurred. Although the overall analysis indicates successful conditioning, 12 participants did not demonstrate differential urge responding to the availability cues. For this reason the analyses of the extinction and renewal phase are presented for the 43 out of the 55 participants showing successful acquisition. The overall effects of availability cues on urge to smoke as measured during the last acquisition trial 
and the extinction phase are depicted in Figure 3.

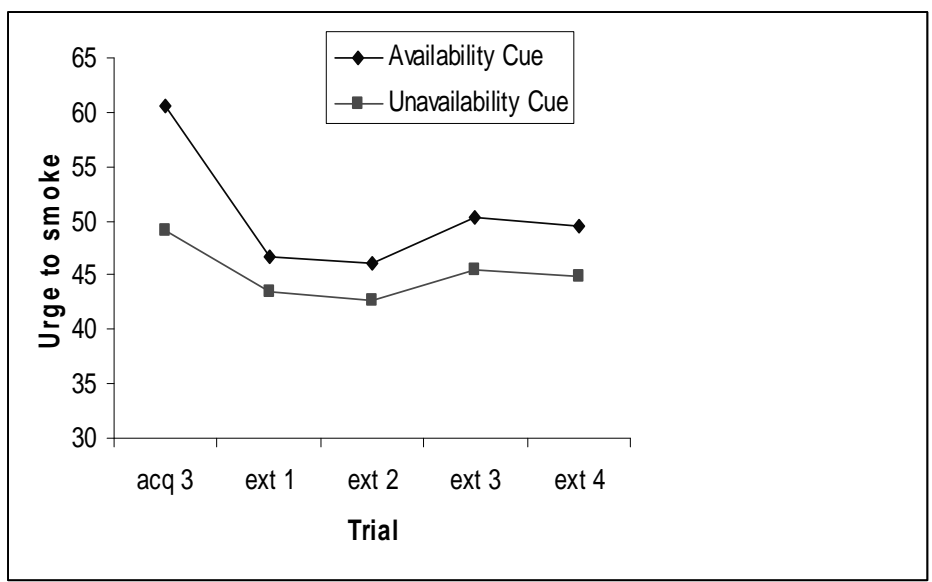

Figure 3. Overall effect of availability cues on the urge to smoke as measured on the third and last acquisition trial (acq 3) and during the subsequent extinction phase (trials ext 1, 2, 3 and 4) for the participants who showed prior acquisition of differential urge responding to the availability cues $(n=43)$.

The availability cues (availability versus unavailability) $\mathrm{x}$ smoking cues (present versus absent) $\mathrm{x}$ trial (last acquisition trial and extinction trials 1 to 4) ANOVA revealed a significant main effect of availability cues, $\mathrm{F}(1,42)=16.20, \mathrm{p}<.001$, demonstrating that, irrespective of the smoking cues, urge to smoke was higher given the availability cue than given the unavailability cue. Furthermore, analyses indicated that participants reported higher levels of urge to smoke when exposed to their smoking cues than when not, $F(1,42)=24.32, p<.001$. Also there was a significant effect of trial revealing an overall decrease of urge to smoke over trials $[\mathrm{F}(2.73,111.71)=10.81, \mathrm{p}<.001]$. More importantly, a significant interaction between availability cues and trial emerged from the data $[\mathrm{F}(3.53,144.74)=3.95, \mathrm{p}<.01]$. This interaction demonstrates ex- 
tinction of differential urge responding to the availability cues over trials. Post-hoc analyses revealed a significant decrease for the availability cue from the last acquisition trial to the last extinction trial $[\mathrm{F}(2.84,119.08)=11.81, \mathrm{p}<.001]$, but also for the unavailability cue there was a significant decrease of urge responding over trials $[F(3.27,132.71)=3.27, p<.05]$. Further t-statistics showed that the difference between the availability cues at the last acquisition trial was significant $(\mathrm{M}$ diff $=10.86 ; \mathrm{t}=4.96 ; \mathrm{df}=42 ; \mathrm{p}<.001)$ and that this difference was decreased at the last extinction trial, although this difference was still significant $(\mathrm{M}$ diff $=4.00 ; \mathrm{t}=2.76$; $\mathrm{df}=42 ; \mathrm{p}<.01)$. All other effects were non-significant.

\subsection{RENEWAL TEST}

Since the results of the extinction phase demonstrated a reduction of differential urge responding to the availability cues, a test for renewal after a context switch was warranted. For the renewal test phase, an availability cue (availability cue, unavailability cue) $x$ smoking cue (present, absent) x renewal group (HLH abc, HLL abc, HLL abb, HHH aac) x trial (last extinction trial, renewal test trial) ANOVA for repeated measures was performed.

Figure 4 depicts the effect of a context change on differential urge responding to the availability cues for all four groups. The ANOVA revealed a significant main effect of availability cue, $F(1$, $39)=10.00, \mathrm{p}<.01$, showing that overall urge to smoke is higher given the availability cue than when given the unavailability cue. Furthermore, a significant effect of smoking cue indicated that smoking cues kept their urge-eliciting capacity $[\mathrm{F}(1,39)=8.50$, $\mathrm{p}<$ $.01]$, although a significant smoking cue $\mathrm{x}$ trial interaction showed that this effect of smoking cue decreased from the last extinction trial to the renewal test $[\mathrm{F}(1,39)=4.16, \mathrm{p}=.05]$. Unexpectedly, there was no significant availability $\mathrm{x}$ renewal group $\mathrm{x}$ trial interaction, hence there was no evidence of any difference in renewal ef- 
fect between the different groups. No other effects reached significance.

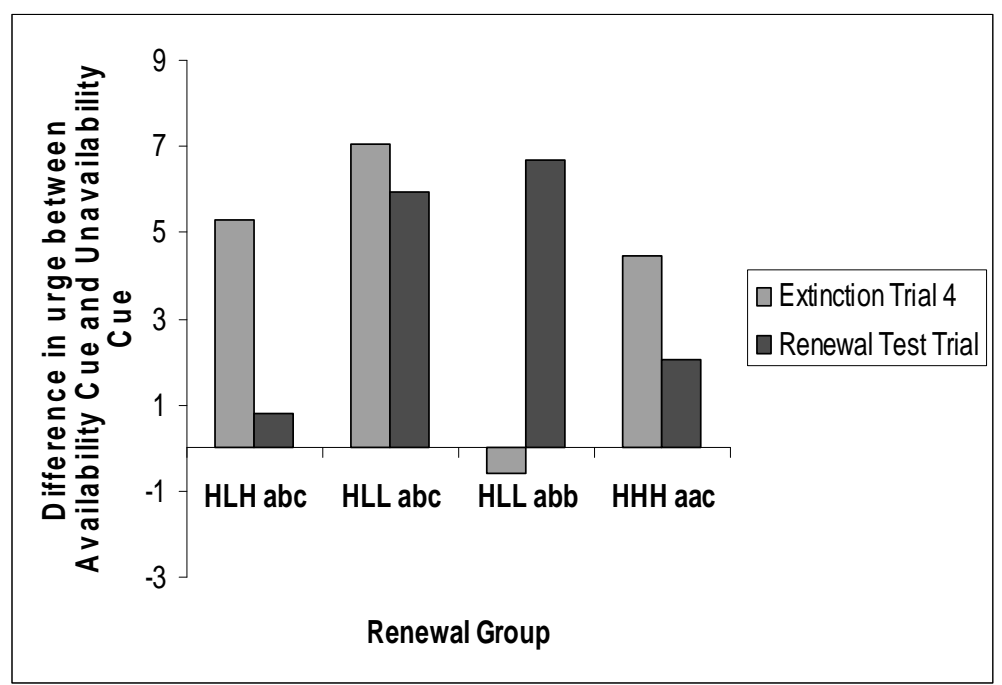

Figure 4. Effect of a context switch on differential urge responding to the availability cues for all four groups. The Y axis represents the mean difference in urge to smoke between the unavailability cue and the availability cue.

Although no renewal effect was found this does not preclude the possibility that smoke relevance of the test contexts did affect the urge to smoke at test. Therefore, we conducted further exploratory analyses. An analysis was performed comparing a group that made a context switch to a high smoke relevant context with a group that made a context switch to a low smoke relevant context at test with the average overall urge to smoke during extinction and during the renewal test as the dependent variable. This analysis revealed a significant interaction between the test phase (last extinction trial versus renewal test trial) and group (switch to low versus switch to high smoke relevant context), $[\mathrm{F}(1,30)=4.28, \mathrm{p}<.05]$. 
This interaction demonstrates that when conducting a context switch to a high smoke relevant context, overall urge responding increases $(\mathrm{t}=1.90 ; \mathrm{df}=21 ; \mathrm{p}<.05,1$-tailed $)$, whereas switching to a low smoke relevant context does not lead to any change in urge responding $\mathrm{t}=-1.10 ; \mathrm{df}=9 ; \mathrm{ns}$ ).

\section{Discussion}

Data of the acquisition phase of the present experiment contributes to the now reliable finding that smokers report higher levels of urge to smoke when presented with a cue signalling the availability of smoking than when presented with a cue signalling the unavailability of smoking (Dols, Willems, van den Hout, \& Bittoun, 2000; Dols, van den Hout, Kindt, \& Willems, 2002; Thewissen, van den Hout, Havermans, \& Jansen, 2005; Thewissen, Snijders, et al. 2006; Thewissen, van der Meijden, et al., 2006). Thus, the availability cues acquired the function of a CS, differentially eliciting urge to smoke. Furthermore, smoking cues tended to slightly loose their urge-inducing capacity towards the end of the acquisition phase. Extinction of the differentially acquired urge to smoke, however, was not as strong as demonstrated previously by Thewissen, Snijders, et al. (2006), although an additional extinction trial was added to the present experimental design.

More importantly though, the present results could not confirm the hypothesis that a context switch from a low smoke relevant context (extinction) to a high smoke relevant context (renewal test) leads to a more pronounced renewal effect than when switching from one low smoke relevant setting to another low smoke relevant context. In fact, no clear evidence of any renewal was found. Why no renewal effect was found in the present study may have had several reasons. Firstly, the renewal paradigm used in this study was an $\mathrm{ABC}$ design which appears to render less robust renewal than when 
using an ABA renewal design (see e.g., Havermans et al., 2005). Secondly, extinction was not complete in the present study, hence a renewal effect may have been obscured by the incomplete extinction of differential urge responding to the availability cues. Nonetheless, the renewal effect typically observed in animals concerns the return of conditioned responding to nearly the same extent as just before extinction treatment (see e.g., Bouton \& Bolles, 1979). Even with incomplete extinction, one would thus have expected some return of conditioned urge responding at test. Clearly, no such renewal was observed in the present experiment. Thirdly, one may argue that the context switch was not salient enough in comparison to a real-life context switch from the clinic (or any other treatment setting) to one's personal environment. For example, when an ex-smoker after treatment (which constitutes not only the physical therapeutic setting, but also the broader context of 'being-under-treatment') enters his/her favourite pub to have a drink he/she could very well be fully aware of the high risk situation and the potential of smoking relapse in that situation. Hence, the salience regarding the relapse-potential of the high risk situation (i.e. high smoke relevant context) is particularly prominent in real-life. Alternatively, in accordance with contemporary conditioning models (e.g. Davey, 1992; Vogel-Sprott \& Fillmore, 1999; Kirsch, Lynn, Vigorito, \& Miller, 2004) an additional (cognitive) informational approach opens up the possibility to enhance salience of a context change by prompting participants to be aware of the context entered in the different phases of the conditioning paradigm

Although no renewal was found in the present study, an exploratory analysis did reveal an effect of smoke relevance of the context on urge to smoke at test. It was demonstrated that when a context switch was made to a high smoke relevant context urge to smoke increased, whereas with a switch to a low smoke relevant context no significant difference in urge responding was observed. 
This suggests that the context switch in the present study (i.e., the switch to a novel high smoke relevant context) was salient and that environmental settings can function as CSs capable of directly eliciting the urge to smoke, irrespective of the presence of other smoking-related cues. This finding corroborates recent results reported by Conklin (2006) who found that idiosyncratic smoking related contexts can function as CSs reliable eliciting urge to smoke. The present finding also demonstrates that when a context switch is conducted to a high smoke relevant context, its salient smoke relevant characteristics overshadow the predictive value of the availability cues (see also Thewissen, van der Meijden, et al., 2006). The present study thus shows that the source of potential relapse of smoking behaviour after cue exposure treatment is not necessarily the result of renewed smoking urges elicited by proximal smoking cues, but rather the result of the failure to extinguish such urges elicited by various more distal smoking related settings. Such settings, or contexts, function as CSs directly eliciting the urge to smoke and as Conklin (2006) recently demonstrated are in that respect just as potent CSs as more proximal smoking cues, such as cigarettes. Indeed, renewal of extinguished conditioned responding is typically tested in contexts that are neutral; that is, they are not associated with the US. Of course, drug dependent persons having undergone cue exposure treatment do not return to such neutral contexts and thus the ABA renewal paradigm does not parallel the treatment situation of drug dependent patients.

The present finding bears implications for further clinical research and extinction-based treatment of smoking dependence. Conklin (2006) proposes to conduct exposure therapy in the most salient personalised contexts to enhance generalisation of extinguished urges to smoke to all (or most) environments in which the client used to smoke. In line with this reasoning, Thewissen et al. (2005) proposed a broader cognitive behavioural treatment in which 
cue exposure can be used as a (final) behavioural experiment to challenge cognitions, expectations, and beliefs concerning the urge to smoke and its relation to smoking behaviour (Beck, Wright, Newman, \& Liese, 1993). To overcome the problem of renewed urges to smoke and subsequent relapse in high risk situations (see also Marlatt \& Gordon, 1985) cue exposure should be conducted in a range of risk situations, starting in the smoking related context that poses the least risk of relapse for the client. Such a gradual exposure is likely to lead to less rapid extinction of urge responding, but is also less aversive than a flooding technique in which one would expose the client immediately to smoking cues in his most salient smoking related context, as was suggested by Conklin (2006). Furthermore, the present results, the findings of Thewissen, van der Meijden, et al. (2006) as well as the data of Conklin point out to the possible limitation of using retrieval cues (Brooks \& Bouton, 1994; Collins \& Brandon, 2002; Mystkowski, et al., 2006; Vansteenwegen et al., 2006) or flashcards (see Marlatt \& Gordon, 1995) to overcome the problem of renewal. As idiosyncratic high smoke relevant contexts can function as a CS evoking urge to smoke the use of retrieval cues or flashcards in such high risk situations should be relatively ineffective at limiting the occurrence of strong urges after treatment. Whether a context exposure therapy is more beneficial in the treatment of smoking dependence than regular cue exposure therapy needs to be evaluated in future research. 


\section{SMOKING IN CONTEXT}

\section{References}

Beck, A. T., Wright, F. D., Newman, C. F., \& Liese, B. S. (1993). Cognitive therapy of substance abuse. New York: The Guilford press.

Bouton, M. E. (1988). Context and ambiguity in the extinction of emotional learning: implications for exposure therapy. Behaviour Research and Therapy, 26, 137-149.

Bouton, M. E., \& Bolles, R. C. (1979). Contextual control of the extinction of conditioned fear. Learning and motivation, 10, 445-466.

Bouton, M. E. \& Brooks, D. C. (1993). Time and contexts effects on performance in a Pavlovian discrimination reversal. Journal of Experimental Psychology: Animal Behavior Processes, 19, 165-179.

Bouton, M. E., \& King, D. A. (1983). Contextual control of the extinction of conditioned fear: Tests for the associative value of the context. Journal of Experimental Psychology: Animal Behavior Processes, 9, 248-265.

Bouton, M. E., \& Peck, C. A. (1989). Context effects on conditioning, extinction, and reinstatement in an appetitive conditioning preparation. Animal Learning \& Behavior, 17, 188-198.

Bouton, M. E., \& Ricker, S. T. (1994). Renewal of extinguished responding in a second context. Animal Learning \& Behavior, 22, 317-324.

Bouton, M. E., \& Swartzentruber, D. (1986). Analysis of the associative and occasion-setting properties of contexts participating in a Pavlovian discrimination. Journal of Experimental Psychology: Animal Behavior Processes, 12, 333-350.

Bouton, M. E., \& Swartzentruber, D. (1991). Sources of relapse after extinction in Pavlovian and instrumental learning. Clinical Psychology Review, 11, 123-140.

Bouton, M. E. (2002). Context, ambiguity, and unlearning: Sources of relapse after behavioural extinction. Biological Psychology, 52, 976-986.

Brooks, D. C., \& Bouton, M. E. (1994). A retrieval cue for extinction attenuates response recovery (renewal) caused by a return to the conditioning context. Journal of Experimental Psychology: Animal Behavior Processes, 20, 366-379.

Carter, B. L., \& Tiffany, S. T. (2001). The cue-availability paradigm: the effects of cigarette availability on cue reactivity in smokers. Experimental and Clinical Psychopharmacology, 9, 183-190.

Collins, B. N., \& Brandon, T. H. (2002). Effects of extinction context and retrieval cues on alcohol cue reactivity among non-alcoholic drinkers. Journal of Consulting and Clinical Psychology, 70, 390-397.

Conklin, C. A. (2006). Environments as cues to smoke: Implications for human extinctionbased research and treatment. Experimental and Clinical Psychopharmacology, 14, 12-19.

Conklin, C. A., \& Tiffany, S. T. (2002). Applying extinction research and theory to cueexposure addiction treatments. Addiction, 97, 155-167.

Davey, G. C. L. (1992). Classical conditioning and the acquisition of human fears and phobias: a review and synthesis of the literature. Advances in Behaviour Research and Therapy, 14, 29-66. 
Dols, M., Willems, B., Van den Hout, M., \& Bittoun, R. (2000). Smokers can learn to influence their urge to smoke. Addictive Behaviors, 25, 103-108.

Dols, M., Van den Hout, M., Kindt, M., \& Willems, B. (2002). The urge to smoke depends on the expectation of smoking. Addiction, 97, 87-93.

Havermans, R. C., \& Jansen, A. T. M. (2003). Increasing the efficacy of cue exposure treatment in preventing relapse of addictive behavior. Addictive Behaviors, 28, 989-994.

Havermans, R. C., Keuker, J., Lataster, T., \& Jansen, A. (2005). Contextual control of extinguished conditioned performance in humans. Learning and Motivation, 36, 1-19.

Heatherton, T. F., Kozlowski, L. T., Frecker, R. C., \& Fagerström, K. O. (1991). The Fagerström Test for Nicotine Dependence: A revision of the Fagerström Tolerance Questionnaire. British Journal of Addiction, 86, 1119-1127.

Kirsch, I., Lynn, S. J., Vigorito, M., \& Miller, R. (2004). The role of cognition in classical and operant conditioning. Journal of Clinical Psychology, 60, 369-392.

Lang, A. J., \& Craske, M. G. (2000). Manipulations of exposure-based therapy to reduce return of fear: A replication. Behaviour Research and Therapy, 38, 1-12.

Marlatt, G. A., \& Gordon, J. R. (1985). Relapse Prevention: Maintenance Strategies in the Treatment of Addictive Behaviors. New York: Guilford Press.

Mineka, S., Mystkowski, J. L., Hladek, D., \& Rodriguez, B. I. (1999). The effects of changing contexts on return of fear following exposure therapy for spider fear. Journal of Consulting and Clinical Psychology, 67, 599-604.

Mystkowski, J. L., Craske, M. G., Echiverri, A. M., \& Labus, J. S. (2006). Mental reinstatement of context and return of fear in spider-fearful participants. Behavior Therapy, 37, 49-60.

Öst, L. G. (1997). Rapid treatment of specific phobias. In G. Davey (Ed.). Phobias: A handbook of theory, research and treatment (pp. 227-246). Chichester: Wiley.

Rodriguez, B. I., Craske, M. G., Mineka, S., \& Hladek, D. (1999). Context-specificity of relapse: effects of therapist and environmental context on return of fear. Behaviour Research and Therapy, 37, 845-862.

Rosas, J. M. \& Bouton, M. E. (1997). Renewal of conditioned taste aversion upon return to the conditioning context after extinction in another one. Learning and Motivation, 28, 216-229.

Rowe, M. K., \& Craske, M. G. (1998). Effects of an expanding-spaced vs massed exposure schedule on fear reduction and return of fear. Behaviour Research and Therapy, 36, 701-717.

Staiger, P. K., Greeley, J. D., \& Wallace, S. D. (1999). Alcohol exposure therapy: generalisation and changes in responsivity. Drug and Alcohol Dependence, 57, 29-40.

Thewissen, R., Van den Hout, M., Havermans, R. C., \& Jansen, A. (2005). Contextdependency of cue-elicited urge to smoke. Addiction, 100, 387-396.

Thewissen, R., van der Meijden, A. F., Havermans, R. C., van den Hout, M., \& Jansen, A. (2006). From the office to the pub: The role of smoke relevant contexts on cueelicited urge to smoke. Submitted for publication.

Thewissen, R., Snijders, S. J. B. D., Havermans, R. C., Hout van den, M., \& Jansen, A. (in press). Renewal of cue-elicited urge to smoke: Implications for cue exposure treatment. Behaviour Research and Therapy. 


\section{SMOKING IN CONTEXT}

Vansteenwegen, D., Hermans, D., Vervliet, B., Francken, G., Beckers, T., Baeyens, F., \& Eelen, P. (2005). Return of fear in a human differential conditioning paradigm caused by a return to the original acquisition context. Behaviour Research and Therapy, 43, 323-336.

Vansteenwegen, D.,Vervliet, B., Hermans, D., Beckers, T., Baeyens, F., \& Eelen, P. (in press). Stronger renewal in human fear conditioning when tested with an acquisition retrieval cue than with an extinction retrieval cue. Behaviour Research and Therapy.

Vogel-sprott, M., \& Fillmore, M. T. (1999). Learning theory and research. In K. E. Leonard \& H. T. Blane (Eds.), Psychological Theories of Drinking and Alcoholism, 292-327. New York: Guilford Press. 
From the Clinic to THE PUB 
SMOKING IN CONTEXT 


\section{Chapter 7}

\section{GENERAL DISCUSSION}

CUES AND CONTEXTS IN SMOKING ADDICTION:

"THEORETICAL AND CLINICAL IMPLICATIONS" 
The present thesis investigated the effects of cues and contexts on self-reported urge to smoke in relation to cue exposure therapy that is specially designed to deal with cue-elicited urge to smoke. During cue exposure therapy one is repeatedly exposed to smoking paraphernalia (cigarettes, ashtray, lighter) but is not allowed to smoke. Specifically, the role of smoke relevant contexts in cue-elicited urge to smoke acquired through conditioning (instructional and trial-bytrial learning) was examined to further tailor clinical analogue designs to real-life phenomenon in human addiction research. The following paragraph will summarise the main conclusions of the experimental studies presented in this thesis. The final paragraphs will discus the theoretical and clinical implications derived from the reported findings.

\section{General Conclusions}

In the first study of the present thesis (chapter 2) the hypothesis was tested that - in line with the incentive sensitization model by Robinson and Berridge (1993, 2003) - an incentive motivation (indexed as a behavioural approach bias towards cues signalling smoking availability or smoking unavailability) can be conditioned. The results indeed showed that for a group of participants who were prompted to detect a contingency between external cues and the availability of smoking an approach tendency was found for the cue signalling the availability of smoking. The finding that subjective urge to smoke did not differentiate between the cue signalling smoking availability and the cue signalling the unavailability of smoking suggests that an incentive motivation can be expressed as behaviour without being subjectively aware of this motivation. This notion is in agreement with Robinson and Berridge who state that the desire to use drugs is automatically elicited by drug cues. This incentive motivation (or wanting) can occur outside awareness, that is, without the subjective 
urge to smoke.

In the following four experimental studies the possible influence of cues and contexts on urge to smoke within a discriminative Pavlovian conditioning paradigm was under investigation. The first of these studies, described in chapter 3, investigated whether previously neutral cues (viz., the availability cues) could acquire the ability to differentially control subjective urge responding when either followed by smoking or not. Furthermore, it was tested whether this acquired differential urge responding would generalise to a new context. It was found that the availability cues immediately acquired the ability to control urge to smoke. Indeed, the cue predicting the availability of smoking elicited higher urge scores than the cue predicting the unavailability of smoking (see also Dols et al., 2000; 2002). Unlike Dols and colleagues (2002) however, smoking cues (e.g., cigarettes, lighter, ahstray) kept their ability to elicit the urge to smoke, irrespective of the availability cues. Further, this differential urge responding generalised well to another context as the availability cues maintained their differential urge-inducing capacities.

In the next study (chapter 4), the role of smoke relevance in generalisation of acquired differential urge responding was further examined. The same discriminative Pavlovian conditioning task was used, but now a context switch was made from a low to a high smoke relevant context and from a high to a low smoke relevant context. Results revealed that differential urge responding to the availability cues was lost with a context switch from a low to a high smoke relevant context, whereas this differential responding generalised well when switching from a high to a low smoke relevant context. These findings confirm the influence of smoke relevance of contexts when conducting a context change within a human conditioning paradigm. That is, not merely a physical context change is necessary to observe changes in differential cue-elicited urge responding, but the 'meaning' of the context as a semantic whole - 
related to smoking behaviour - is an important factor determining the potential of contexts to moderate conditioned responding in humans. Apparently, the smoking related characteristics of a context are of overriding importance in eliciting conditioned urge responding in humans.

In chapter 5, the phenomenon of renewal of extinguished differential urge responding was examined and demonstrated in human smokers. More specifically, it was found that when differential conditioning of the urge to smoke took place in context A and a subsequent extinction treatment in another context $\mathrm{B}$, renewal of conditioned differential urge responding occurred when smokers were tested again in the acquisition context $\mathrm{A}$ but not in the extinction context B. Hence, ABA-renewal was found in humans smokers. However, also in this experiment we used only low smoke relevant contexts.

In chapter 6, renewal of differential urge responding was again under investigation, but now with the use of low and high smoke relevant contexts in an $\mathrm{ABC}$-renewal design. This was done to further tailor the experimental situation to the clinical reality in which cue exposure therapy is applied, with the potential risk of relapse after "successful" treatment. Although no significant differences were found between the different renewal groups (no renewal occurred at all), there was an overall effect observed of high smoke relevant contexts on the urge to smoke. That is, results revealed that switching to a high smoke relevant context increases the general urge to smoke. It was concluded that high smoke relevant contexts act as conditioned stimuli eliciting urge to smoke because they predict the availability of smoking in that particular environment. This is in line with recent findings (Conklin, 2006). 


\section{Theoretical Implications}

The first study of the present thesis confirmed the prediction following the incentive sensitisation model of Robinson and Berridge $(1993,2003)$ that an automatic incentive motivation - indexed by a measurement of approach bias - can be conditioned. During conditioning smoking related cues, i.e. the availability cues (conditioned stimuli, CSs), were associated with the occurrence or absence of smoking (unconditioned stimulus, US) and evoked urge to smoke (conditioned response, CR). In line with contemporary learning theory, this only occurred in the group which was explicitly prompted to detect the contingency between availability cues and smoking. This provides further support for the notion that contingency awareness is necessary for cues to be able to discriminatively control urge responding, to selectively attend to these cues and to control drugseeking behaviour (Hogarth, et al., 2003; 2005; Hogarth \& Duka, 2006). It has often been argued that Pavlovian conditioning is a simple associative learning process and as such does not depend on conscious awareness. However, demonstrations of unconscious Pavlovian conditioning are an extreme rarity. As a rule, conditioning seems to involve conscious cognition and can be referred to as propositional or expectancy learning (see Lovibond \& Shanks, 2002). Clearly, the conditioning of an incentive motivation forms no exception to this rule.

The next four studies reported in the present thesis build upon earlier animal research related to human psychopathology and its treatment in general and to addictive behaviour specifically. Bouton $(1988,2000,2004)$ has repeatedly demonstrated that extinction, the Pavlovian procedure on which cue exposure therapy is based, is not the "unlearning" of the CS-US association, but is the learning of a new inhibitory association between the CS and the US. As a result, the CS has an ambiguous relation with the US, that is, after 
extinction it predicts the occurrence and the absence of the US (see also Rescola, 2004). According to Bouton (1988, 2000), this ambiguity is resolved by the context in which extinction took place. Extinction is said to be context-dependent. In other words, the CS-No US (i.e. inhibitory CS-US association) is only valid and behaviourally manifested when the CS is presented in the extinction context. Therefore, when the CS is presented outside the extinction context the excitatory association is retrieved allowing for renewed conditioned responding. The notion that extinction is not the unlearning of an association is also supported by related learning phenomena as spontaneous recovery, reinstatement, and reacquisition (Hermans, et al., 2005).

As mentioned above, Bouton derived his notion that extinction is not unlearning from animal research. An important purpose of this thesis was to translate this notion to smoking addiction in humans. Following the work of Dols et al. (2000; 2002) the present thesis extended the procedure and design used by Dols by adding a true environmental context manipulation. Thus the experimental design of Dols and colleagues was implemented in a more naturalistic environment (i.e. room contexts) to investigate the influence of environmental setting on learned expectations (i.e. CS-US associations) regarding the availability of smoking. Moreover, the contexts used in the present experiments were not merely settings that differed on their physical characteristics, but they also differed on a more functional level; that is, their smoke relevant characteristics were different (i.e., low and high smoke relevant contexts). This was done to further approximate the clinical reality of the smoker. Smokers do not smoke their cigarettes in a vacuum, but in environments they recognise as contexts in which one is allowed to smoke (e.g., a pub, or designated public smoking areas at railway stations or airports).

In the second study of the present thesis (chapter 3) it was 
found that when a context switch was made from one low smoke relevant context to another low smoke relevant context differentially acquired cue-elicited urge to smoke generalised well, whereas in the third study (chapter 4) it was found that generalisation of acquisition was lost when a context switch was made from a low to a high smoke relevant context. This, although preliminary, demonstrates the importance of smoke relevant contexts in human conditioning research. The findings of these two studies also suggest that the expectation of the US (smoking) when the CS (availability cue) is presented can be influenced by the context in which the CS is presented, as has already been proposed by contemporary learning models (see Rescola \& Wagner, 1972; Davey, 1992; Vogel-sprott \& Fillmore, 1999; Kirsch, 2004) These models are built on extensive empirical work from fundamental, fear related as well as addiction related research (e.g. Dawson, 1973; Dawson \& Shell, 1987; Lovibond, 2003; Dols et al, 2000; 2002; Field \& Duka, 2001; Hogarth et al; 2003; 2005). Indeed, one can argue that a meaningful context change affects the perceived predictive value of the availability to smoke. The expectation of being allowed to smoke in the high smoke relevant context is particularly salient after a context switch from a low to a high smoke relevant context; hence, this expectation overrides the previously acquired inhibitory association between the unavailability cue (CS) and smoking (US). Note that high smoke relevant contexts can be conceptualised as high risk situations (see Marlatt \& Gordon, 1985) that posses information about smoking behaviour such as: smokers experience higher urge to smoke and less control to refrain from smoking; refer to it as a smoking context and expect to be allowed to smoke. This conceptualisation of context goes beyond the definition offered by Bouton and colleagues (e.g. Bouton \& Swartzentruber, 1991, p. 132) who state "that context can be any background event or stimulus in which target learning and memory events are imbedded". These can include, accord- 
ing to Bouton and Swartzentruber, drug states (i.e. interoceptive cues), emotional states and the mere passage of time. The findings and rationale of the present studies extend this definition by emphasizing the meaningful quality of the background event or stimulus (i.e. the context) that predicts the occurrence of the targeted behaviour or event imbedded in that context. In other words, with regard to the motivation to smoke, there exists a complex relationship between smoking cues, availability cues (any initially neutral cue that comes to predict the occurrence or absence of smoking) and the broader context in which these cues are imbedded.

For extinction and the possibility of renewal with a context change after extinction, the influence of smoking related contexts seems different than after acquisition. As was found in the fourth study of this thesis (chapter 5), renewal occurs when a context change was made from one low smoke relevant context to another low smoke relevant context when the test was conducted outside the extinction context (ABA-renewal). However, the results of the final study (chapter 6) showed no stronger renewal effect when using a context switch from a low smoke relevant context to a new high smoke relevant context (HaLbHc renewal group) than when switching from one low to another low smoke relevant context (HaLbLc renewal group). In fact, there was no renewal observed in any of the experimental groups. Instead, analyses revealed that the high smoke relevant context overall increased general urge responding, just as any CS would have when having acquired a predictive association with the US. Although this study was exploratory and thus preliminary, it is in line with other research by Conklin (2006) who found that smoking related environments are capable of directly eliciting urge to smoke just as more proximal smoking cues do. The results described in chapter 6 are important for understanding relapse of smoking behaviour after an exposure treatment. Several researchers have attributed this to a renewal effect (see e.g., Havermans \& 
Jansen, 2003). However, in a typical renewal experiment, the acquisition context is presumed to remain neutral with regard to the occurrence of the US (Bouton, 2000). Clearly, this is not the case when considering smoking addiction. Smokers not only learn to associate proximal smoking cues (e.g., cigarettes), but also the more distal context with smoking. Ascribing relapse of smoking behaviour to a renewal effect thus oversimplifies clinical reality.

\section{Clinical Implications}

The main problem with smoking dependence and drug dependence in general is not quitting drug taking behaviour, but remaining abstinent. Relapse after treatment remains a big concern and issue for both clients and clinicians, hence, preventing relapse has become the primary goal of treating drug dependence. Cue exposure therapy has been advocated to target one of the most important obstacles in maintaining drug abstinence, namely the urge to use a given drug (in this thesis the urge to smoke). From a learning perspective environmental cues and contexts are capable of eliciting urge responses (i.e. cue reactivity) and this cue reactivity can be extinguished using exposure-based procedures (e.g. cue exposure with response prevention). However, extinction is not the "unlearning" of the CS-US association, hence allowing for renewal or recovery of cue reactivity after 'successful' treatment (e.g. Bouton, 1988; 2002).

The main purpose of this thesis was to determine the possible influence of cues and contexts on urge to smoke and to derive some potential modifications for cue exposure therapy in the treatment of smoking addiction. Some researchers in the addiction field advocate the use of retrieval cues in cue exposure therapy, such as reminder flash cards (see Marlatt \& Gordon, 1985). Animal research has shown that cues that remind one of the extinction treatment context undermines the renewal effect (Bouton, 2000). The merits of 
such an approach may, however, be limited. A pragmatic problem with the use of retrieval cues is that clients have to remember to use these cues in order for them to have any effect. More importantly though, as mentioned above, the living environment of a smoker is bound to be smoke relevant and thus able to directly elicit a strong urge to smoke. Without previous exposure to this context, the retrieval cue will be able to activate the inhibitory association between proximal smoking cues and smoking, but this will not affect the urge elicited by the context rendering the retrieval cue ineffective.

Another and perhaps more beneficial way to resolve the problem of renewal of extinguished urge responses is to conduct cue exposure therapy in the clients' own living environment, that is, in the clients' own high smoke relevant contexts or high risk situations. Thus the emphasis of the rationale of cue exposure therapy should be on exposing the client to his/her most difficult high risk situations/contexts. By doing so, urges elicited by both proximal and distal cues are extinguished. Moreover, as extinction treatment is conducted within the client's own living environment, one need not worry whether extinguished urge responding will generalize to this setting (see also Havermans \& Jansen, 2003). This is in line with the work with of Conklin (2006) who showed that personal smokingrelated environments (i.e. high smoke relevant contexts) are capable to act as a CS eliciting urge to smoke. Form these findings it is very plausible to argue that not proximal cues like drug paraphernalia (e.g. smoking cues: cigarettes, ashtray, lighter,...) mainly should be target when conducting exposure therapy but rather more distal cues like the high smoke relevant contexts themselves. Thus, a 'context exposure' in a clients' personal living environment would probably be more fruitful. A study on cue exposure for bulimia nervosa conducted in the binge context supports this idea: context cue exposure was highly successful in reducing the binge frequency (Jansen, Elgersma, Nederkoorn \& Smeets, 2002). Whether a 'context exposure 
therapy' is more beneficial than a standard cue exposure treatment of addictive behaviours remains to be empirically validated.

It should be noted that context in the present thesis is not merely conceptualised as a physical environment but as a 'meaningful whole' which possesses information regearding the targeted behaviour or responses (e.g., smoking). This definition thus includes cognitions (beliefs, expectations, attitudes,...), biological state (e.g., drug states), emotions and mood states semantically related to smoking (or any drug taking) behaviour. Thus, any situation (physical, cognitive, and/or emotional) related to smoking behaviour can be defined as a high smoke relevant context that bears an urgeinducing capacity, hence, holding a risk for relapse. Therapists conducting cognitive therapy, cue exposure therapy, relapse prevention, communication skills training, or any other way of treating addiction may want to take into account their clients' inevitable exposure to high risk situations and must teach their clients that especially in these situations urges must and can be controlled. Not only teaching adequate coping responses (see Marlatt \& Gordon, 1985) in high risk situations, but also prolonged exposure to these high risk situations (this thesis and Conklin, 2006) and cognitive restructuring (see Beck et al. 1993) in these high risk situations should be considered when treating addiction. Within such a more eclectic cognitive behavioural therapy practice has to be repeated over and again so a new relatively automatic pattern of behaviour can be consolidated as an adequate alternative to drug use. Again, whether such an approach comprises an effective treatment of addictive behaviour needs to be addressed in future research.

\section{Suggestions for further research}

Although the present thesis sought to answer some key questions in the most recent development of learning psychology applied to the 
case of smoking addiction and the use of cue exposure treatment for addiction, there still remain many unresolved questions that need to be addressed in future research.

Renewal was found to occur in low-dependent smokers who had no intention to stop smoking. Obviously, future research should replicate these findings with smokers who have the intention to quit ensuring that the findings presented in this thesis also generalises to this population. Thus, findings from fundamental and clinical analogue studies should be replicated in clinical samples to ascertain their ecological validity.

Albeit no renewal was found in the renewal groups described in the last study (chapter 6) using an ABC-renewal design, it remains unclear whether this was due to the fact that extinction was not as strong as in study 4 (chapter 5) of this thesis, or that $\mathrm{ABC}$ renewal simply does not occur in human subjects. Note that Havermans and colleagues (2005) also found evidence for ABArenewal, but not for ABC-renewal in human subjects. This finding is problematic for Bouton's model $(1988,2002)$ that claims that context modulates the CS-No US association thus resolving the ambiguous meaning of the CS after extinction. Havermans et al. (2005) argued that their pattern of results can be ascribed to the acquisition of an association between the compound context A plus the CS and the US during the initial conditioning phase. This means that the acquisition context $\mathrm{A}$ also functions as a $\mathrm{CS}$ making $\mathrm{ABA}$ renewal much more likely than $\mathrm{ABC}$ renewal. This explanation concurs with the results described in chapter 6. It was found that a high smoke relevant context acted as a CS increasing overall urge to smoke when tested after an extinction procedure. This, however, also suggests that any context with high smoke relevant characteristics will override other cues signalling the absence or occurrence of smoking (the US) regardless of the type of context switch made after an extinction procedure. Although this reasoning is in line with other 
work (see e.g., Conklin, 2006), this suggestion awaits further empirical validation.

In sum, fundamental as well as clinical analogue studies can further build upon the existing knowledge concerning the etiology and treatment of addiction. A fairly recent development within the addiction research field shows that addiction models are increasingly incorporating knowledge from multiple disciplines (see e.g., DiChiara, 2002; Orford, 2001; Wiers, de Jong, Havermans, \& Jelicic, 2004). Such models have tremendous potential as they provide many new angles for future research. Moreover, through the convergence of multiple accounts of addiction (conditioning, cognitive, social learning, neuropsychological, et cetera) a more profound picture of how addiction develops and can be treated will emerge. 


\section{SMOKING IN CONTEXT}

\section{References}

Beck, A. T., Wright, F. D., Newman, C. F., \& Liese, B. S. (1993). Cognitive therapy of substance abuse. New York: The Guilford press.

Bouton, M. E. (1988). Context and ambiguity in the extinction of emotional learning: implications for exposure therapy. Behaviour Research and Therapy, 26, 137-149.

Bouton, M. E., \& Swartzentruber, D. (1991). Sources of relapse after extinction in Pavlovian and instrumental learning. Clinical Psychology Review, 11, 123-140.

Bouton, M. E. (2002). Context, ambiguity, and unlearning: Sources of relapse after behavioural extinction. Biological Psychology, 52, 976-986.

Bouton, M. E. (2004). Context and behavioural process in extinction. Learning \& Motivation, $11,485-494$.

Conklin, C. A. (2006). Environments as cues to smoke: Implications for human extinctionbased research and treatment. Experimental and Clinical Psychopharmacology, 14, $12-19$.

Davey, G. C. L. (1992) Classical conditioning and the acquisition of human fears and phobias: A review and synthesis of the literature. Advances in Behaviour Research and Therapy, 14, 29-66.

Dawson, M. E. (1973) Can classical conditioning occur without contingency learning? A review and evaluation of the evidence. Psychophysiology, 10, 82-86.

Dawson, M. E. \& Schell, A. M. (1987) The role of 'controlled' and 'automatic' cognitive processes in human autonomic classical conditioning. In G. C. L. Davey (Ed.), Cognitive processes and Pavlovian conditioning in humans. Chichester: John Wiley.

Di Chiara, G. (2002). Nucleus accumbens shell and core dopamine: differential role in behavior and addiction. Behavioural Brain Research, 137, 75-114.

Dols, M., Willems, B., Van den Hout, M., \& Bittoun, R. (2000). Smokers can learn to influence their urge to smoke. Addictive Behaviors, 25, 103-108.

Dols, M., Van den Hout, M., Kindt, M., \& Willems, B. (2002). The urge to smoke depends on the expectation of smoking. Addiction, 97, 87-93.

Field, M. \& Duka, T. (2001) Smoking expectancy mediates the conditioned responses to arbitrary smoking cues. Behavioural Pharmacology, 12, 183-194.

Havermans, R. C., \& Jansen, A. T. M. (2003). Increasing the efficacy of cue exposure treatment in preventing relapse of addictive behavior. Addictive Behaviors, 28 , 989-994.

Havermans, R. C., Keuker, J., Lataster, T., \& Jansen, A. (2005). Contextual control of extinguished conditioned performance in humans. Learning and Motivation, 36, 1-19.

Hermans, D., Dirikx, T., Vansteenwegen, D., Baeyens, F., Van den Bergh, O., \& Eelen, P. (2005). Reinstatement of fear responses in human aversive conditioning. Behaviour Research and Therapy, 43, 533-551.

Hogarth, L., Dickinson, A., \& Duka, T. (2003). Discriminative stimuli that control instrumental tobacco-seeking by human smokers also command selective attention. Psychopharmacology, 168, 435-445. 


\section{GENERAL DICSUSSION}

Hogarth, L. Dickinson, A., \& Duka, T. (2005). Explicit knowledge of stimulus-outcome contingencies and stimulus control of selective attention and instrumental action in human smoking behaviour. Psychopharmacology, 177, 428-437.

Hogarth, L., Dickinson, A., Hutton, S. B., Bamborough, H., \& Duka, T. (2006). Contingency knowledge is necessary for learned motivated behaviour in humans: relevance for addictive behaviour. Addiction, 101, 1153-1166.

Jansen, A., Elgersma, H., Nederkoorn, C., \& Smeets, T. (2002). What makes treatment of Bulimia Nervosa successful? Paper presented at the European Association for Cognitive and Behaviour Therapies. Maastricht, 18-21 September 2002.

Kirsch, I., Lynn, S. J., Vigorito, M., \& Miller, R. R. (2004). The role of cognition in classical and operant conditioning. Journal of Clinical Psychology, 60 (4), 369-392.

Lovibond, P.F. (2003). Causal beliefs and conditioned responses: retrospective revaluation induced by experience and instruction. Journal of Experimental Psychology: Learning, Memory, and Cognition, 29, 97-106.

Lovibond, P.F., \& Shanks, D. R. (2002). The role of awareness in Pavlovian conditioning: Empirical evidence and theoretical implications. Journal of Experimental Psychology: Animal Behaviour Processes, 28, 3-26.

Marlatt, G. A., \& Gordon, J. R. (1985). Relapse Prevention: Maintenance Strategies in the Treatment of Addictive Behaviors. New York: Guilford Press.

Orford, J. (2001). Addiction as excessive appetite. Addiction, 96, 15-31.

Rescorla, R. A. (2004). Spontaneous Recovery. Learning \& Motivation, 11, 501-509.

Rescorla, R. A., \& Wagner, A. R. (1972). A theory of Pavlovian conditioning: Variations in the effectiveness of reinforcement and nonreinforcement. In A. Black, \& W. F. Prokasy (Eds.), Classical Conditioning II (pp. 64-99). New York: Apple-Century-Crofts.

Robinson, T. E., \& Berridge, K. C. (1993). The neural basis of drug craving: an incentive sensitization theory of addiction. Brain Research and Review, 18, 247-291.

Robinson, T. E., \& Berridge, K. C. (2003). Addiction. Annual Review of Psychology, 54, 2553.

Vogel-sprott, M., \& Fillmore, M. T. (1999). Learning theory and research. In K. E. Leonard \& H. T. Blane (Eds.), Psychological Theories of Drinking and Alcoholism, 292-327. New York: Guilford Press.

Wiers, R. W., De Jong, P., Havermans, R., \& Jelicic, M. (2004). How to change implicit drug-related cognitions in prevention: A transdisciplinary integration of findings from experimental psychopathology, social cognition, memory and experimental learning psychology. Substance Use and Misuse, 39, 1625-1684. 
SMOKING IN CONTEXT 


\section{Samenvatting}

Stoppen met roken is helemaal niet moeilijk en vele rokers stoppen dan ook zeer regelmatig met hun 'slechte gewoonte'. Het volhouden nadat men eenmaal gestopt is, blijkt echter veel moeilijker. Toch lukt het vele mensen om na (vaak meerdere) stoppogingen van de sigaret af te blijven en als herboren niet-roker door het leven te gaan. Sommigen zoeken hulp bij het stoppen met roken: advies van de huisarts, pillen, nicotinepleisters, hypnose, acupunctuur, of een of andere vorm van gesprekstherapie. Gedragstherapie is hierbij een vaak gebruikte en zeer doelgerichte vorm van het behandelen van rookverslaving. Cue exposure therapie (cue blootstellingtherapie) is zo'n vorm van gedragstherapie waarbij rokers worden blootgesteld aan hun rookwaren, maar uiteraard niet toegestaan te roken. Het is namelijk zo dat als rokers of ex-rokers worden blootgesteld aan hun rookwaren dit een grote drang of zin om te roken ontlokt (Carter \& Tifanny, 1999). Dit is een voorbeeld van zogeheten geconditioneerde cue reactiviteit, dat wil zeggen, de rookwaren voorspellen (of zijn voorwaardelijk voor) de inname van rook en lokken daarom drang of zin om te roken uit. Als men nu herhaaldelijk de roker blootstelt aan zijn of haar rookwaren dan zien we dat de drang of zin om te roken afneemt en soms in zijn geheel verdwijnt. Dit illustreert het leertheoretische principe van 'uitdoven' van voormalig geconditioneerde cue reactiviteit. Na een cue exposure behandeling zou de eerder geleerde associatie tussen de rookwaren (de rook cues) en het roken (de rookinname) verbroken zijn. Blootstelling aan de rookwaren (de rook cues) wordt immers niet meer gevolgd door rookinname en zodoende kan men een verslaving afleren. Echter niets is minder waar. Uit fundamenteel onderzoek bij mensen en dieren 
blijkt dat aangeleerde associaties niet zomaar weer kunnen worden afgeleerd met een uitdovingsprocedure zoals een cue exposure behandeling. Cue exposure therapie zorgt voor het leren van een nieuwe associatie tussen de rook cues en het uitblijven van rookinname. Deze nieuwe associatie lijkt sterk onder de invloed te staan van de omgeving of context waarin de therapie heeft plaatsgevonden. Alleen in de omgeving of context waarin cue exposure heeft plaatsgevonden geldt de associatie tussen de rook cues en het uitblijven van rookinname. Dit is een probleem voor de generalisatie van de "uitdoving" effecten van cue exposure therapie naar situaties en omgevingen uit het leven van de ex-roker. Dat wil zeggen, in de therapiekamer ervaart de ex-roker geen drang om te roken in aanwezigheid van zijn of haar rookwaren, maar voor de buis thuis of aan de toog op café zullen dezelfde rookwaren opnieuw drang om te roken uitlokken. Dit maakt de kans dus groot om weer aan de verleiding van de sigaret toe te geven

Ratten vertonen inderdaad terugval van verslavingsgedrag na een uitdovingsprocedure, maar hoe zit dat bij mensen? Onderzoek bij ratten naar de contextgevoeligheid van leren, gebeurt met name in speciaal ontworpen kooien die dan van elkaar verschillen op een aantal kenmerken zoals geur, inrichting, belichting, en zo meer. Maar hoe doen we dat dan bij mensen? Ook in verschillende kooien plaatsen? Uiteraard niet! De vraag die hier rijst is hoe vertalen we de kunstmatige omgeving van labratten naar een laboratoriumsituatie met mensen en hoe vertalen we die situatie dan weer naar de echte situatie van de roker buiten het laboratorium? In een poging om deze vertaalslag zo goed mogelijk te maken, zijn er verschillende kamers ontworpen in het psychologisch laboratorium van de Universiteit Maastricht. Een living ('woonkamer' voor de Nederlanders onder ons), een therapiekamer, een bureau ('kantoor' in het Nederlands), een laboratorium en een café (een Hollandse 'kroeg') werden gebruikt voor de proefpersonen als tegenhanger voor de 
kooien van de ratten in eerdere dierexperimentele studies. Al deze kamers verschilden niet alleen op basis van hun fysieke uiterlijkheden, maar ze verschilden ook op gronde van hun betekenis en functie! Voor de roker is een living en een café niet zomaar een kamer met vier muren, stoelen, banken of een toog; het is ook een ruimte waarin ze vaker gerookt hebben, verwachten te mogen roken, zich heel aangenaam en ontspannen kunnen voelen en makkelijk goesting ('drang of zin') hebben om een sigaretje op te steken dan wel moeilijk kunnen weigeren. Een bureau, een therapiekamer en een laboratorium doet de roker in de regel niet direct denken aan een kamer waar gerookt mag worden. Ook zal de roker zich minder aangenaam en ontspannen voelen in deze kamers waar de verleiding om een sigaret op te steken laag zal zijn. De invloed van het verschil tussen deze 'hoog rookrelevante' en 'laag rookrelevante' kamers op drang, zin of goesting om te roken werd verder onderzocht en staat beschreven in dit proefschrift.

In een eerste onderzoek, beschreven in hoofdstuk 2, werd context nog niet op de hierboven beschreven wijze gemanipuleerd. In deze studie werd de veronderstelde relatie tussen 'incentive motivation' (of ook 'belonende motivatie') en geconditioneerde cue reactiviteit bij rokers onderzocht. In het incentive sensitization model van Robinson en Berridge (1993) wordt er een verband gelegd tussen hersensystemen die gevoelig zijn voor de belonende waarde van drugs, geconditioneerde reacties van cues die het gebruik van drugs voorspellen en het werkelijk gaan opzoeken en gebruiken van drugs (lees: omzetten in gedrag). Rokers werden in ons lab achter een computer geplaatst waar ze twee situaties kregen gepresenteerd waarin ze aan hun favoriete rookwaren werden blootgesteld. Deze twee situaties werden aangegeven door twee verschillende achtergrondkleuren van het computerscherm. De blootstelling aan rookwaren hield in dat de proefpersonen een sigaret in de hand namen, eraan roken, vervolgens de sigaret aan hun lippen brachten en een 
vlammetje van hun aansteker erbij hielden, maar niet de sigaret aanstaken. Een blauwe achtergrondkleur van het computerscherm voorspelde de beschikbaarheid van roken (het nemen van één trekje van hun favoriete merk sigaret) na de blootstelling. Een gele achtergrondkleur van het computerscherm voorspelde de onbeschikbaarheid van roken (geen trekje van de sigaret) na blootstelling. Na blootstelling aan de achtergrondkleur en de rookwaren werd tegen dezelfde achtergrondkleur de drang om te roken gemeten. Voorgaand onderzoek (Dols et al, 2000; 2002) met dit conditioneringparadigma toonde aan dat rokers meer drang rapporteren na blootstelling aan de kleur (bijvoorbeeld blauw) die de beschikbaarheid van roken voorspelt dan aan de kleur (geel) die het uitblijven van roken voorspelt. In het eerste experiment van dit proefschrift kregen de proefpersonen voor en na deze procedure een computertaak waarmee we hun toenaderingsgedrag naar rookgerelateerde cues (plaatjes van sigaretten bijvoorbeeld) konden meten. Dit gebeurde tegen zowel het blauwe als gele beeldscherm. Nu blijkt dat rokers sterker toenaderingsgedrag laten zien voor rookgerelateerde plaatjes dan voor andere plaatjes (van zeep bijvoorbeeld) op de voormeting. Op de nameting vertoonden rokers een sterk toenaderingsgedrag ten aanzien van de kleur achtergrond die de beschikbaarheid van roken voorspelde ongeacht of de plaatjes rookgerelateerde of rookneutrale plaatjes. Deze kleur achtergrond ontlokte echter geen sterkere drang. Kennelijk hadden de proefpersonen een associatie geleerd tussen kleur van het scherm en roken wat zich vooral uit in verschillen in toenaderingsgedrag. Wanneer een roker wordt geconfronteerd met rookgerelateerde cues, zal dit gedrag ontlokken ten behoeve van het kunnen roken, zonder dat dit noodzakelijkerwijze gepaard gaat met een bewust ervaren motivatie (drang) om te gaan roken.

De vier volgende studies werden speciaal ontworpen om de meer complexe leefsituatie van de roker na te bootsen en daarin de mogelijke invloed van context op aangeleerde drang om te roken te 
onderzoeken. Hiervoor werd gebruik gemaakt van het hierboven beschreven conditioneringparadigma.

In een eerste studie (hoofdstuk 3) werd eerst het verschil aangeleerd tussen een blauw en geel dienblad in een bepaalde kamer die laag rookrelevant was (bijvoorbeeld een kantoorruimte). Het dienblad dat de beschikbaarheid van roken voorspelde, lokte bij de deelnemende rokers meer drang uit dan het dienblad dat de onbeschikbaarheid van roken voorspelde. Dit noemen we aangeleerde, differentiële, door cues uitgelokte drang. Hierna werden de proefpersonen naar een andere laag rookrelevante kamer geleid, bijvoorbeeld een therapiekamer. Hier kregen ze wederom de gekleurde dienbladen met en zonder rookwaren aangeboden en werd hun zelfgerapporteerde drang om te roken gemeten. De resultaten lieten zien dat het verschil in door cues uitgelokte drang gehandhaafd bleef in een andere laag rookrelevante ruimte. Aangeleerde verschillen in cue reactiviteit generaliseren dus naar andere contexten.

De contexten in de hierboven beschreven studie betroffen ruimtes die rokers niet gauw associëren met roken. In een vervolgstudie (hoofdstuk 4) vond de aanleerfase plaats in een laag of in een hoog rookrelevante ruimte waarna de proefpersonen wisselden naar een zelfde of een andere laag of hoog rookrelevante kamer. De resultaten van dit experiment toonden aan dat wanneer proefpersonen wisselden van een laag naar een hoog rookrelevante context, deze een verlies van generalisatie van differentiële door cues uitgelokte drang lieten zien, dan wanneer ze van een hoog naar een laag rookrelevante context wisselden. Deze studie toont dus aan dat context wel degelijk invloed heeft op aangeleerde drang om te roken. Verder tonen de resultaten dat niet zomaar een wisseling van de ene context naar een andere context voldoende is om verlies van generalisatie te bekomen, maar dat de contextwisseling betekenisvol dient te zijn in relatie tot rookrelevante kenmerken van de twee contexten. Wanneer je wisselt van een laag naar een hoog rookrelevante kamer 
dan springt deze wissel heel erg in het oog (lees: is saillant). Deze laatste kamer voorspelt namelijk roken en ontlokt hierbij reeds een sterke drang om te roken. Als je omgekeerd van een hoog naar een laag rookrelevante context wisselt is deze wissel niet zo saillant - in een laag rook relevante kamer verwacht men niet te mogen roken en lokt op zich weinig drang uit - en de kleur van het dienblad dat roken voorspelt zal dus nog drang blijven ontlokken in vergelijking tot de kleur van het dienblad dat het uitblijven van rookinname voorspelt.

Om de invloed van rookrelevante contexten op drang in het geval van cue exposure therapie te onderzoeken, was het eerst van belang om aan te tonen dat uitgedoofde drang om te roken kan terugkeren na een contextwissel waarbij er geen verschil is in de eerder genoemde rookrelevantie van contexten. Daarna konden we gaan kijken of een meer op de realiteit geënte contextwissel - van een klinisch laag rookrelevante context naar de thuisomgeving die hoog rookrelevant is - tot een sterkere terugkeer leidt. In het voorlaatste experiment van dit proefschrift (hoofdstuk 5) leerden proefpersonen het verschil tussen de twee gekleurde dienbladen in een laag rookrelevante context A. Daarna leerden ze dit verschil weer af in een andere laag rookrelevante context B (dit lijkt erg op wat er tijdens een cue exposure behandeling gebeurd). Dit wil zeggen dat ze na presentatie van beide gekleurde dienbladen en rookwaren niet mochten roken en dat ze dus geen verschil meer lieten zien in drangscores tussen beide gekleurde dienbladen. Als de proefpersonen nu terug in de context A kwamen, keerde dat verschil terug. Als men dus terugkeert naar de originele aanleercontext kan eerder uigedoofde drang om te roken terugkeren. In de laatste studie van dit proefschrift (hoofdstuk 6) werd de experimentele situatie verder op maat gesneden van de klinische realiteit waarin cue exposure therapie doorgaans plaatsvindt. Het aanleren van de differentiële drang tussen de gekleurde dienbladen gebeurde in een hoog rook- 
relevante context, bijvoorbeeld café context. Vervolgens vond er 'uitdoving' (afleren van de differentiële drang) plaats in een laag rookrelevante context, bijvoorbeeld een kantoor. Proefpersonen werden vervolgens getest in een nieuwe hoog rookrelevante context, bijvoorbeeld een living. Deze experimentele situatie lijkt veel op de werkelijke situatie waarin rokers allerlei cues leren associëren met roken en de beschikbaarheid van roken in contexten die allemaal het roken gaan voorspellen (zoals huiskamer, café, etcetera). De resultaten van deze laatste studie lieten zien dat uitgedoofde differentiële drang niet terug keert in een nieuwe hoog rookrelevante context. Iedere wissel van een laag naar hoog rookrelevante context leidde echter wel tot een algemene verhoging van drang om te roken! De hoog rookrelevante contexten lijken dus zelf zoveel drang te ontlokken dat het niet uit maakt of er nog andere cues aanwezig zijn die geassocieerd zijn met roken of niet; de ex-roker zal dus bij terugkeer in de eigen leefomgeving geconfronteerd worden met een hoge mate van drang om te roken, ongeacht de aanwezigheid van andere rookgerelateerde cues. Dit resultaat komt overeen met ander onderzoek dat aantoont dat persoonlijke hoog rookrelevante contexten sterke drang ontlokken bij rokers (Conklin, 2006).

Wat kunnen we nu allemaal concluderen uit bovenstaand onderzoek?

Terugval (of herval) na cue exposure therapie is deels te verklaren door terugkeer van uitgedoofde drang om te roken in met name hoog rookrelevante contexten. In de toekomst zullen clinici en cliënten rekening dienen te houden met de invloed van hoog rookrelevante contexten op drang om te roken in hun behandeling van rookverslaving. Een manier waarop dit kan, is door de cue exposure therapie juist in dergelijke situaties uit te voeren. Verder onderzoek is nodig om te kunnen bepalen of een dergelijke context exposure therapie inderdaad een betere lange-termijn effectiviteit laat zien dan de reguliere cue exposure therapie. 
SMOKING IN CONTEXT

\section{Referenties}

Carter, B. L. \& Tiffany, S. T. (1999) Meta-analysis of cue reactivity in addiction research. Addiction, 94, 327-340.

Robinson, T. E., \& Berridge, K. C. (1993). The neural basis of drug craving: an incentive sensitization theory of addiction. Brain Research and Review, 18, 247-291.

Dols, M., Willems, B. W., van den Hout, M. \& Bittoun, R. (2000) Smokers can learn to influence their urge to smoke. Addictive Behaviors, 25, 103-108.

Dols, M., van den Hout, M., Kindt, M. \& Willems, B. (2002) The urge to smoke depends on the expectation of smoking. Addiction, 97, 87-93.

Conklin, C. A. (2006). Environments as cues to smoke: Implications for human extinctionbased research and treatment. Experimental and Clinical Psychopharmacology, 14, 12-19. 
GENERAL DICSUSSION 
SMOKING IN CONTEXT 


\section{E en w oord van dank}

Ik ben er bij gratie van de ander. Ook dit proefschrift en het onderzoek dat ik hiervoor gedurende vier jaar heb uitgevoerd is tot stand gekomen door de bijdrage van vele andere mensen.

Een woord van dank is allereerste gericht aan Remco Havermans, mijn voormalig facultaire stagebegeleider tijdens mijn onderzoeksstage, mijn vriend/collega in mijn eerste jaren als $\mathrm{AIO}$ /promovendus/doctoraatstudent, mijn dagelijks begeleider en zelfs uiteindelijk copromotor. Vanaf de eerste dag als stagiair tot op de dag van vandaag heb gij mij gemotiveerd, gestimuleerd, bekritiseerd, gesteund en bovenal vertrouwd bij het doen van onderzoek! In het godverlaten vakgebied van de experimentele leerpsychologie kon ik bij u altijd te rade om mij verder te bekwamen in het vak en mij ook vaak genoeg te bewapenen tegen vele 'tiranniserende' reviewers uit de academische wereld. Remco bedankt hiervoor!

Ook mijn promotoren, professoren Marcel van den Hout en Anita Jansen verdienen een woord voor dank voor allereerst het vertrouwen dat ze me geschonken hebben door mij aan te nemen als AIO/doctoraatstudent en mij dus de kans hebben geboden mij op dit gebied waar te maken! Ook hun professionele ondersteuning heb ik erg gewaardeerd tijdens het gehele proces. Marcel, van u heb ik vooral geleerd nauwgezet onderzoek te plannen, uit te voeren, analyseren en interpreteren. Anita, van u heb ik dan weer geleerd om ook de praktische en organisatorische kant van het onderzoek doen, in acht te nemen. Heer en dame, bedankt hiervoor!

Mijn eerste stappen in de wereld van de experimentele leerpsychologie heb ik ook leren zetten onder begeleiding van Dr. Deb Vansteenwegen van de Katholieke Universiteit Leuven. Een woord van dank voor u Deb, voor je kennis en kunde alsook kritiek en 
mogelijkheden om me verder te bekwamen in het doen van onderzoek zowel fundamenteel als klinisch!

Vervolgens richt ik een woord van dank aan mijn collega AIO's waar ik vooral veel plezier mee heb beleefd op de werkvloer, dansvloer, eettafel dan wel modderig Limburgs wandelpad. Allereerst het vele vrouwelijk schoon bij Experimentele Psychologie: Esther 'Van De Wilde Nachten', Ellen Dreezens, Joke Opdenacker, Martien Schrooten, Ellen Jongen; Jill Withingham, Katrijn Houben, Caroline Tush, Elke Smeets, Ramona Guerrieri, Saskia van Bergen, Esther Jansen, Marieke Kools, Loes Kessels, Beatrijs Hauer, Christine Firk, Elke Geraerts, De meiden van "NO PANIC" Kim van Oorsouw, Ingrid Candel, Marieke Wereij, Nicole T; Vervolgens de Dudes: Jeroen Stouten, Pepijn van Empelen, Tim Schoenmakers, Hugo Alberts, G.J. Peters, Hans Feenstra, Dirk Franssens, Jochen Mikolajczak, Marijn de Bruin, Maarten Peters, Tom Smeets, Timo Giesbrechts, Ewout Meijer. Ook mijn fysiek minder nabije collega's van DMKEP aan jullie een woord van dank.

De vele stagiaires en studentassistenten die mij hebben geholpen met het vaak tot verveling toe werven en testen van proefpersonen, wisten mijn werk altijd te koppelen aan veel plezier. Loes Weusten, Ingrid Bessems, Steffie Snijders, Valerie van der Meijden, Kelly Hermans, Daisy Thijs, Viviane Bruninx, Evelien Ketelaar, Anne Boverhof \& Nicole Geschwindt, aan jullie een woord van dank.

Verder wil ik een woord van dank uiten aan de therapeuten van het voormalig CAD Zuid-Limburg van de Mondriaan Zorg Groep, in het bijzonder Rolf Sanderson en Wim Mulders voor een leerzame samenwerking tussen kliniek en universiteit.

Gebouwbeheerder Allert Andella voor u een woord van dank voor uw onuitstaanbare dwang tot strikte naleving van de letter van de wet zonder enige blijk van realiteitszin. 
Zonder de vele rokende proefpersonen, waarvan het merendeel kwam uit België en Duitsland, had ik niet veel om te onderzoeken. Dus ook aan hen een woord van dank!

Vrienden en vriendinnen vanuit mijn bewogen studententijd in Leuven en Maastricht. Vele woorden van dank voor vele onvergetelijke momenten!

Een bijzonder woord van dank is gereserveerd voor mijn familie. $\mathrm{Pa}, \mathrm{Ma}$, zonder jullie was ik er niet, althans niet in deze vorm, en dankzij jullie steun in materiële en vooral liefdevolle zin heb ik mijn leven kunnen leiden zoals ik dat tot nu toe heb willen doen! Mike mijn broer in vlees, bloed en geest, bedankt voor je steun, kritische reflecties, vriendschap en zoveel meer! 
SMOKING IN CONTEXT 


\section{CURRICULUM VITAE}

Roy Thewissen werd op 4 augustus 1977 geboren te Maaseik in België. In 1995 ronde hij zijn secundair onderwijs af aan het Technisch Instituut Maasmechelen (Industriële Wetenschappen). Hij startte zijn studie psychologie aan de Katholieke Universiteit Leuven (KUL) te België in 1995 en zette deze voort in 1997 aan de Universiteit Maastricht (UM). In 2001 studeerde hij af in de richting Experimentele Psychopathologie met Biologische Psychologie als basisopleiding. Hiervoor deed hij onderzoek naar de rol van contexten bij exposure therapie van spinfobici bij het centrum voor leerpsychologie en gedragstherapie van de KUL. Ter voltooiing van zijn vervolmakingjaar in de Klinische Psychologie (volwassenen) aan de KUL in 2002, liep hij een klinische stage bij het Instituut voor Stress en Werk (spin-off KUL). In datzelfde jaar werd hij aangesteld als Assistent in Opleiding (AIO; thans Promovendus) bij het Departement Experimentele, Medische en Klinische Psychologie (DMKEP) en de capaciteitsgroep Experimentele Psychologie (EP) van de Universiteit Maastricht. Gedurende zijn aanstelling als AIO vervolledigde hij het theoretische gedeelte van zijn opleiding tot cognitief gedragstherapeut bij het Regionaal Instituut voor Nascholing en Opleiding (RINO) en liep hij een psychodiagnositek stage bij de divisie verslavingszorg van de Mondriaan Zorg Groep. Momenteel is hij werkzaam als psycholoog/therapeut bij de dagbehandeling Fybromyalgie van Huize Blankenberg (attaché academisch ziekenhuis Maastricht, azM) te Cadier en Keer. En als toegevoegd docent bij het Departement Experimentele, Medische en Klinische Psychologie van de Universiteit Maastricht. Hij volgt momenteel ook de opleiding tot Mindfulness Meditation therapeut. 
Roy Thewissen was born on 4th of august 1977, in Maaseik, Belgium. In 1995 he graduated from secondary school at the Technical Institute Maasmechelen (Industrial Sciences). He started his study in Psychology at the Catholic University Leuven (CUL) in Belgium and continued his study in 1997 at Maastricht University. In 2001 he graduated with a specialization in Experimental Psychopathology with a basic course in Biological Psychology. During this time he investigated the role of contexts in exposure therapy for spider phobic people at the centre of learning psychology and behavioral therapy of the CUL. He completed his study in Clinical Psychology (adult population) at the CUL in 2002, during which he did a clinical internship at the Institute of Stress and Work (spin-off CUL). In that same year he was appointed as $\mathrm{PhD}$ student at the Department Experimental, Medical and Clinical Psychology and the department Experimental Psychology of Maastricht University. During his appointment as $\mathrm{PhD}$ student he completed the theoretical section of his training as a cognitive behavioral therapist at the Regional Institute of Post-education and Training and he did an internship in psychodiagnostics at the division addiction care of the Mondriaan Care Group. At this time he works as a psychologist/therapist at the outpatients' treatment Fibromyalgia of Huize Blankenberg (attaché academic hospital Maastricht) in Cadier en Keer. And as an academic teatcher at the Department Experimental, Medical and Clinical Psychology of Maastricht University. Currently he is also being trained to be a Mindfulness Meditation therapist. 


\section{Publications}

Thewissen, R. (2003). Op het kruispunt van verslavingsonderzoek. Bespreking van academisch proefschrift 'Cognitive and Neuropsychopharmacological processes in human drug cra ving' van I.H.A. Franken. De Psycholoog, december, 661663.

Thewissen, R., van den Hout, M., Havermans, R. \& Jansen, A. (2005). Context-dependency of cue-elicited urge to smoke. Addiction, 100, 387-396.

Thewissen, R., Snijders, S. J. B. D., Havermans, R. C., van den Hout, M. \& Jansen, A. (2006). Renewal of cue-elicited urge to smoke: implications for cue exposure treatment.

Behaviour Research and Therapy, 44, 1441-1449.

Thewissen, R., Havermans, R. C., Geschwind, N., van den Hout, M., \& Jansen, (Accepted pending revision). Conditioning incentive motivation in low-dependent smokers.

Psychopharmacology.

Thewissen, R., Havermans, R. C., van den Hout, M., \& Jansen, A. (submitted for publication). From the clinic to the pub: The effect of smoke relevant contexts on urge to smoke.

Thewissen, R., van der Meijden, V. A. F., Havermans, R. C., van den Hout, M., \& Jansen, A. (submitted for publication). From the office to the pub: The role of smoke relevant con texts on cue-elicited urge to smoke.

Vansteenwegen, D., Vervliet, B., Hermans, D., Thewissen, R., \& Eelen, P. (2007). Verbal, behavioral and physiological as sessment of the generalization of exposure-based fear re duction in spider anxious population.

Behaviour Research and Therapy, 45 (2), 291-300. 
SMOKING IN CONTEXT

Havermans, R. C., Lataster, T., Thewissen, R. \& Jansen, A. (2004). Uitdoven is geen afleren: implicaties voor ex posure therapie. Gedragstherapie,37, 77-86.

Havermans, R. C., Thewissen, R., Wiers, R. W., \& Jansen A. (in press). Een verslaving kun je leren, maar wat wordt er nu precies geleerd: een slechte gewoonte of een onbeheersbare drang? De Psycholoog. 